\title{
Supporting Information: Comparative Coordination Chemistry of PNP and SNS Pincer Ruthenium Complexes
}

Danielle N. Chirdon, ${ }^{a}$ Steven P. Kelley, ${ }^{a}$ Nilay Hazari ${ }^{b}$ and Wesley H. Bernskoetter ${ }^{a, *}$

a The Department of Chemistry, The University of Missouri, Columbia, Missouri, 65211, USA. E-mail: bernskoetterwh@missouri.edu

b The Department of Chemistry, Yale University, P. O. Box 208107, New Haven, Connecticut, 06520, USA.

\section{Table of Contents:}

Experimental Details

Synthesis and Characterization

X-ray Crystallography

SNS Electrochemical Characterization

Fe PNP Electrochemistry

Attempted Electrocatalytic $\mathrm{CO}_{2}$ Reduction

DFT Calculations

Optimized Coordinates (also available as mol files)

References
S2-S3

S3-S16

S17-S19

S20-S21

S22

S22-S26

S27-S34

S35-S46

S47 


\section{Experimental Details}

Materials \& Methods: Solvents toluene, THF, diethyl ether, pentane, and acetonitrile were dried and degassed using an MBraun solvent system. DME, EtOH, benzene, DCM, and NMR solvents were purified and dried by standard vacuum transfer techniques. ${ }^{1}$ The ruthenium sources $\left[\mathrm{Ru}(\mathrm{DMSO})_{4}(\mathrm{Cl})_{2}\right]_{1}{ }^{2}\left[\mathrm{Ru}\left(\mathrm{PPh}_{3}\right)_{2}(\mathrm{CO})(\mathrm{DMF})(\mathrm{Cl})_{2}\right],{ }^{3}$ and $\left[\mathrm{Ru}(\mathrm{CO})_{2}(\mathrm{Cl})_{2}\right]_{n}{ }^{4}$ were prepared according to literature procedures. The known ligands ${ }^{\mathrm{tBu}}{ }^{\mathrm{SN}} \mathbf{N}^{\mathrm{H}} \mathbf{S}$ and ${ }^{\mathrm{tBu}} \mathbf{S} \mathbf{N}_{\mathrm{py}} \mathbf{S}$ were both synthesized using methods described by Waser et al..$^{5}$, and aliphatic ligand ${ }^{\mathrm{tBu}} \mathrm{SN}^{\mathrm{H}} \mathrm{S}$ was stored in dilute pentane solution at $-31^{\circ} \mathrm{C}$. [( $\left.\left.{ }^{\mathrm{tBu}} \mathrm{SN}_{\mathrm{py}} \mathrm{S}\right) \mathrm{ZnCl}_{2}\right]$ was synthesized by the method of Albert using anhydrous $\mathrm{ZnCl}_{2}$ instead of $\mathrm{ZnBr}_{2}$ hydrate as the starting material. ${ }^{6}$ Unless otherwise noted below, all other chemicals were obtained from commercial sources and used as received. ${ }^{1} \mathrm{H}$ and ${ }^{31} \mathrm{P}$ NMR spectra were collected using a Bruker DRX $300 \mathrm{MHz}$ spectrometer and ${ }^{13} \mathrm{C}$ spectra were recorded via a Bruker DRX $600 \mathrm{MHz}$ instrument. ${ }^{31} \mathrm{P}$ NMR spectra were referenced to an $85 \%$ phosphoric acid external standard while solvent signals were used in referencing proton and carbon spectra. Air stability was assessed on NMR samples by comparing proton spectra before and after opening the NMR tube to air for at least 5 minutes; no SNS complexes showed sensitivity. IR characterization was conducted on pressed $\mathrm{KBr}$ pellets using a Nicolet Summit Pro FTIR spectrometer with iD1 transmission accessory. X-ray crystallography was conducted with a Bruker SMART CCD system. Crystal structures were solved from direct methods and Fourier syntheses with refinement by full-matrix least-squares procedures using anisotropic thermal parameters for all non-hydrogen atoms. Elemental analysis was performed by Robertson Microlit Laboratories in Ledgewood, NJ.

DFT Calculations: Free energy, geometry, and orbital calculations were completed via DFT using Gaussian 16 Revision A. 03.7 Orbitals were rendered using Gaussview (isovalue $=0.04$ ) with access provided by the University of Missouri Research Computing Support Services. All calculations were performed in the ground state and employed the B3LYP functional ${ }^{8}$ with a split basis set: Lanl2dz for the heavy Ru center and $6-31+\mathrm{G}^{* *}$ for all other atoms. ICPM was used to model acetonitrile solvent while default parameters determined gradient convergence. Where possible, calculations were conducted starting from the coordinates of a crystal structure. To reduce computation time, sulfur t-butyl substituents were modeled as methyl groups while triphenylphosphine was modeled as $\mathrm{PMe}_{3}$. Effects of the former simplification were judged to be minimal through repetition of some calculations with full t-butyl groups.

Electrochemistry: All electrochemical analysis was performed using a Gamry Interface 1010B Potentiostat and a custom glass cell (Adams and Chittenden). For cyclic voltammetry, the cell was equipped with a glassy carbon disk working $\left(0.071 \mathrm{~cm}^{2}\right)$ electrode and a $\mathrm{Ag} / \mathrm{AgNO}_{3}$ reference in its main compartment as well as a platinum counter electrode located in a separate, fritted compartment. Bulk electrolysis was conducted by replacing the disk working electrode with a glassy carbon rod $(6 \mathrm{~mm}$ dia, type 2$)$. Unless otherwise noted, electrochemical analysis was performed under constant argon pressure in acetonitrile solutions containing $0.1 \mathrm{M}$ TBAPF $_{6}$ electrolyte. Decamethylferrocene was added as an internal standard and all potentials were reported relative to ferrocene by adjusting the standard's potential to $-0.51 \mathrm{~V} .{ }^{9}$ Negative 
polarity was used with a scan rate of $100 \mathrm{mV} / \mathrm{s}$. Analyte concentrations were kept at $1.7-1.8 \mathrm{mM}$ except for 7-CO which was poorly soluble and was run at saturation (just over $0.4 \mathrm{mM}$ ).

\section{Synthesis \& Characterization}

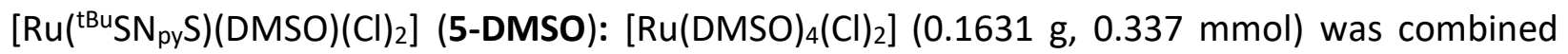
with $\mathrm{MeOH}(15 \mathrm{~mL})$ in a $50 \mathrm{~mL}$ Schlenk flask. ${ }^{\mathrm{tBu}} \mathrm{SN}_{\mathrm{py}} \mathrm{S}$ ligand $(0.1142 \mathrm{~g}, 0.403 \mathrm{mmol})$ was added in $\mathrm{MeOH}(12 \mathrm{~mL})$ and the resulting mixture was degassed with argon for $10 \mathrm{~min}$. A reflux condenser was added to the reaction flask before refluxing at $72^{\circ} \mathrm{C}$ overnight under argon atmosphere. $\mathrm{MeOH}$ solvent was then removed under reduced pressure to give a golden solid. Inside a glovebox, the solid was washed with cold, dry EtOH $(1.5 \mathrm{~mL})$ as well as room temperature EtOH $(3 \mathrm{~mL})$, min. toluene $(\sim 1 \mathrm{~mL})$, and copious pentane. Yield $=0.1307 \mathrm{~g}(72.6 \%)$.

${ }^{1} \mathrm{H}$ NMR (benzene-d6, 300MHz): $\delta 1.30\left(\mathrm{~s}, 18 \mathrm{H}, \mathrm{SC}\left(\mathrm{CH}_{3}\right)_{3}\right), 3.27\left(\mathrm{~s}, 3 \mathrm{H}, \mathrm{SOCH}_{3}\right), 3.37(\mathrm{~s}, 3 \mathrm{H}$, $\left.\mathrm{SOCH}_{3}\right), 3.46\left(\mathrm{~d}, J=16.67 \mathrm{~Hz}, 2 \mathrm{H}, \mathrm{CH}_{2} \mathrm{~S}\right), 4.99$ (d, J=16.35 Hz, $\left.2 \mathrm{H}, \mathrm{CH}_{2} \mathrm{~S}\right), 6.29$ (d, J= $7.69 \mathrm{~Hz}, 2 \mathrm{H}$, $\mathrm{NCCH}), 6.61(\mathrm{t}, J=7.69,1 \mathrm{H}, \mathrm{NCCHCH}) .{ }^{13} \mathrm{C}\left\{{ }^{1} \mathrm{H}\right\}$ NMR (benzene-d6, $150 \mathrm{MHz}$ ): $\delta$ 29.35, 43.95, 46.52, 46.76, 50.71, 118.80, 134.46, 164.34. IR (KBr, v (cm-1)) 1094 (SO), 436 (Ru-S). Elem. Anal. found (calcd) for $\mathrm{C}_{17} \mathrm{H}_{31} \mathrm{Cl}_{2} \mathrm{NORuS}_{3}$ : C 38.46 (38.27); $\mathrm{H} 5.78$ (5.86); N 2.55 (2.63).

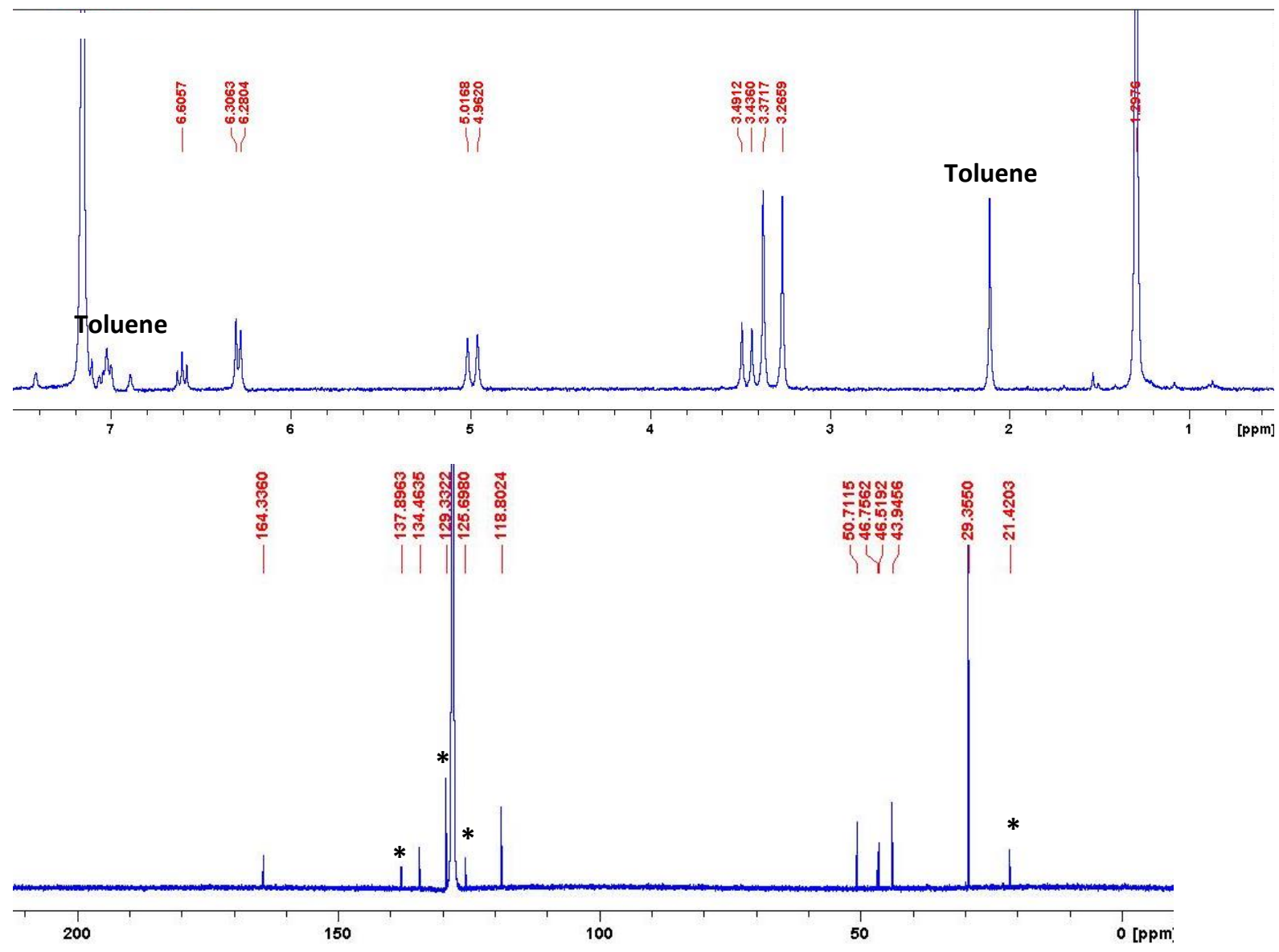

Figure S1: NMR spectra for 5-DMSO in $\mathrm{C}_{6} \mathrm{D}_{6}$. Residual toluene signals are denoted with annotation or an asterisk. (Top) ${ }^{1} \mathrm{H}$ NMR (Bottom) ${ }^{13} \mathrm{C}$ NMR. 
$\left[\mathrm{Ru}\left({ }^{(\mathrm{Bu}} \mathrm{SN}_{\mathrm{py}} \mathrm{S}\right)(\mathrm{CO})(\mathrm{Cl})_{2}\right]$ (5-CO): Inside a glovebox, 5-DMSO (0.0557 g, $\left.0.104 \mathrm{mmol}\right)$ was suspended in benzene $(7 \mathrm{~mL})$ in a $50 \mathrm{~mL}$ bomb flask. The suspension was placed under CO ( 1 atm) and irradiated by a UV arc lamp (Ace Glass 7825 Immersion Lamp) without stirring until becoming a colorless solution with large, orange-brown crystals on flask walls ( $\sim \mathrm{hrs})$. Benzene supernatant was decanted leaving the crystals which were washed with copious diethyl ether. To transfer crystals from the bomb flask, they were dissolved in minimal DCM and then reprecipitated as tan powder by adding diethyl ether and chilling to $-30^{\circ} \mathrm{C}$. Product was obtained as a mixture of $c i s$ and trans isomers with cis being predominant. Yield $=0.042 \mathrm{~g}(83.2 \%)$.

${ }^{1} \mathrm{H}$ NMR (chloroform-d, 300MHz): Major (cis) $\delta 1.47$ (s, 18H, SC(CH3) $\left.)_{3}\right), 4.28$ (d, $J=16.67 \mathrm{~Hz}, 2 \mathrm{H}$, $\mathrm{CH}_{2} \mathrm{~S}$ ), 4.89 (d, J=16.67 Hz, 2H, CH $2 \mathrm{~S}$ ), $7.49(\mathrm{~d}, J=7.69 \mathrm{~Hz}, 2 \mathrm{H}, \mathrm{NCCH}), 7.76(\mathrm{t}, J=7.05,1 \mathrm{H}$, $\mathrm{NCCHCH}$ ). Observable Minor (trans) $\delta 1.53\left(\mathrm{~s}, \mathrm{SC}\left(\mathrm{CH}_{3}\right)_{3}\right), 4.53\left(\mathrm{~d}, \mathrm{~J}=15.07 \mathrm{~Hz}, \mathrm{CH}_{2} \mathrm{~S}\right), 4.72$ (d, J= $15.71 \mathrm{~Hz}, 2 \mathrm{H}, \mathrm{CH}_{2} \mathrm{~S}$ ). ${ }^{13} \mathrm{C}\left\{{ }^{1} \mathrm{H}\right\} \mathrm{NMR}$ (chloroform-d, $150 \mathrm{MHz}$ ): Major (cis) $\delta 29.04,44.48,50.73$, 120.45, 137.64, 161.02, 201.00. Minor (trans) $\delta$ 29.51, 29.86, 43.89, 51.02, 121.13, 138.27, 160.34. IR (KBr, $\left.v\left(\mathrm{~cm}^{-1}\right)\right)$ 1964.1 (CO). Elem. Anal. found (calcd) for $\mathrm{C}_{16} \mathrm{H}_{25} \mathrm{Cl}_{2} \mathrm{NORuS}_{2}$ : $\mathrm{C} 39.74$ (39.75); H 5.09 (5.21); N 2.92 (2.90).

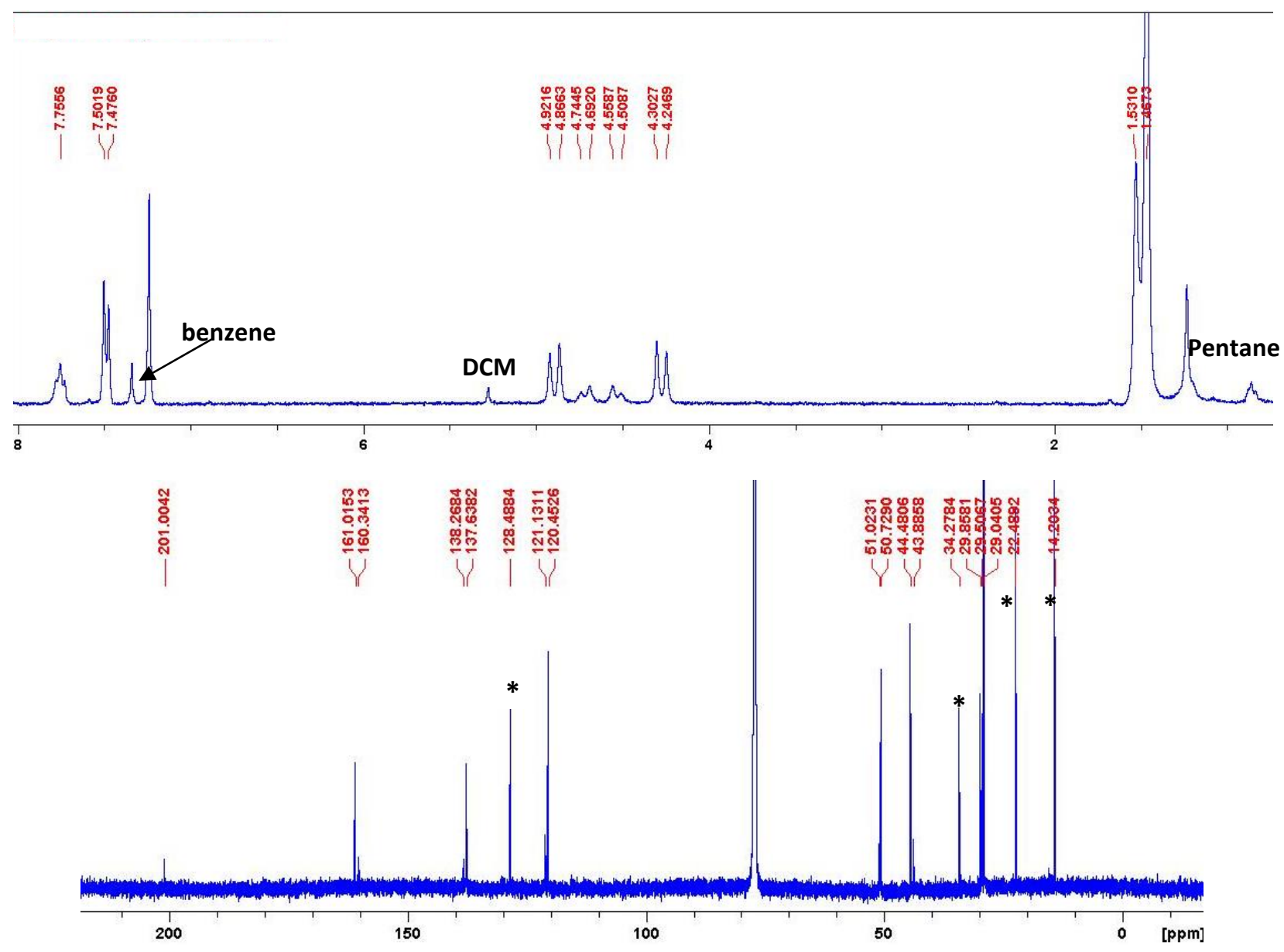

Figure S2: NMR spectra for 5-CO in $\mathrm{CDCl}_{3}$. (Top) ${ }^{1} \mathrm{H}$ NMR with solvent signals annotated. (Bottom) ${ }^{13} \mathrm{C}$ NMR with benzene and pentane signals marked by asterisks. 
$\left[\mathrm{Ru}\left({ }^{\mathrm{tBu}} \mathrm{SN}_{\mathrm{py}} \mathrm{S}\right)(\mathrm{CO})_{2} \mathrm{Cl}\right]\left(\mathrm{PF}_{6}\right)(5-2 \mathrm{CO}):{ }^{\mathrm{tBu}} \mathrm{SN}_{\mathrm{py}} \mathrm{S}$ ligand $(0.1131 \mathrm{~g}, 0.399 \mathrm{mmol})$ and $\left[\mathrm{Ru}(\mathrm{CO})_{2}(\mathrm{Cl})_{2}\right]_{\mathrm{n}}$ $(0.0847 \mathrm{~g}, 0.373 \mathrm{mmol})$ were combined in $\mathrm{MeOH}(65 \mathrm{~mL})$ which was degassed with argon ( 10 $\mathrm{min}$ ) and left to reflux overnight under argon in the dark. Upon cooling, the reaction mixture was opened to air and diluted with water $(20 \mathrm{~mL})$. The resulting aqueous solution was filtered through glass fiber before $\mathrm{KPF}_{6}(0.3100 \mathrm{~g})$ was introduced in minimal water. $\mathrm{MeOH}$ then was removed via rotary evaporator, and the remaining solution was allowed to stand at room temperature overnight to give product as light yellow, X-ray quality crystals. Product crystals were collected via filtration and washed with copious water, diethyl ether, and hexanes. Yield= $0.1090 \mathrm{~g}(47.2 \%)$

${ }^{1} \mathrm{H}$ NMR (ACN-d3, 300MHz): $1.56\left(\mathrm{~s}, 18 \mathrm{H}, \mathrm{SC}\left(\mathrm{CH}_{3}\right)_{3}\right), 4.71\left(\mathrm{~d}, J=16.28 \mathrm{~Hz}, 2 \mathrm{H}, \mathrm{CH}_{2} \mathrm{~S}\right), 4.90$ (d, J= $\left.16.52 \mathrm{~Hz}, 2 \mathrm{H}, \mathrm{CH}_{2} \mathrm{~S}\right), 7.75(\mathrm{~d}, J=7.54 \mathrm{~Hz}, 2 \mathrm{H}, \mathrm{NCCH}), 8.02-8.14(\mathrm{~m}, 1 \mathrm{H}, \mathrm{NCCHCH}) .{ }^{13} \mathrm{C}\left\{{ }^{1} \mathrm{H}\right\} \mathrm{NMR}$ (ACN-d3, $150 \mathrm{MHz}): \delta 28.94,45.55,53.43,124.48,142.09,160.07,193.09 . \mathrm{IR}\left(\mathrm{KBr}, \mathrm{v}\left(\mathrm{cm}^{-1}\right)\right)$ 2082, 2031 (CO). Elem. Anal. found (calcd) for $\mathrm{C}_{17} \mathrm{H}_{25} \mathrm{ClF}_{6} \mathrm{NO}_{2} \mathrm{PRuS}_{2}$ : C 33.14 (32.88); H 4.34 (4.06); N 2.33 (2.26).

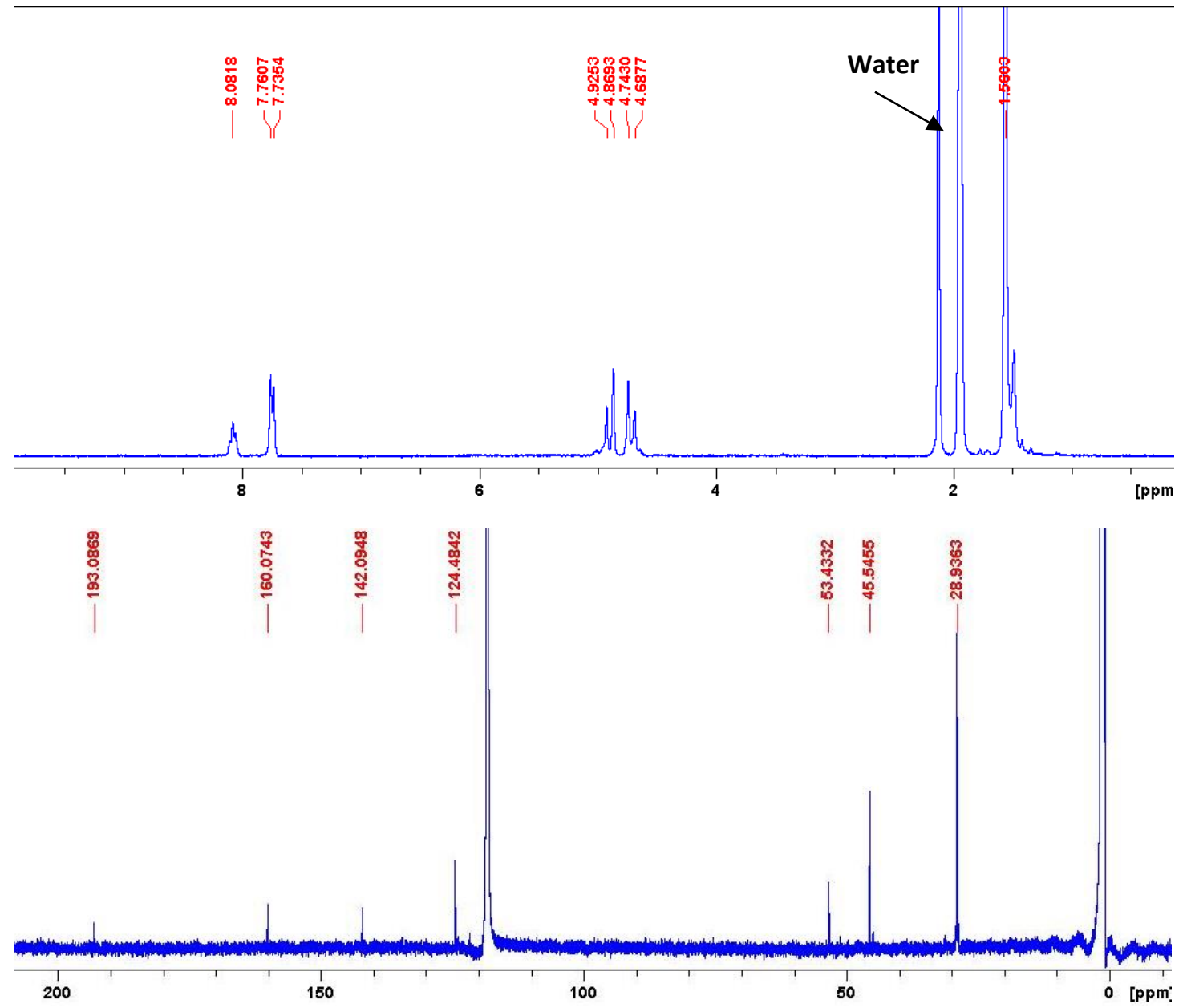

Figure S3: NMR spectra for $5-2 \mathrm{CO}$ in $\mathrm{CD}_{3} \mathrm{CN}$. (Top) ${ }^{1} \mathrm{H}$ NMR (Bottom) ${ }^{13} \mathrm{C} \mathrm{NMR}$. 
$\left[\mathrm{Ru}\left({ }^{\mathrm{tBu} S N}{ }^{\mathrm{H} S}\right)(\mathrm{DMSO})(\mathrm{Cl})_{2}\right]$ (7-DMSO): $\left[\mathrm{Ru}(\mathrm{DMSO})_{4}(\mathrm{Cl})_{2}\right](0.381 \mathrm{~g}, 0.786 \mathrm{mmol})$ was combined with $\mathrm{MeOH}(30 \mathrm{~mL})$ in a $100 \mathrm{~mL}$ Schlenk flask. ${ }^{\mathrm{tBu}} \mathrm{SN}^{\mathrm{H} S}$ ligand $(0.234 \mathrm{~g}, 0.938 \mathrm{mmol})$ was added in $\mathrm{MeOH}(22 \mathrm{~mL})$ via syringe and the resulting mixture was degassed with argon for $10 \mathrm{~min}$. A reflux condenser was added to the reaction flask before refluxing at $68^{\circ} \mathrm{C}$ overnight under argon atmosphere. $\mathrm{MeOH}$ solvent was then removed under reduced pressure to give an orange, waxy solid. Inside a glovebox, the solid was washed with minimal cold, dry EtOH ( $3 \mathrm{~mL}$ ) and ultimately suspended in room temperature $\mathrm{EtOH}(12 \mathrm{~mL})$. After the suspension settled, EtOH supernatant was removed leaving behind the pure product as an orange powder. Additional pure product was precipitated from the EtOH supernatant by concentrating the solution to just under half of its original volume and letting it stand in the freezer overnight. Combined Yield $=0.236 \mathrm{~g}(60.2 \%)$. X-ray quality crystals were obtained through recrystallization from dilute EtOH.

${ }^{1} \mathrm{H}$ NMR (benzene- $\left.d 6,300 \mathrm{MHz}\right): \delta 1.56\left(\mathrm{~s}, 18 \mathrm{H}, \mathrm{C}\left(\mathrm{CH}_{3}\right)_{3}\right), 1.87-2.05\left(\mathrm{~m}, 4 \mathrm{H}, \mathrm{CH}_{2}\right), 2.30-2.53(\mathrm{~m}$, $\left.4 \mathrm{H}, \mathrm{CH}_{2}\right), 3.31\left(\mathrm{~s}, 6 \mathrm{H}, \mathrm{SO}\left(\mathrm{CH}_{3}\right)_{2}\right), 4.52(\mathrm{~s}-\mathrm{br}, 1 \mathrm{H}, \mathrm{NH}) .{ }^{13} \mathrm{C}\left\{{ }^{1} \mathrm{H}\right\}$ NMR (benzene-d6, $\left.150 \mathrm{MHz}\right): \delta$ 30.90, 32.70, 44.14, 50.56, 52.86. IR (KBr, v ( $\left.\left.\mathrm{cm}^{-1}\right)\right) 1083$ (SO), 440 (Ru-S). Elem. Anal. found (calcd) for $\mathrm{C}_{14} \mathrm{H}_{33} \mathrm{Cl}_{2} \mathrm{NORuS}_{3}$ : C 33.78 (33.66); $\mathrm{H} 6.45$ (6.66); N 2.80 (2.80).

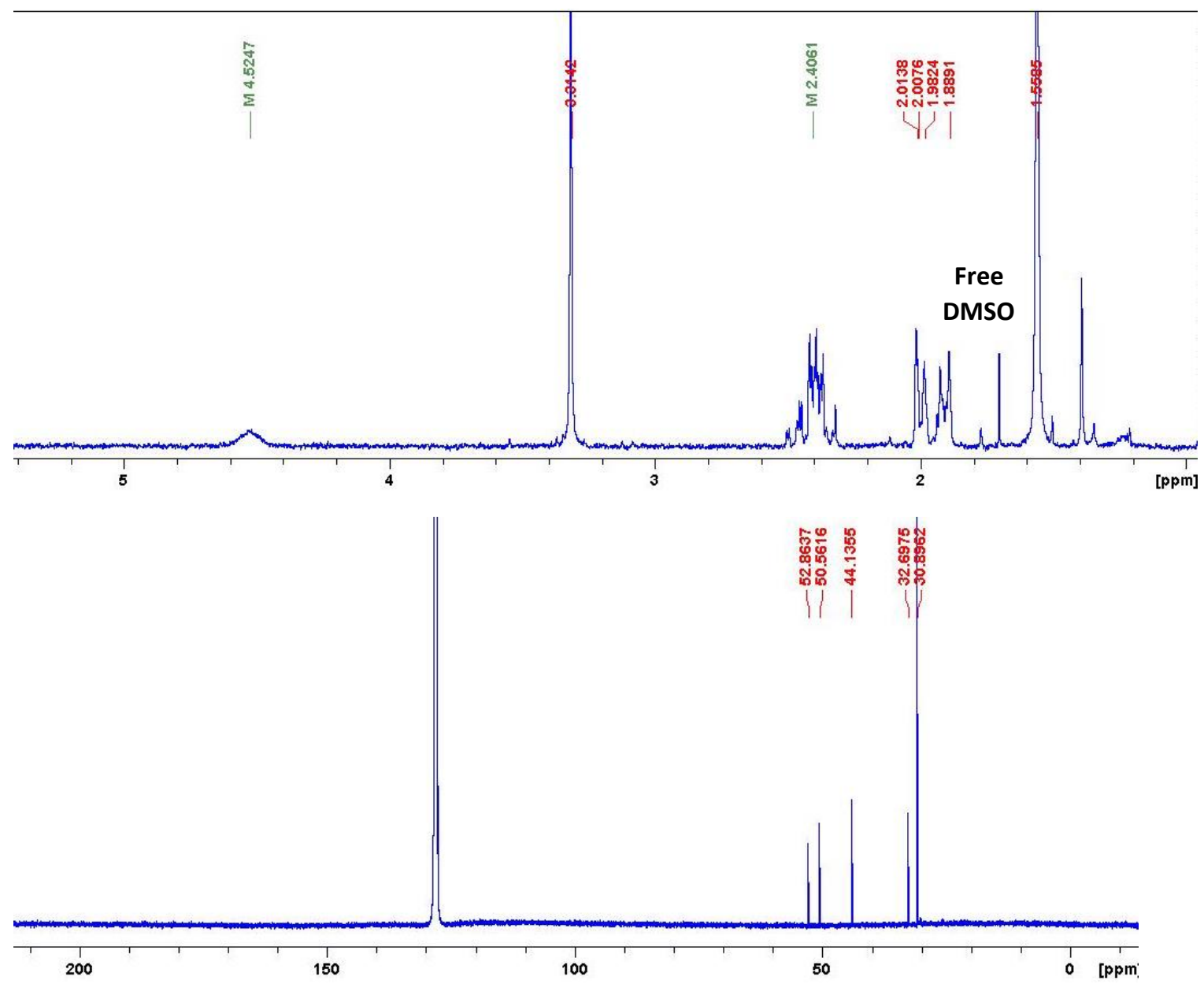

Figure S4: NMR spectra for 7-DMSO in $\mathrm{C}_{6} \mathrm{D}_{6}$. (Top) ${ }^{1} \mathrm{H}$ NMR (Bottom) ${ }^{13} \mathrm{C}$ NMR. 
$\left[\mathrm{Ru}\left({ }^{\mathrm{tBu}} \mathrm{SN}^{\mathrm{H} S}\right)(\mathrm{CO})(\mathrm{Cl})_{2}\right]$ (7-CO): Inside a glovebox, a $25 \mathrm{~mL}$ bomb flask was charged with 7-DMSO $(0.0573 \mathrm{~g}, 0.115 \mathrm{mmol})$ and toluene $(9.5 \mathrm{~mL})$. The flask was placed under CO pressure ( $1 \mathrm{~atm})$ and sealed before stirring at $66^{\circ} \mathrm{C}$ for 3 hours $15 \mathrm{~min}$. The resulting suspension of fine yellow powder was concentrated to $2 / 3$ its original volume under vacuum and allowed to settle. The toluene supernatant was decanted off and the settled powder was washed with copious diethyl ether to give the product. Yield $=0.0487 \mathrm{~g}(94.5 \%)$.

The presence of a shoulder on the $\mathrm{C}=\mathrm{O}$ IR stretch of 7-CO suggests that the complex exists as a mixture of at least two isomers. ${ }^{1} \mathrm{H}$ NMR spectroscopy does not show distinct sets of signals for two isomers, but the spectral features are broad and non-descript in line with possible overlap or exchange of isomers. Although the poor solubility of 7-CO prohibits any further analysis, its assignment as a single species has been confirmed by EA as well as ESI-MS conducted on a methanol solution via a Thermo LCQ Deca XP ion trap spectrometer.

${ }^{1} \mathrm{H}$ NMR (acetone- $\left.d 6,300 \mathrm{MHz}\right): \delta 1.54\left(\mathrm{~s}, 18 \mathrm{H}, \mathrm{SC}\left(\mathrm{CH}_{3}\right)_{3}\right), 2.53-2.91\left(\mathrm{~m}, 4 \mathrm{H}, \mathrm{CH}_{2}\right), 3.17(\mathrm{~d}, J=$ $\left.10.9 \mathrm{~Hz}, 2 \mathrm{H}, \mathrm{CH}_{2}\right), 3.36-3.52\left(\mathrm{~m}, 2 \mathrm{H}, \mathrm{CH}_{2}\right), 4.51(\mathrm{~s}-\mathrm{br}, 1 \mathrm{H}, \mathrm{NH}) .{ }^{13} \mathrm{C}\left\{{ }^{1} \mathrm{H}\right\}$ NMR (DMSO-d6, 150 $\mathrm{MHz}): \delta 29.09,29.22,33.64,33.82,34.90,52.13 . \mathrm{IR}\left(\mathrm{KBr}, \mathrm{v}\left(\mathrm{cm}^{-1}\right)\right)$ 1946, $1923 \mathrm{sh}$ (CO). Elem. Anal. found (calcd) for $\mathrm{C}_{13} \mathrm{H}_{27} \mathrm{Cl}_{2} \mathrm{NORuS}_{2}$ : C 35.22 (34.74); H 5.86 (6.06); N 3.02 (3.12). MS (m/z; $\mathrm{ESI}+, \mathrm{MeOH}): 413.7$ (100\%, M-Cl), 444.4 (66\%, $\mathrm{M}-\mathrm{Cl}+\mathrm{OMe})$. 


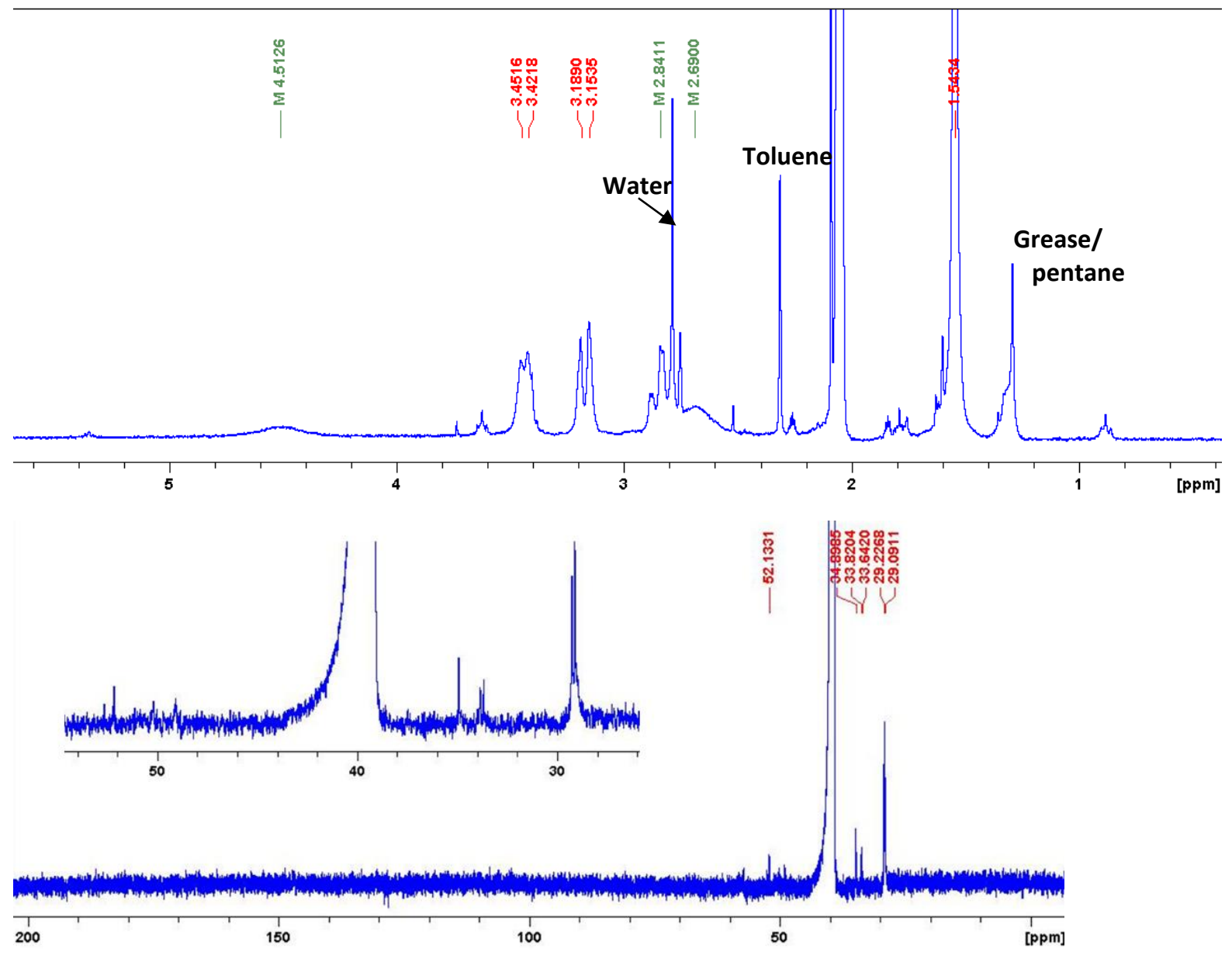

Figure S5: NMR spectra for 7-CO. (Top) ${ }^{1} \mathrm{H}$ NMR in $\left(\mathrm{CD}_{3}\right)_{2} \mathrm{CO}$ with minor solvent signals annotated. (Bottom) ${ }^{13} \mathrm{C} N M R$ in $\left(\mathrm{CD}_{3}\right)_{2} \mathrm{SO}$ with inset to show details of the relevant signals.

$\left[\mathrm{Ru}\left({ }^{\mathrm{tBu}} \mathrm{SN}^{\mathrm{H}} \mathrm{S}\right)(\mathrm{CO})(\mathrm{MeCN}) \mathrm{Cl}\right]\left(\mathrm{BF}_{4}\right)(7-\mathrm{ACN}):$ 7-CO $(0.0287 \mathrm{~g}, 0.064 \mathrm{mmol})$ was suspended in ACN (7 $\mathrm{mL}$ ) in a bomb flask inside a glove box. Tritylium tetrafluoroborate $(0.0209 \mathrm{~g}, 0.063 \mathrm{mmol})$ was added drop-wise in ACN (3.5 mL) and the reaction flask was sealed for heating at $75^{\circ} \mathrm{C}$. Heating was continued for $2 \mathrm{hr}$ during which the reaction solution changed from bright yellow to nearly colorless. After heating, the colorless solution was filtered through celite inside a glove box. The filtrate was evaporated to dryness before being washed with 1:1 toluene:diethyl ether $(6 \mathrm{~mL})$ as well as diethyl ether $(3 \mathrm{~mL})$. Washed solids were re-precipitated from minimal DCM/diethyl ether at $-30^{\circ} \mathrm{C}$ to give the product as a white solid with a slight green tint. Yield $=0.0236 \mathrm{~g}$ (68.8\%). The complex was isolated as one major isomer and a very minor second isomer marked in ${ }^{1} \mathrm{H}$ NMR spectra by small shoulders on the major isomer's singlets for $\mathrm{S}-{ }^{\mathrm{t}} \mathrm{Bu}$ and bound ACN. Assignment of the NMR signals as isomers has been established in the reaction of the 7-ACN with CO during which the isomer signals interconvert and ultimately converge to one $\mathrm{CO}$ adduct product. The minor isomer concentration becomes enriched and clearly defined during $\mathrm{CO}$ addition reaction likely due to a slower rate of $\mathrm{CO}$ substitution for the minor isoimer as compared to the major isomer. NMR signals for both isomers are described below. 
${ }^{1} \mathrm{H}$ NMR (300MHz): Major (acetone- $\left.d 6\right) \delta 1.60\left(\mathrm{~s}, 18 \mathrm{H}, \mathrm{SC}\left(\mathrm{CH}_{3}\right)_{3}\right), 2.68\left(\mathrm{~s}, 3 \mathrm{H}, \mathrm{NCCH}_{3}\right), 2.84-3.10$ $\left(\mathrm{m}, 4 \mathrm{H}, \mathrm{CH}_{2}\right), 3.35-3.49\left(\mathrm{~m}, 2 \mathrm{H}, \mathrm{CH}_{2}\right), 3.49-3.71\left(\mathrm{~m}, 2 \mathrm{H}, \mathrm{CH}_{2}\right), 4.89(\mathrm{~s}-\mathrm{br}, 1 \mathrm{H}, \mathrm{NH})$. Minor (chloroform-d) $\delta 1.54\left(\mathrm{~s}, 18 \mathrm{H}, \mathrm{SC}\left(\mathrm{CH}_{3}\right)_{3}\right), 2.41\left(\mathrm{~s}, 3 \mathrm{H}, \mathrm{NCCH}_{3}\right), 2.91-3.24\left(\mathrm{~m}, 8 \mathrm{H}, \mathrm{CH}_{2}\right), 5.75$ (s-br, $1 \mathrm{H}, \mathrm{NH}) .{ }^{13} \mathrm{C}\left\{{ }^{1} \mathrm{H}\right\} \mathrm{NMR}$ (chloroform-d,150 MHz): $\delta 4.24,18.61,29.30(\mathrm{br}), 29.86,34.07,58.65 . \mathrm{IR}$ $\left(\mathrm{KBr}, v\left(\mathrm{~cm}^{-1}\right)\right) 1961$ (CO). Elem. Anal. found (calcd) for $\mathrm{C}_{15} \mathrm{H}_{30} \mathrm{BClF}_{4} \mathrm{~N}_{2} \mathrm{ORuS}_{2}$ : C 32.73 (33.25); $\mathrm{H}$ 5.51 (5.58); N 4.90 (5.17).

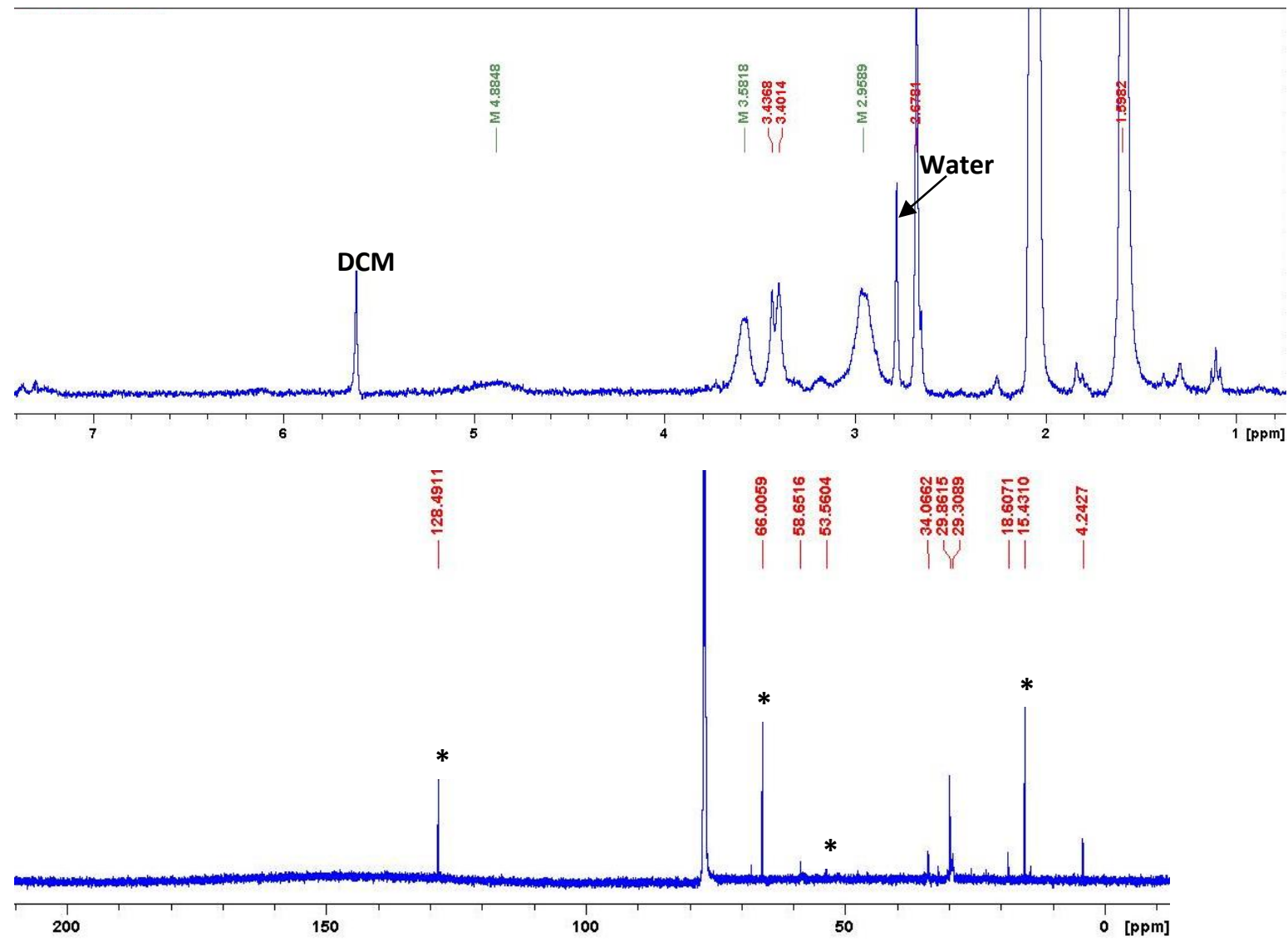

Figure S6: NMR spectra showing predominantly the major isomer of 7-ACN. (Top) ${ }^{1} \mathrm{H}$ NMR in $\left(\mathrm{CD}_{3}\right)_{2} \mathrm{CO}$ with solvent signals annotated. (Bottom) ${ }^{13} \mathrm{C} \mathrm{NMR}$ in $\mathrm{CDCl}_{3}$ with signals from benzene, diethyl ether, and DCM noted with asterisks.

$\left[\mathrm{Ru}\left({ }^{\mathrm{tBu}} \mathrm{SN}^{\mathrm{H} S}\right)(\mathrm{CO})_{2} \mathrm{Cl}\right]\left(\mathrm{BF}_{4}\right)(7-2 \mathrm{CO}):$ 7-ACN $(0.0516 \mathrm{~g}, 0.0952 \mathrm{mmol})$ was dissolved in chloroform $(17 \mathrm{~mL})$ in a $50 \mathrm{~mL}$ bomb flask and placed under $1 \mathrm{~atm} \mathrm{CO}$. The reaction was heated at $70^{\circ} \mathrm{C}$ for 18.5 hours and the solvent was then removed for NMR analysis. However, this analysis revealed incomplete conversion of the starting material, so the partially reacted solids were once again dissolved in chloroform $(10.5 \mathrm{~mL})$ and placed under CO $(1 \mathrm{~atm})$ to allow heating at $70^{\circ} \mathrm{C}$ for an additional 4.5 hours. The resulting clear, colorless solution was filtered, evaporated to dryness, and washed with diethyl ether before being recrystallized from DCM/diethyl ether at $-30^{\circ} \mathrm{C}$. This purification gives the product as an off-white solid which is typically contaminated with 89\% 7-ACN. Yield $=0.0279 \mathrm{~g}(55.5 \%)$. A small amount of highly pure X-ray quality crystals could be grown from DCM/DME. 
${ }^{1} \mathrm{H}$ NMR (chloroform- $\left.d, 300 \mathrm{MHz}\right): \delta 1.58\left(\mathrm{~s}, 18 \mathrm{H}, \mathrm{SC}\left(\mathrm{CH}_{3}\right)_{3}\right), 3.07-3.23\left(\mathrm{~m}, 4 \mathrm{H}, \mathrm{CH}_{2}\right), 3.27-3.37$ $\left(\mathrm{m}, 2 \mathrm{H}, \mathrm{CH}_{2}\right), 3.41-3.53\left(\mathrm{~m}, 2 \mathrm{H}, \mathrm{CH}_{2}\right), 6.53(\mathrm{~s}-\mathrm{br}, 1 \mathrm{H}, \mathrm{NH}) .{ }^{13} \mathrm{C}\left\{{ }^{1} \mathrm{H}\right\} \mathrm{NMR}$ (chloroform-d, $150 \mathrm{MHz}$ ): $\delta 29.73,35.92,48.66,52.30$. IR ( $\left.\mathrm{KBr}, v\left(\mathrm{~cm}^{-1}\right)\right)$ 2008, 2072 (CO).

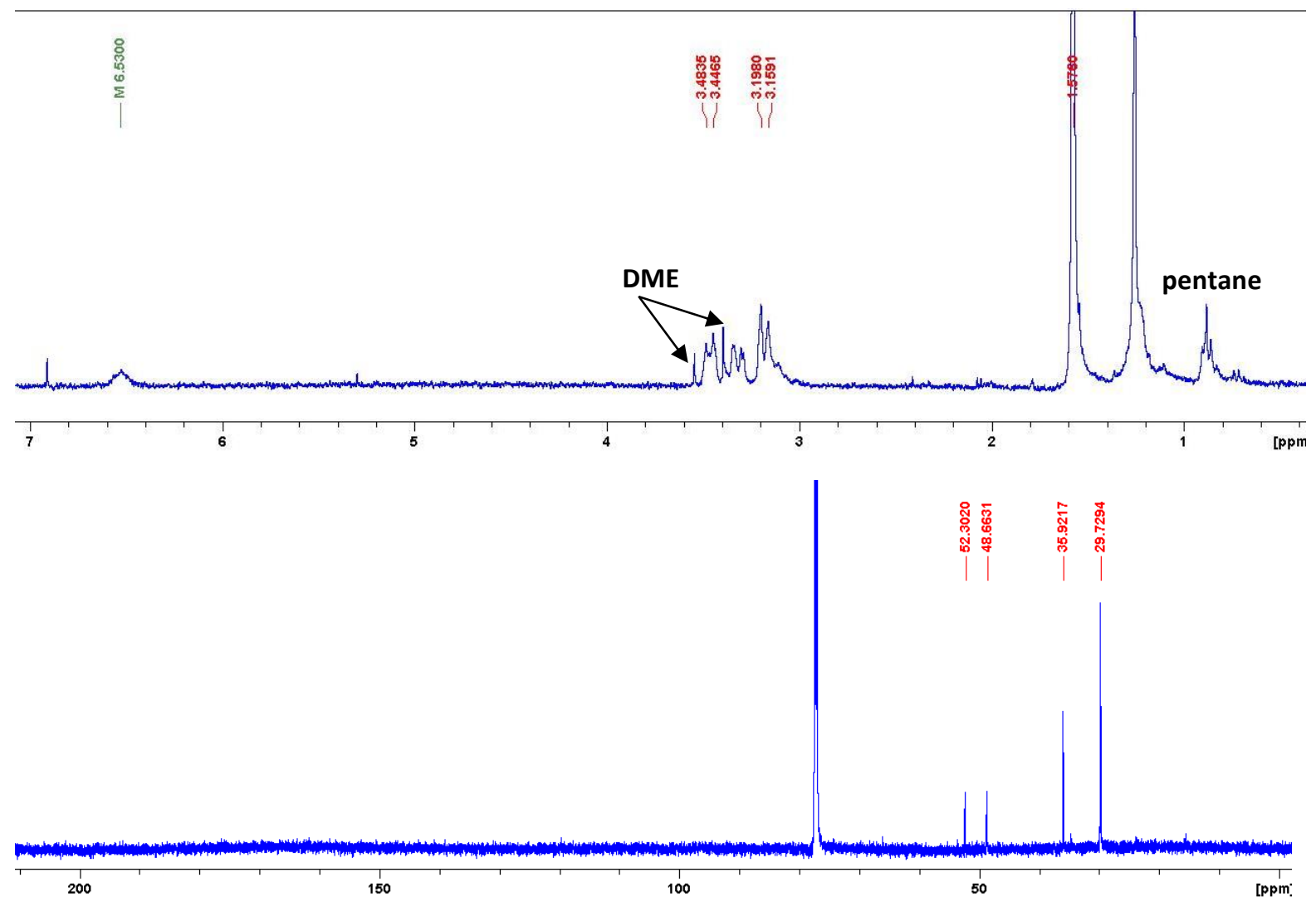

Figure S7: NMR spectra for 7-2CO in $\mathrm{CDCl}_{3}$. (Top) ${ }^{1} \mathrm{H}$ NMR with residual solvent annotated (Bottom) ${ }^{13} \mathrm{C}$ NMR.

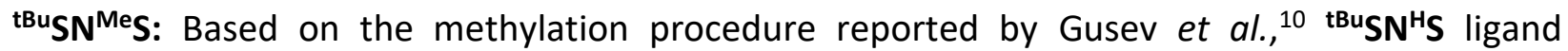
$(0.2856 \mathrm{~g}, 1.145 \mathrm{mmol})$ was combined with solid paraformaldehyde $(0.1745 \mathrm{~g})$ in a round bottom flask. Water $(1.05 \mathrm{~mL})$ was added along with formic acid $(0.2126 \mathrm{~g})$ and the flask was equipped with a reflux condenser before heating to $\sim 105^{\circ} \mathrm{C}$ in open air for 2 hours $15 \mathrm{~min}$. Upon cooling to room temperature, $5 \mathrm{M} \mathrm{NaOH}(4.6 \mathrm{~mL})$ was added to give an emulsion which was extracted with diethyl ether $(3 \times 6 \mathrm{~mL})$. The combined ether layers were then washed with water $(2 \times 6 \mathrm{~mL})$ and dried over sodium sulfate. Dried solutions were filtered through celite, and ultimately, diethyl ether was removed under vacuum to give the product as a colorless, viscous liquid. For stable, long term storage, the product was kept as a pentane solution inside a glovebox freezer. Yield= $0.2045 \mathrm{~g}(68 \%)$

${ }^{1} \mathrm{H}$ NMR (chloroform-d, 300MHz): $\delta 1.32\left(\mathrm{~s}, 18 \mathrm{H}, \mathrm{SC}\left(\mathrm{CH}_{3}\right)_{3}\right), 2.31\left(\mathrm{~s}, 3 \mathrm{H}, \mathrm{N}\left(\mathrm{CH}_{3}\right)\right), 2.54-2.71(\mathrm{~m}$, $\left.8 \mathrm{H}, \mathrm{CH}_{2}\right) .{ }^{13} \mathrm{C}\left\{{ }^{1} \mathrm{H}\right\} \mathrm{NMR}$ (chloroform-d, $150 \mathrm{MHz}$ ): $\delta 26.19,31.17,42.12,42.23,57.70$. 


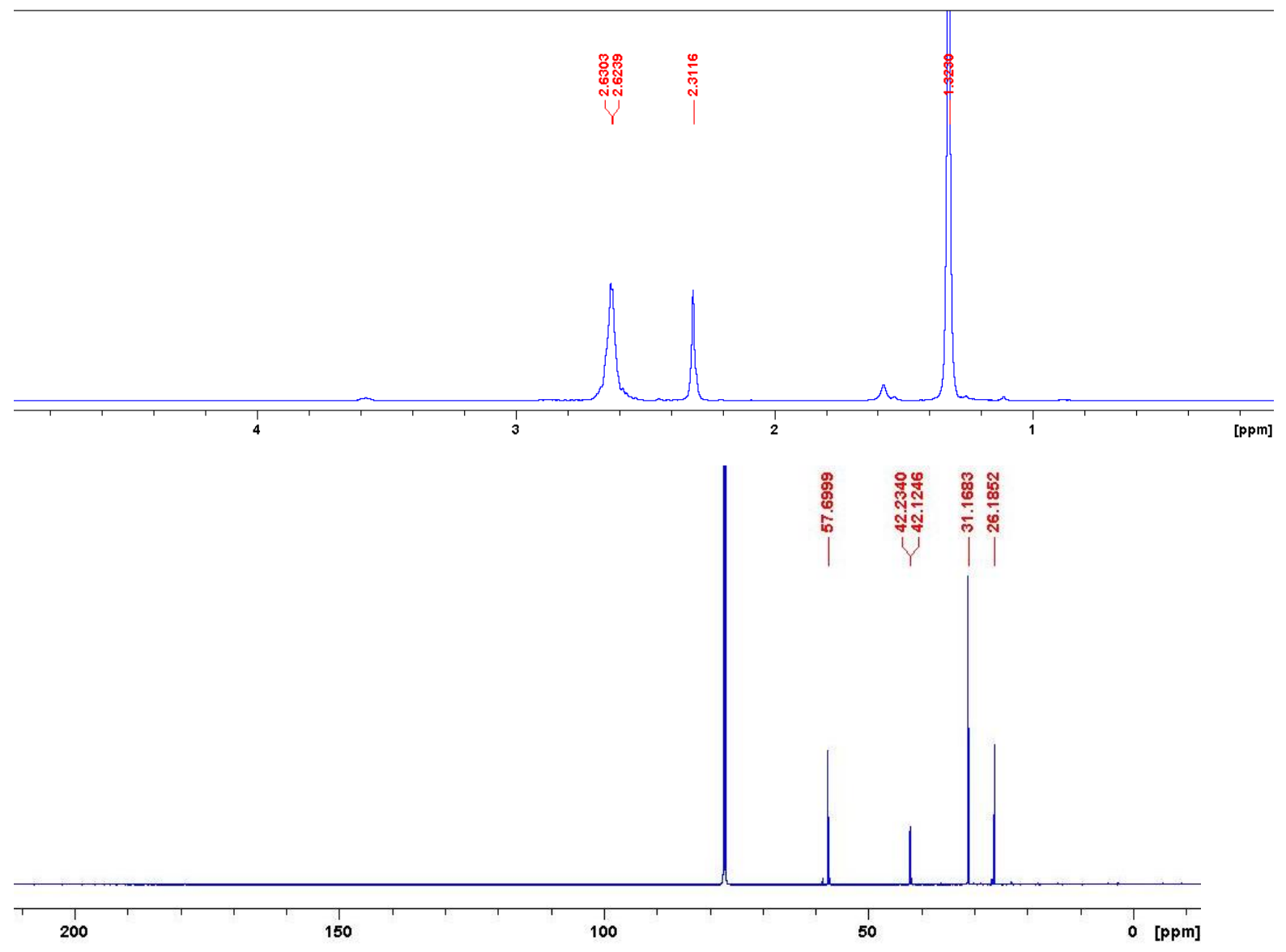

Figure S8: NMR spectra for ${ }^{\mathrm{tBu}} \mathrm{SN}^{\mathrm{Me}} \mathrm{S}$ in $\mathrm{CDCl}_{3}$. (Top) ${ }^{1} \mathrm{H} \mathrm{NMR}$ (Bottom) ${ }^{13} \mathrm{C}$ NMR.

[Ru(tBusN $\left.\left.{ }^{\mathrm{Te}} \mathrm{S}\right)(\mathrm{DMSO})(\mathrm{Cl})_{2}\right]$ (10-DMSO): Similar to the synthesis described above for 7-DMSO, $\left[\mathrm{Ru}(\mathrm{DMSO})_{4}(\mathrm{Cl})_{2}\right](0.2223 \mathrm{~g}, 0.459 \mathrm{mmol})$ and ${ }^{\mathrm{tBu}} \mathrm{SN}^{\mathrm{Me}} \mathrm{S}(0.1455 \mathrm{~g}, 0.552 \mathrm{mmol})$ were refluxed in degassed $\mathrm{MeOH}$ (30 $\mathrm{mL}$ ) under argon overnight. The next day, solvent was removed under vacuum to leave an orange residue. Inside a glovebox, this residue was washed with minimal cold EtOH $(1.5 \mathrm{~mL})$ and then suspended in room temperature $\mathrm{EtOH}(7 \mathrm{~mL})$. Decanting the suspension gave some pure product as an orange solid $(0.0329 \mathrm{~g})$. More product was collected in crystalline form $(0.0448 \mathrm{~g})$ by filtering the decanted supernatant, concentrating to half its original volume, and letting it stand in a freezer overnight. Liquids were removed and solids washed with diethyl ether to give X-ray quality crystals. Combined yield $=0.0777 \mathrm{~g}(32.9 \%)$.

As seen with other SNS complexes, broadening of the product's NMR peaks may stem from existence of multiple, similar isomers differentiated by relative positioning of the $\mathrm{S}$ - ${ }^{\mathrm{B}} \mathrm{Bu}$ groups. Hindered rotations or other fluxionality behavior also cannot be ruled out. ${ }^{11,12}$

${ }^{1} \mathrm{H}$ NMR (chloroform-d, 300MHz): $\delta 1.54\left(\mathrm{~s}, 18 \mathrm{H}, \mathrm{SC}\left(\mathrm{CH}_{3}\right)_{3}\right), 2.59-3.06\left(\mathrm{~m}, 8 \mathrm{H}, \mathrm{CH}_{2}\right), 3.13(\mathrm{~s}, 3 \mathrm{H}$, $\left.\mathrm{N}\left(\mathrm{CH}_{3}\right)\right), 3.53\left(\mathrm{~s}, 6 \mathrm{H}, \mathrm{SO}\left(\mathrm{CH}_{3}\right)_{2}\right) .{ }^{13} \mathrm{C}\left\{{ }^{1} \mathrm{H}\right\} \mathrm{NMR}$ (chloroform-d, $\left.150 \mathrm{MHz}\right): \delta 30.78,41.21,47.44(\mathrm{br})$, 48.77(br), 51.99, 60.45(br), 62.37(br). IR (KBr, v (cm-1)) 1090 (SO). Elem. Anal. found (calcd) for $\mathrm{C}_{15} \mathrm{H}_{35} \mathrm{Cl}_{2} \mathrm{NORuS}_{3}$ : C 35.17 (35.08); H 6.47 (6.87); N 2.72 (2.73). 


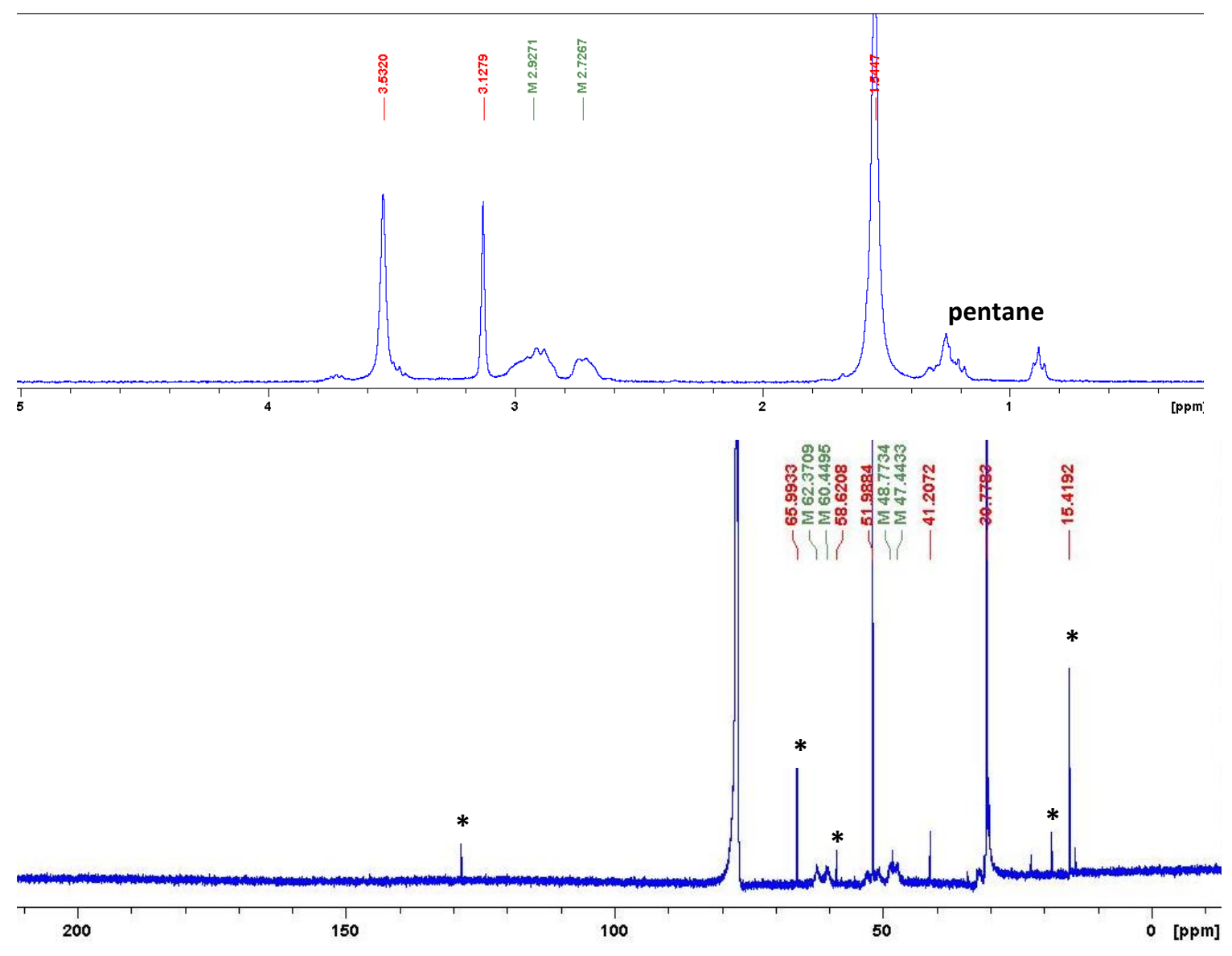

Figure S9: NMR spectra for 10-DMSO in $\mathrm{CDCl}_{3}$. (Top) ${ }^{1} \mathrm{H}$ NMR (Bottom) ${ }^{13} \mathrm{C}$ NMR with solvent peaks for residual benzene, diethyl ether, and ethanol denoted by asterisks.

$\left[\mathrm{Ru}\left({ }^{\mathrm{tBu}} \mathrm{SN}^{\mathrm{Me}} \mathrm{S}\right)(\mathrm{CO})(\mathrm{Cl})_{2}\right]$ (10-CO): The DMSO complex 10-DMSO (0.0418g, 0.081mmol) was suspended in benzene $(7.5 \mathrm{~mL})$ and added to a bomb flask within a glovebox. CO pressure ( 1atm) was added using Schlenk techniques and the reaction was stirred at $70^{\circ} \mathrm{C}$ for 21 hours. After heating, the resulting suspension was concentrated to $2 / 3$ its original volume and allowed to settle. The liquids were then decanted leaving yellow solid which was washed with diethyl ether to give pure product. Yield $=0.0164 \mathrm{~g}(43.5 \%)$. X-ray quality crystals were obtained from $\mathrm{DCM} /$ pentane.

${ }^{1} \mathrm{H}$ NMR (chloroform-d, 300MHz): $\delta 1.59\left(\mathrm{~s}, 18 \mathrm{H}, \mathrm{SC}\left(\mathrm{CH}_{3}\right)_{3}\right), 2.40$ (dd, J=3.90, $12.35 \mathrm{~Hz}, 2 \mathrm{H}, \mathrm{CH}_{2}$ ), $2.82\left(\mathrm{~s}, 3 \mathrm{H}, \mathrm{N}\left(\mathrm{CH}_{3}\right)\right), 2.85-3.12\left(\mathrm{~m}, 4 \mathrm{H}, \mathrm{CH}_{2}\right), 3.83\left(\mathrm{~m}, 2 \mathrm{H}, \mathrm{CH}_{2}\right) .{ }^{13} \mathrm{C}\left\{{ }^{1} \mathrm{H}\right\} \mathrm{NMR}$ (chloroform-d, 150 $\mathrm{MHz}): \delta 29.50,33.14,51.57(\mathrm{br}), 53.36,61.03 . \mathrm{IR}\left(\mathrm{KBr}, \mathrm{v}\left(\mathrm{cm}^{-1}\right)\right) 1944(\mathrm{CO})$. Elem. Anal. found (calcd) for $\mathrm{C}_{14} \mathrm{H}_{29} \mathrm{Cl}_{2} \mathrm{NORuS}_{2}$ : C 36.32 (36.28); H 6.12 (6.31); N 3.04 (3.02). 


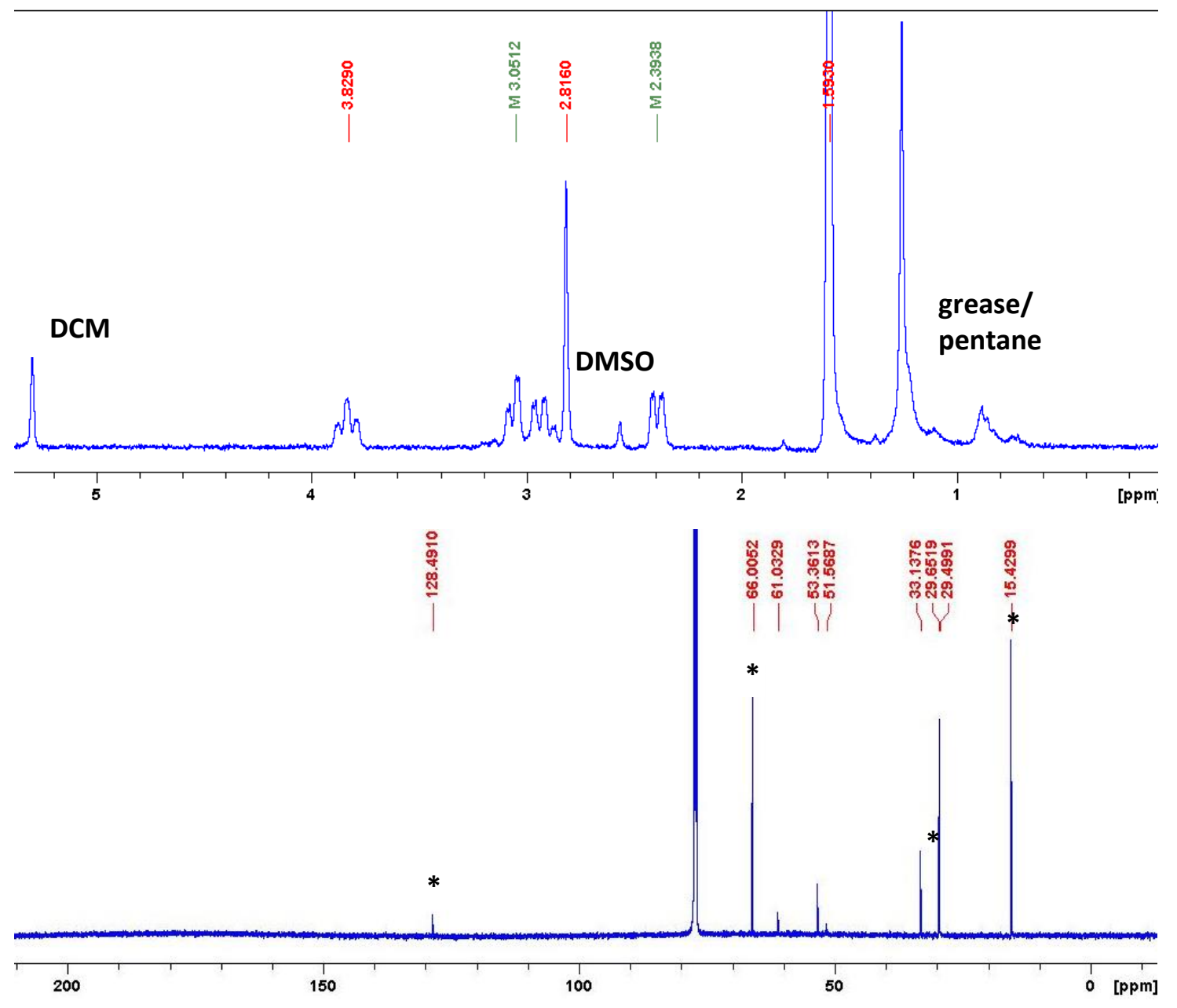

Figure S10: NMR spectra for 10-CO in $\mathrm{CDCl}_{3}$. (Top) ${ }^{1} \mathrm{H}$ NMR with residual solvent and grease peaks annotated. (Bottom) ${ }^{13} \mathrm{C}$ NMR with solvent peaks for residual benzene, diethyl ether, and grease denoted by asterisks.

$\left[\mathrm{Ru}\left({ }^{\left({ }^{P r} P N^{H} P\right.}\right)(\mathrm{CO})(\mathrm{Cl})_{2}\right](8-\mathrm{CO})$ : Inspired by the previous synthetic work of Gusev et al., ${ }^{13}$ a $50 \mathrm{~mL}$ Schlenk flask was charged with $\left[\mathrm{Ru}\left(\mathrm{PPh}_{3}\right)_{2}(\mathrm{CO})(\mathrm{DMF})(\mathrm{Cl})_{2}\right](0.0624 \mathrm{~g}, 0.078 \mathrm{mmol}), \mathrm{DME}(2 \mathrm{~mL})$, and ${ }^{~}{ }^{P r} P N^{H} P$ ligand solution $(10 \% \mathrm{w} / \mathrm{w}$ in THF, $0.276 \mathrm{~g}, 0.090 \mathrm{mmol})$. This mixture was refluxed under argon for 4 hours, and then, the DME was removed under vacuum. Inside a glovebox, residual solid was re-dissolved in minimal DME and the resulting solution was filtered through celite before being concentrated to $\sim 1 \mathrm{~mL}$. Pentane was added drop-wise until precipitation seemed eminent, and then, the mixture was left to crystallize in the freezer overnight. The supernatant was removed to leave product as yellow crystals. A $2^{\text {nd }}$ batch of crystals was obtained from the supernatant through addition of extra pentane and further chilling. Combined Yield: 0.0289g (73.4\%)

The first batch of crystals often contained a mixture of cis and trans isomers, although sometimes, nearly pure cis was obtained. The second batch of crystals made up the majority of the yield and consisted of pure trans isomer as identified by crystallography. Strong ${ }^{31} \mathrm{P}_{-}{ }^{31} \mathrm{P}$ coupling in both complex isomers causes virtual NMR coupling ${ }^{14}$ meaning that ligand carbons 
attached to the phosphine appear as virtual triplets (vt) while the proton signal for isopropyl $\mathrm{CH}_{3}$ often is a virtual doublet of triplets (vdt).

\section{cis-8-CO}

${ }^{1} \mathrm{H}$ NMR (benzene- $\left.d 6,300 \mathrm{MHz}\right): \delta 1.00(\mathrm{vdt}, J=6.41 \mathrm{~Hz}, 6 \mathrm{H}), 1.07-1.62(\mathrm{~m}, 18 \mathrm{H}), 1.70(\mathrm{vdt}, J=$ $7.62 \mathrm{~Hz}, 6 \mathrm{H}), 2.00-2.27(\mathrm{~m}, 4 \mathrm{H}), 3.43-3.60(\mathrm{~m}, 2 \mathrm{H}) .{ }^{31} \mathrm{P}\{1 \mathrm{H}\} \mathrm{NMR}$ (benzene-d6, $\left.120 \mathrm{MHz}\right): \delta 46.60$ (s). ${ }^{13} \mathrm{C}\left\{{ }^{1} \mathrm{H}\right\}$ NMR (benzene-d6, $150 \mathrm{MHz}$ ): $\delta 18.10,19.11,19.71,20.22,24.76$ (vt, J=10.11Hz), 25.26 (vt, J=10.53Hz), 27.05 (vt, J=9.41Hz), 55.93 (vt, J=2.74Hz). IR (KBr, v (cm $\left.\left.{ }^{-1}\right)\right) 1931$ (CO). Yield=0.0107g (27.2\%). Elem. anal. found (calcd) for $\mathrm{C}_{17} \mathrm{H}_{37} \mathrm{Cl}_{2} \mathrm{NOP}_{2} \mathrm{Ru}$ : C 40.97 (40.40); H 7.16 (7.38); N 2.84 (2.77).

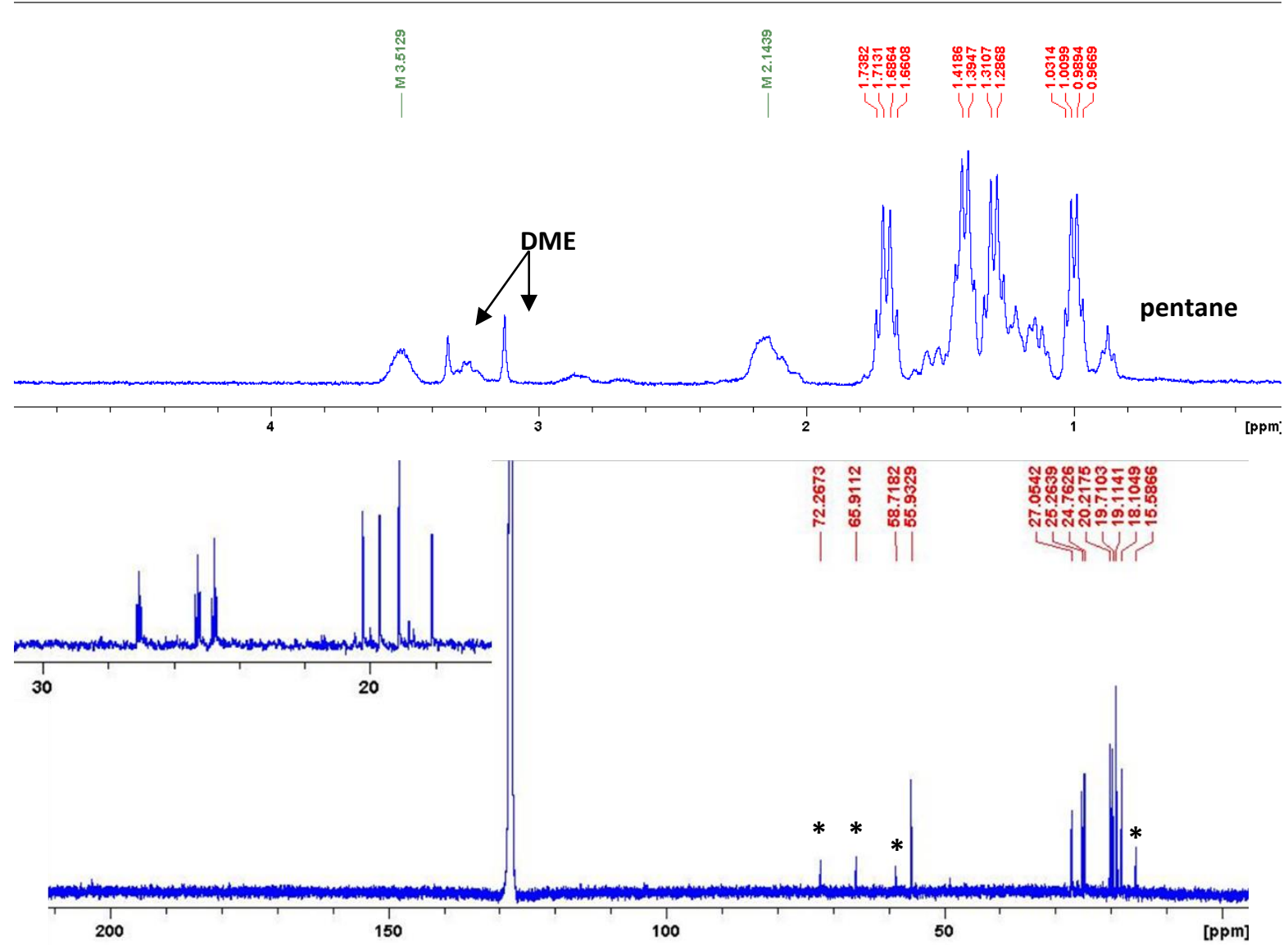

Figure S11: NMR spectra for cis-8-CO with minimal trans-8-CO in $\mathrm{C}_{6} \mathrm{D}_{6}$. (Top) ${ }^{1} \mathrm{H}$ NMR with solvent peaks annotated (Bottom) ${ }^{13} \mathrm{C}$ NMR with an inset showing the crowded alkyl region. Residual solvent signals for diethyl ether and DME are marked by asterisks.

\section{trans-8-CO}

${ }^{1} \mathrm{H}$ NMR (benzene-d6, 300MHz): $\delta 1.13(\mathrm{vdt}, J=6.82 \mathrm{~Hz}, 6 \mathrm{H}), 1.18-1.51(\mathrm{~m}, 20 \mathrm{H}), 1.67-1.80(\mathrm{~m}$, $2 \mathrm{H}), 2.17-2.39(\mathrm{~m}, 2 \mathrm{H}), 2.61-2.95(\mathrm{~m}, 6 \mathrm{H}) .{ }^{31} \mathrm{P}\{1 \mathrm{H}\}$ NMR (benzene-d6, $\left.120 \mathrm{MHz}\right): \delta 56.38(\mathrm{~s})$. ${ }^{13} \mathrm{C}\left\{{ }^{1} \mathrm{H}\right\}$ NMR (benzene-d6, $150 \mathrm{MHz}$ ): $\delta$ 18.68, 18.80, 20.00, 20.46, 21.39 (vt, J=10.39Hz), 23.58 (vt, J=11.69Hz), 26.90 (vt, J=8.03Hz), 48.91 (vt, J=3.89Hz), 207.06 (vt, J=10.76Hz). IR ( KBr, v (cm ${ }^{-}$ $\left.\left.{ }^{1}\right)\right) 1928$ (CO). Yield=0.0182g (46.2\%). Elem. anal. found (calcd) for $\mathrm{C}_{17} \mathrm{H}_{37} \mathrm{Cl}_{2} \mathrm{NOP}_{2} \mathrm{Ru}$ : C 41.02 (40.40); H 7.32 (7.38); N 2.84 (2.77). 


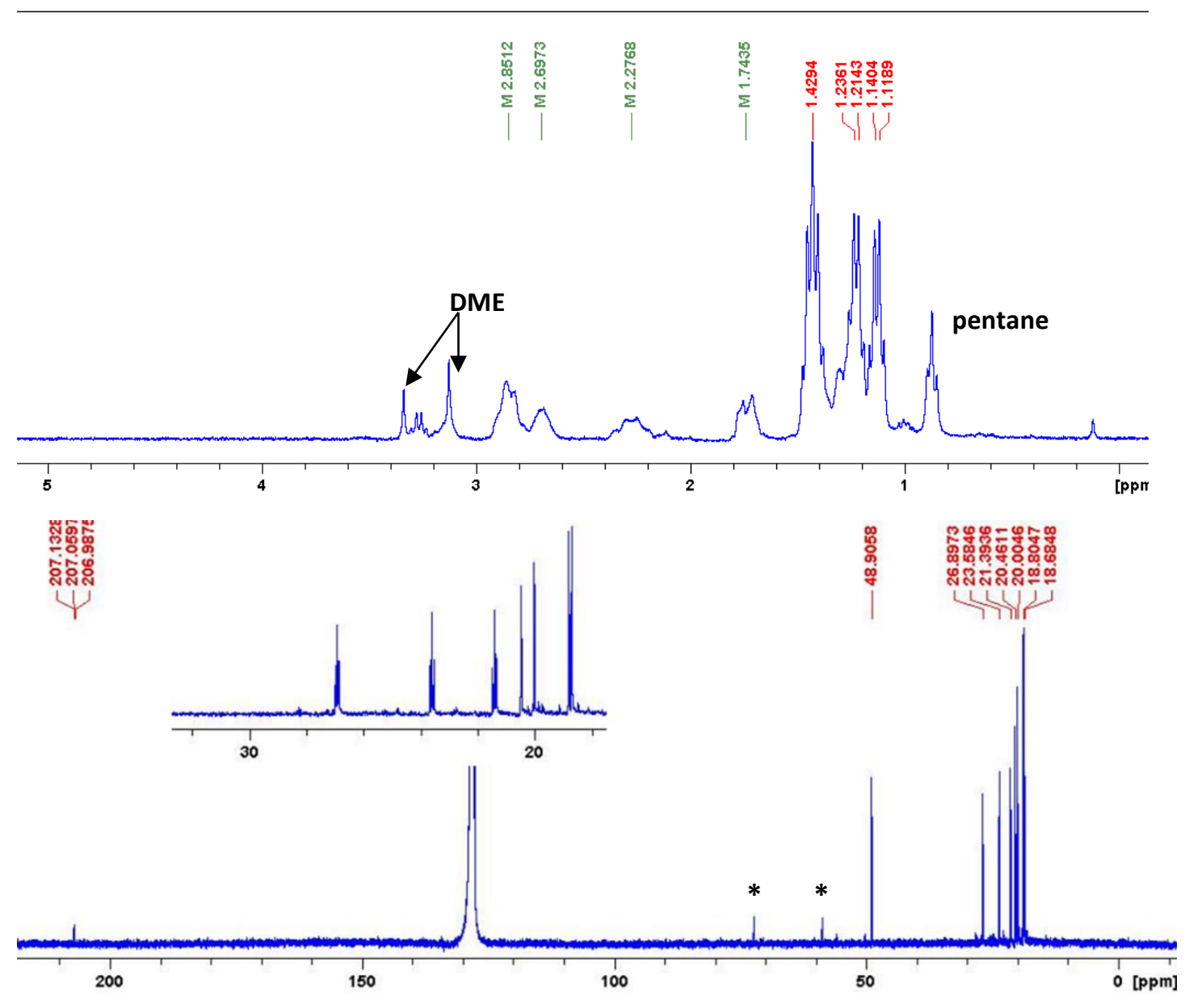

Figure S12: NMR spectra for trans-8-CO in $\mathrm{C}_{6} \mathrm{D}_{6}$. (Top) ${ }^{1} \mathrm{H}$ NMR with solvent peaks annotated (Bottom) ${ }^{13} \mathrm{C}$ NMR with residual DME signals denoted by asterisks. The inset shows an expansion of the crowded alkyl region.

NMR Scale Observation of 9: A J. Young NMR tube was charged with $\left[\mathrm{Ru}\left(\mathrm{PPh}_{3}\right)_{2}(\mathrm{CO})(\mathrm{DMF})(\mathrm{Cl})_{2}\right]$ $(0.006 \mathrm{~g}, 0.0075 \mathrm{mmol})$ and ${ }^{\mathrm{tBu}} \mathrm{SN}^{\mathrm{H} S}(0.0021 \mathrm{~g}, 0.0084 \mathrm{mmol}, 1.12 \mathrm{eq})$ in a mixture of 1,4 -dioxane $(0.56 \mathrm{~mL})$ and $\mathrm{C}_{6} \mathrm{D}_{6}(8 \mathrm{drops})$. The sealed tube was heated at $90-92^{\circ} \mathrm{C}$ for a total of $5 \mathrm{hr}$ with progress tracked through in situ ${ }^{31} \mathrm{P}$ NMR spectroscopy. After heating, the solvent was removed under vacuum in a glove box and solid residues were washed with pentane. The remaining solids were then dissolved in $\mathrm{C}_{6} \mathrm{D}_{6}$ for ${ }^{1} \mathrm{H}$ NMR spectroscopy. The high solubility of the product alone signified that it was not the desired, sparingly soluble 7-CO. Time elapsed ${ }^{31} \mathrm{P}$ spectra show that during the ligation reaction, free $\mathrm{PPh}_{3}(-4.7 \mathrm{ppm})$ and a new complexed phosphine (34.5ppm) evolve in a near 1 to 1 ratio suggestive of displacement of one $\mathrm{PPh}_{3}$ from the starting material by ${ }^{\text {tBu}}{ }^{-} N^{H} S$ and continued attachment of the other phosphine in the new SNS complex. The product ${ }^{1} \mathrm{H}$ spectrum shows expected signals for free ligand and dissociated $\mathrm{PPh}_{3}$, but it also shows unknown alkyl and aromatic signals again suggesting a product complex containing both SNS and $\mathrm{PPh}_{3}$. Notably, among the unknown alkyl signals, two potential S- ${ }^{\mathrm{t}} \mathrm{Bu}$ singlets can be observed with one appearing downfield of free ligand (1.27 ppm) as expected for a bound group and the other shifted significantly upfield $(0.70 \mathrm{ppm})$. The distinct 1 to 1 ratio of these 
signals means that the two different $\mathrm{S}-{ }^{\mathrm{t}} \mathrm{Bu}$ groups likely exist in one product complex. Taking the ${ }^{31} \mathrm{P}$ and ${ }^{1} \mathrm{H}$ NMR evidence together, the most likely course of the reaction is replacement of weak DMF ligand and one $\mathrm{PPh}_{3}$ by ${ }^{\mathrm{tBu}} \mathrm{SN}^{\mathrm{H} S}$ to give product 9 which retains one bound $\mathrm{PPh}_{3}$ and has $\mathrm{K}^{2}$-SNS coordination with one bound and one free $\mathrm{S}-{ }^{\mathrm{t}} \mathrm{Bu}$. The extreme upfield shifting of the suspected unbound $\mathrm{S}-{ }^{\mathrm{t}} \mathrm{Bu}$ could implicate ring current from close proximity to $\mathrm{PPh}_{3}$.
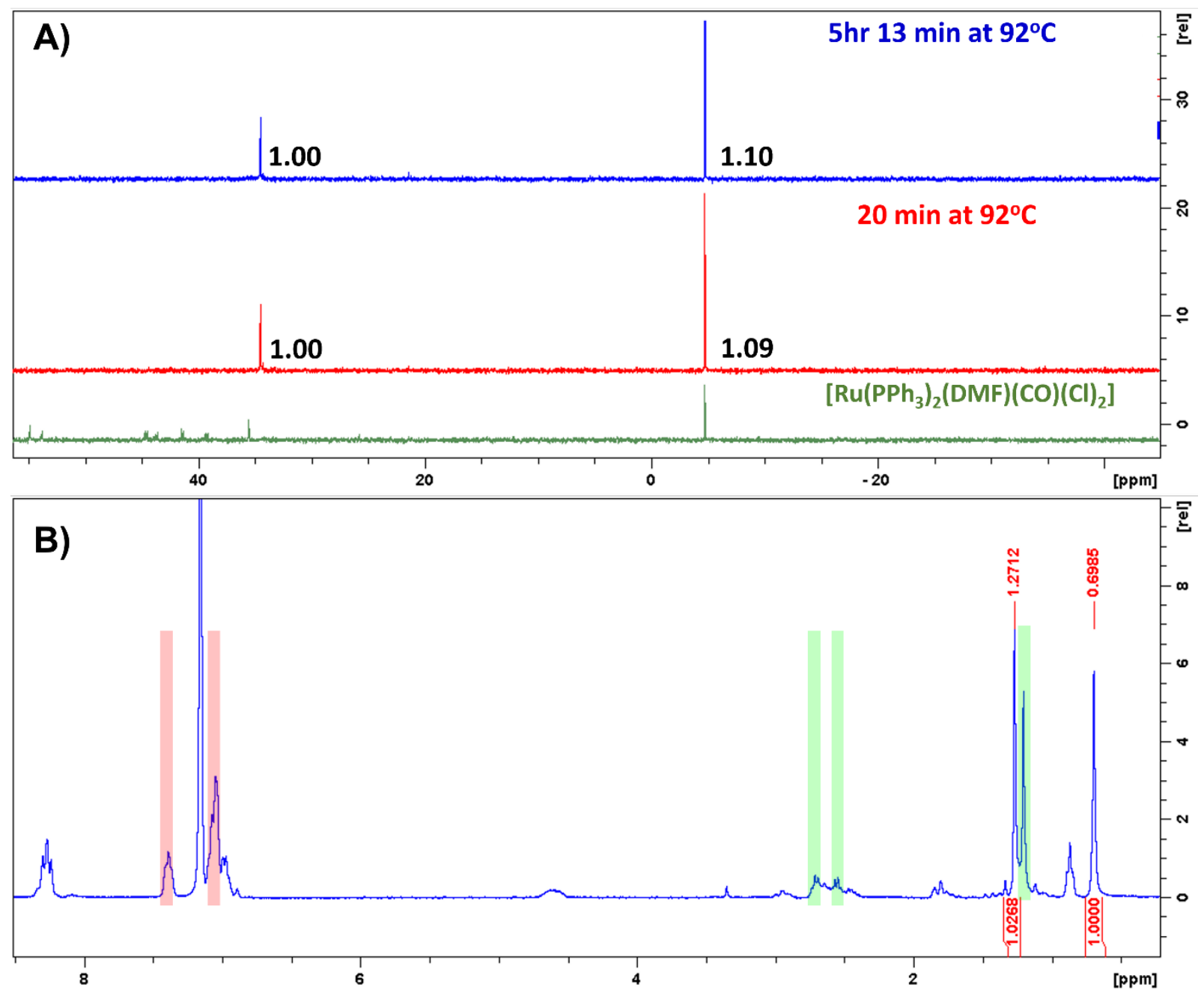

Figure S13: Spectra from an NMR scale reaction of $\left[\mathrm{Ru}\left(\mathrm{PPh}_{3}\right)_{2}(\mathrm{DMF})(\mathrm{CO})(\mathrm{Cl})_{2}\right]$ and ${ }^{\mathrm{Bu}} \mathrm{SN}^{\mathrm{H} S}$. (A) ${ }^{31} \mathrm{P}$ spectra comparing Ru starting material (heated to dissolution) without SNS ligand and the reaction mixture after heating to $92^{\circ} \mathrm{C}$ for $20 \mathrm{~min}$ (red) as well as $5 \mathrm{hr} 13 \mathrm{~min}$ (blue). Key peak integration values are noted in black. (B) ${ }^{1} \mathrm{H}$ NMR spectrum of the crude reaction products with known signals for excess ligand and free $\mathrm{PPh}_{3}$ shaded in green and red respectively. 


\section{$\underline{\text { X-ray Crystallography }}$}

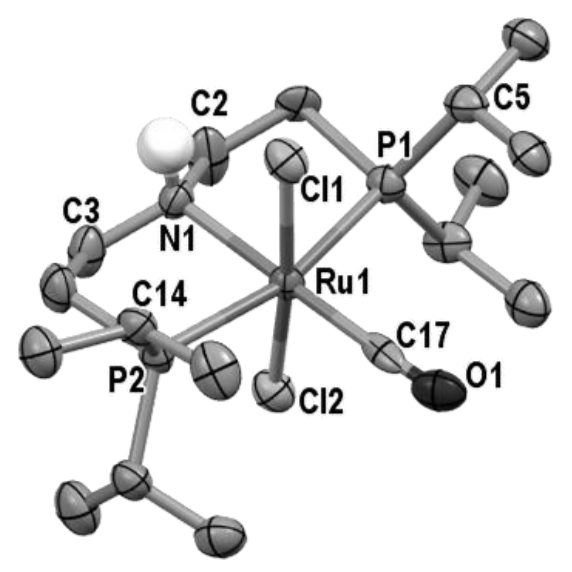

Figure S14: Crystal structure for the major isomer of 8-CO shown with displacement ellipsoids at $30 \%$. Inconsequential hydrogens are omitted for clarity. Select bond lengths: Ru1-P1 = 2.328(2), Ru1-P2 = 2.347(2), Ru1-C17 = 1.85(1), Ru1-N1 = 2.165(9), Ru1-Cl1 = 2.338(3), Ru1-Cl2 $=2.408(3), \mathrm{P} 1-\mathrm{C} 5=1.83(1), \mathrm{P} 2-\mathrm{C} 14=1.82(1), \mathrm{N} 1-\mathrm{C} 2=1.44(1), \mathrm{N} 1-\mathrm{C} 3=1.46(1)$. 
Table S1: Select bond lengths (Å) and angles (deg) for 5-2CO

\begin{tabular}{|c|c|}
\hline Bond & $\begin{array}{c}\text { Bond Lengths (Å) \& } \\
\text { Angles ( }\end{array}$ \\
\hline Ru1-S1
\end{tabular}


Table S2: Select bond lengths $(\AA ̊)$ and angles (deg) for aliphatic SNS crystal structures

\begin{tabular}{|c|c|c|c|c|}
\hline \multirow{2}{*}{ Bond } & \multicolumn{4}{|c|}{ Bond Lengths $(\AA)$ and Angles $\left({ }^{\circ}\right)$} \\
\hline & 7-DMSO & $7-2 \mathrm{CO}$ & 10-DMSO & $10-\mathrm{CO}$ \\
\hline Ru1-S1 & $2.367(2)$ & $2.372(1)$ & $2.3284(8)$ & $2.3580(7)$ \\
\hline Ru1-S2 & $2.357(2)$ & $2.371(1)$ & $2.3244(8)$ & $2.3544(7)$ \\
\hline Ru1-Cl1 & $2.446(2)$ & $2.4280(9)$ & $2.4186(8)$ & $2.4149(6)$ \\
\hline $\mathrm{Ru} 1-\mathrm{Cl} 2$ & $2.434(2)$ & & $2.4197(8)$ & $2.4542(7)$ \\
\hline Ru1-N1 & $2.123(4)$ & $2.147(3)$ & $2.192(2)$ & $2.141(2)$ \\
\hline $\mathrm{N} 1-\mathrm{C} 2$ & $1.464(9)$ & $1.479(5)$ & $1.494(4)$ & $1.490(3)$ \\
\hline N1-C3 & $1.462(8)$ & $1.482(6)$ & $1.485(4)$ & $1.479(3)$ \\
\hline $\mathrm{N} 1-\mathrm{H} 1$ & $1.03(7)$ & $0.79(7)$ & & \\
\hline N1-C13 (or C12) & & & $1.485(4)$ & $1.482(3)$ \\
\hline S2-C9 (or COAA) & $1.855(7)$ & $1.864(4)$ & $1.879(3)$ & $1.849(3)$ \\
\hline S1-C5 & $1.848(6)$ & $1.856(5)$ & $1.858(3)$ & $1.841(2)$ \\
\hline Ru1-S3 & $2.209(2)$ & & $2.2343(8)$ & \\
\hline S3-01 & $1.481(4)$ & & $1.475(3)$ & \\
\hline C13-01 & & $1.131(4)$ & & $1.143(3)$ \\
\hline C14-O2 & & $1.126(4)$ & & \\
\hline N1-Ru1-S1 & $81.93^{\circ}$ & $83.82^{\circ}$ & $84.98^{\circ}$ & $85.22^{\circ}$ \\
\hline N1-Ru1-S2 & $82.95^{\circ}$ & $83.51^{\circ}$ & $84.65^{\circ}$ & $84.52^{\circ}$ \\
\hline H1-N1-Ru1 & $91.81^{\circ}$ & $106.94^{\circ}$ & & \\
\hline C13(C12)-N1-Ru1 & & & $101.01^{\circ}$ & $113.66^{\circ}$ \\
\hline C5-S1-Ru1 & $125.15^{\circ}$ & $121.04^{\circ}$ & $127.12^{\circ}$ & $121.70^{\circ}$ \\
\hline N1-Ru1-S3 & $98.19^{\circ}$ & & $177.76^{\circ}$ & \\
\hline
\end{tabular}




\section{Electrochemistry}

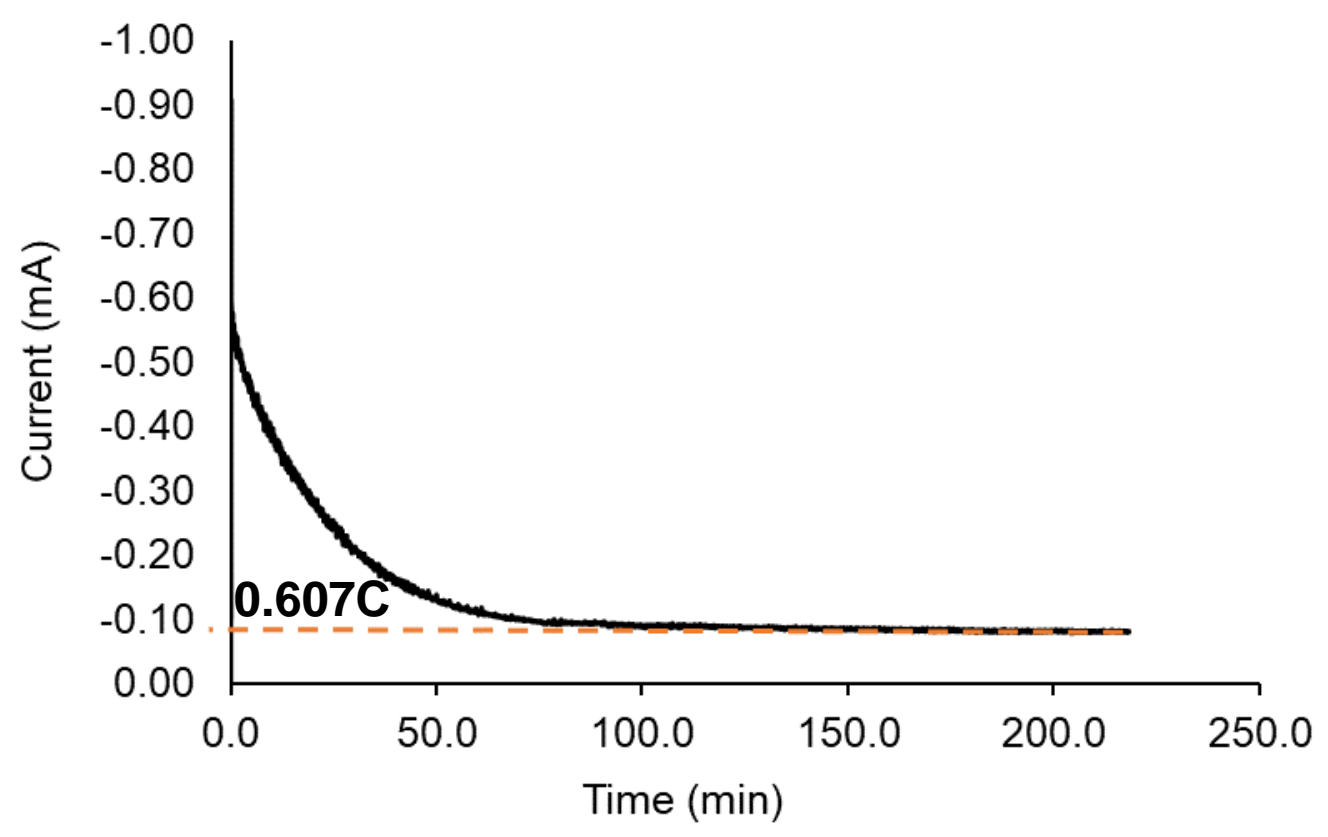

Figure S15: Electrolysis of 7-CO at a potential just slightly more cathodic than its first reduction (-2.42V vs Fc) under argon in $\mathrm{ACN}_{\text {with } 0.1 \mathrm{M} \mathrm{TBAPF} 6}$ electrolyte. Integration under the curve with subtraction of background current (denoted by orange, dashed line) reveals that the first reduction process involves 1 electron per molecule of Ru complex (0.607C per $2.5 \mathrm{mg} \mathrm{Ru}$ ).

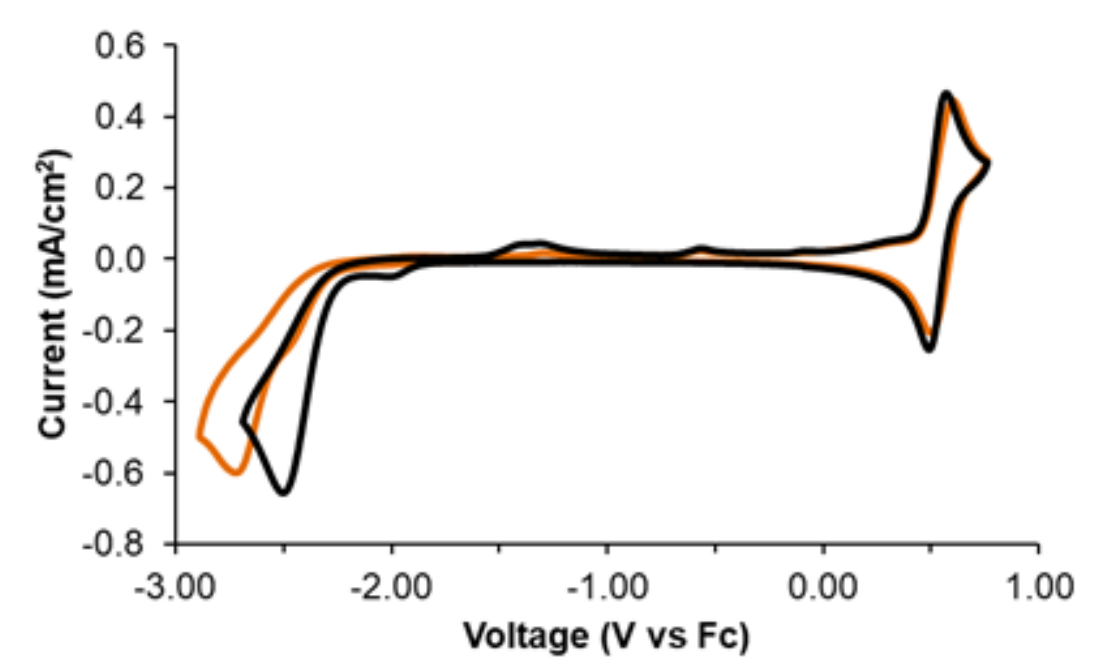

Figure S16: Cyclic voltammograms comparing the trans (black) and cis (orange) isomers of 8-CO. The cis isomer could not be isolate completely free of trans, so its reduction has a shoulder representing a minor amount of trans-8-CO contamination. Voltammetry was conducted in $0.1 \mathrm{M} \mathrm{TBAPF}_{6} / \mathrm{ACN}$ under argon using a scan rate of $100 \mathrm{mV} / \mathrm{s}$ with a glassy carbon electrode. 

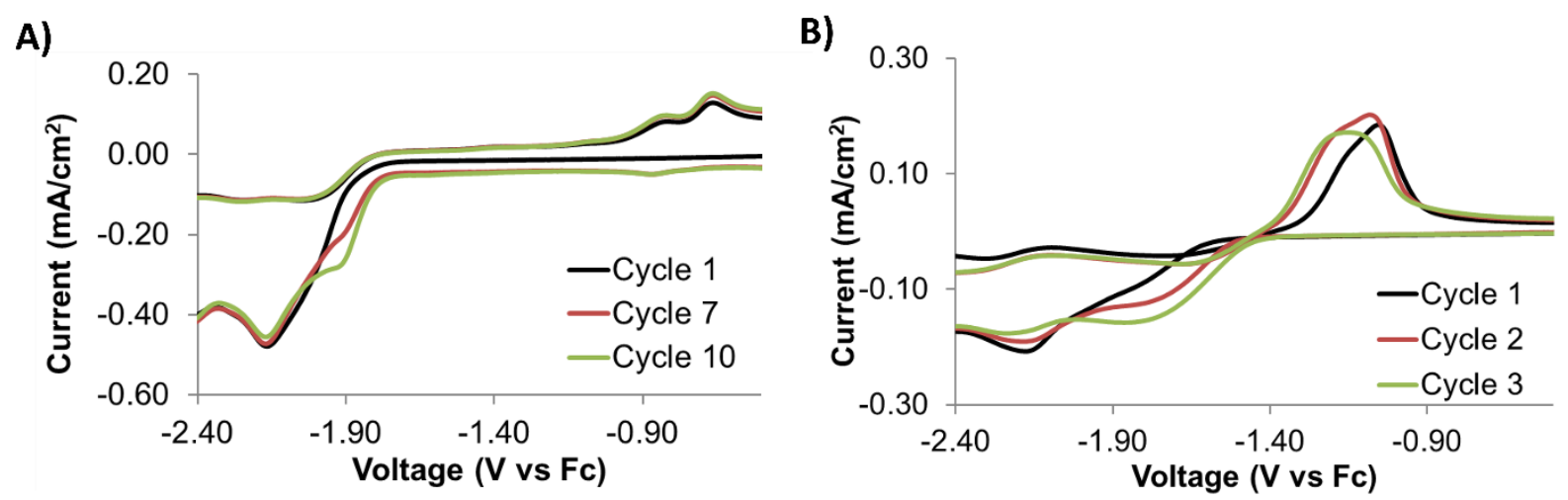

Figure S17: Voltammetry revealing similarities in the cycling of reduction for (A) 5-PPh 3 and (B) $\left[\left({ }^{\text {tBu}} \mathrm{SN}_{\mathrm{py}} \mathrm{S}\right) \mathrm{Zn}(\mathbf{C l})_{2}\right.$ ]. Cycling was conducted under argon in $0.1 \mathrm{M}$ TBAPF 6 /ACN with a glassy carbon electrode. Scan rate was $100 \mathrm{mV} / \mathrm{s}$ and analyte concentration was $1.8 \mathrm{mM}$. 


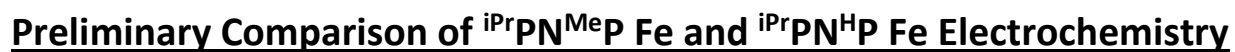

Cyclic voltammograms were collected on the previously reported PNP Fe complexes $\left[\mathrm{Fe}\left({ }^{\mathrm{iPr} P N}{ }^{\mathrm{R} P}\right)(\mathrm{CO}){ }_{2} \mathrm{H}\right](\mathrm{OTf})(\mathrm{R}=\mathrm{H} \text { or } \mathrm{Me})^{15-18}$ and $\left[\mathrm{Fe}\left({ }^{\left(\mathrm{Pr}^{2} \mathrm{PN}\right.}{ }^{\mathrm{R} P}\right)(\mathrm{HCOO})(\mathrm{CO}) \mathrm{H}\right](\mathrm{R}=\mathrm{H} \text { or } \mathrm{Me})^{16,19}$ to provide additional information on the electronic influence of $\mathrm{N}-\mathrm{H} / \mathrm{N}-\mathrm{Me}$ pincer backbone effects. The voltammograms show that for direct PNP Fe analogues differing only in methylation of their ligand nitrogen, the methylated complexes undergo a milder reduction by ca 0.10 to $0.15 \mathrm{~V}$. These findings appear to contradict expected inductive donation of the tertiary amine $\mathrm{v}$. secondary amine ligand. However, these results are in agreement with relative reduction potentials observed for $\mathrm{SN}^{\mathrm{H} S}$ and $\mathrm{SN}^{\mathrm{Me}} \mathrm{S}$ complexes (7-CO vs 10-CO) where again the $\mathrm{N}$-Me congener is easier to reduce (Table 1, main text). This suggests that non-inductive effects dominate the electronic impact of this ligand variation. Abbreviations: ${ }^{\mathrm{Pr} P N^{H} \mathrm{P}=}$ $\mathrm{HN}\left\{\mathrm{CH}_{2} \mathrm{CH}_{2}\left(\mathrm{P}\left({ }^{\mathrm{i} P r}\right)_{2}\right)\right\}_{2}$, ${ }^{\text {iPr PN }}{ }^{\mathrm{MeP}}=\left(\mathrm{CH}_{3}\right) \mathrm{N}\left\{\mathrm{CH}_{2} \mathrm{CH}_{2}\left(\mathrm{P}\left({ }^{\mathrm{i} P r}\right)_{2}\right)\right\}_{2}$
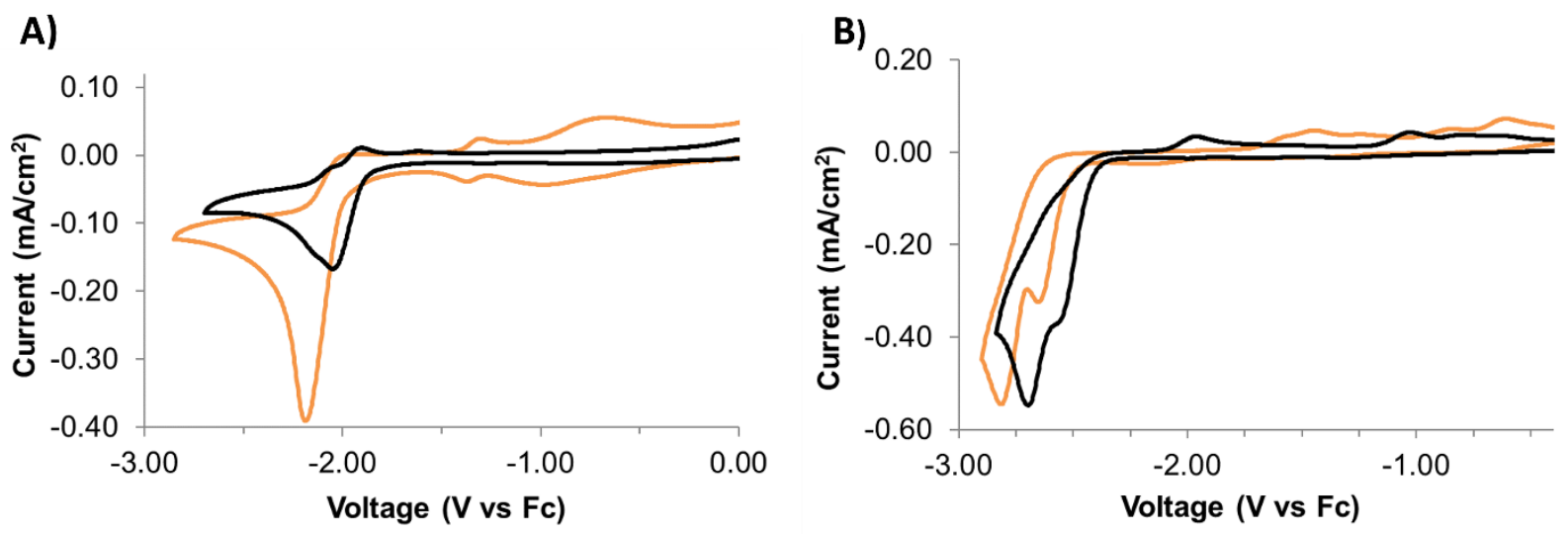

Figure S18: Cyclic voltammograms illustrating the difference in reduction observed for Fe complexes with methylated versus secondary amine PNP ligands. (A) Comparison of $\left[\mathrm{Fe}\left({ }^{(\mathrm{PrPN}}{ }^{\mathrm{H} P}\right)(\mathrm{CO}){ }_{2} \mathrm{H}\right](\mathrm{OTf})$ (orange, $\left.\mathrm{E}_{\mathrm{pc}}=-2.19 \mathrm{~V}, 1.6 \mathrm{mM}\right)^{15,16}$ and $\left[\mathrm{Fe}\left({ }^{\mathrm{iPr} P N}{ }^{\mathrm{MeP}}\right)(\mathrm{CO}){ }_{2} \mathrm{H}\right](\mathrm{OTf})^{17,18}$ (black, $E_{p c}=-2.04 \mathrm{~V}, 0.8 \mathrm{mM}$ ) under argon in $0.11 \mathrm{M}$ TBAPF $6 / T H F$. (B) Comparison of $\left[\mathrm{Fe}\left({ }^{\mathrm{iPr} P N}{ }^{\mathrm{H} P}\right)(\mathrm{HCOO})(\mathrm{CO}) \mathrm{H}\right]$ (orange, $\left.\mathrm{E}_{\mathrm{pc}}=-2.65,-2.81,1.6 \mathrm{mM}\right)^{16}$ and [Fe( $\left.\left.{ }^{\text {(PrPN }}{ }^{\mathrm{MeP}}\right)(\mathrm{HCOO})(\mathrm{CO}) \mathrm{H}\right]$ (black, $\left.E_{p c}=-2.56 s h,-2.69,1.5 \mathrm{mM}\right)^{19}$ under argon in $0.1 \mathrm{M} \mathrm{TBAPF}_{6} / \mathrm{ACN}$. Voltammograms were collected with a glassy carbon disk working electrode scanning at $100 \mathrm{mV} / \mathrm{s}$.

\section{$\underline{\text { Attempted Electrocatalytic } \mathrm{CO}_{2} \text { Reduction }}$}

Catalyst Screening: Complexes 5-CO, 5-2CO, 7-CO, 7-ACN, and 10-CO were screened as possible electrocatalysts for $\mathrm{CO}_{2}$ reduction by comparing voltammograms collected under inert $\mathrm{Ar}$ and those taken under $\mathrm{CO}_{2}$ both with and without TFE added as a proton source (Figure S19). 5-2CO has no response to $\mathrm{CO}_{2}$. However, in line with possible catalytic turnover, complexes 5-CO, 7$\mathrm{CO}$, and 10-CO all respond to $\mathrm{CO}_{2}$ with enhanced reduction current which further increases upon addition of TFE. 7-ACN does not show significant enhancement of its first reduction under $\mathrm{CO}_{2}$ but cannot be ruled out as a catalyst because a new, high current process appears directly after initial reduction. 
Bulk Electrolysis Results: Promising candidates from voltammetry (5-CO, 7-CO, and 7-ACN) were further explored as catalysts via electrolysis conducted in the presence of $\mathrm{CO}_{2}$ and TFE at a constant potential just negative of the complex's reduction. After application of potential, the state of the original Ru complex was ascertained by running a follow-up cyclic voltammogram. Moreover, the electrolysis solution as well as the headspace were analyzed for products commonly observed during $\mathrm{CO}_{2}$ reduction including oxalate, formate, $\mathrm{CO}$, and $\mathrm{H}_{2}$ (see details below). None of these products are detected from electrolysis of 5-CO. Furthermore, current from that complex decays rapidly overtime, and its post electrolysis voltammogram indicates loss of original signals more suggestive of decomposition than catalysis (Figure S20). Complexes 7-CO and 7-ACN allow more stable current output. They produce no detectable oxalate (by precipitation) but do give CO and formate in low faradaic efficiency (Table S3, Figures S21-S22) as well as hydrogen in more moderate efficiency.

For 7-CO, further exploration has been conducted including using water as a weaker proton source instead of TFE to suppress hydrogen generation in favor of $\mathrm{CO}_{2}$ reduction. This change successfully blocks hydrogen evolution but only moderately improves CO production and actually decreases formate yield. Interestingly, in all electrolysis runs with 7-CO, total faradaic efficiency consistently sits below $40 \%$ despite evidence against major decomposition including sustained current over time and strong retention of 7-CO's reduction in the post electrolysis voltammogram. To account for the missing faradaic efficiency, possible methanol formation was investigated, but ultimately, no methanol was detected by GC and the processes underlying the poor faradaic efficiency remain undetermined. All available observations suggest 7-CO is not a strong electrocatalyst for $\mathrm{CO}_{2}$ reduction.

Electrolysis Experimental: Electrolysis was conducted in the same air-tight two compartment cell used for voltammetry (see experimental materials and methods). Constant voltage was applied using a $\mathrm{Ag} / \mathrm{AgNO}_{3}$ reference and platinum coil counter electrode with a glassy carbon rod (Alfa Aesar, 6mm dia., type 2) as the working electrode. Mechanical stirring was maintained throughout via a magnetic stir bar. Typical electrolysis solutions consisted of 0.1M TBAPF 6 in ACN with $68 \mathrm{mM}$ distilled TFE. Analyte concentration was $1.8-2 \mathrm{mM}$ or saturation in the case of poorly soluble 7-CO.

\section{Product Analysis Details}

$\mathrm{CO} / \mathrm{H}_{2}$ : Directly after electrolysis, two separate headspace samples $(54 \mu \mathrm{L})$ were analyzed for gaseous products using a Thermo Fisher 1300 Trace GC equipped with a TCD detector and Restek ShinCarbon ST packed column (2m, I.D. 1mm, O.D. 1/16"). Helium was employed as the carrier and reference gas.

Formate: Following headspace analysis, $\mathrm{KOH}$ was added to the electrolysis solution in order to convert any volatile formic acid to formate. Solvents were then removed under vacuum and residual solids were extracted with $\mathrm{D}_{2} \mathrm{O}$. After extraction, remaining solids were dissolved in chloroform which then was again extracted with $\mathrm{D}_{2} \mathrm{O}$. Both $\mathrm{D}_{2} \mathrm{O}$ samples were probed via ${ }^{1} \mathrm{H}$ NMR using sodium benzoate as an internal standard for quantification. 
Oxalate: $\mathrm{CaCl}_{2}$ was added to the combined $\mathrm{D}_{2} \mathrm{O}$ samples from formate analysis and $\mathrm{pH}$ was adjusted to 7 using dilute $\mathrm{HCl}$. Resulting precipitate was inspected via ATR IR spectroscopy but only calcium carbonate was ever observed.

$\mathrm{MeOH}$ : Volatile liquids from the electrolysis solution were separated from electrolyte via vacuum transfer into a bomb flask. Collected liquids were analyzed by ${ }^{1} \mathrm{H}$ NMR with solvent suppression as well as by gas chromatography. The latter employed helium carrier gas with a Thermo Fisher 1300 Trace GC having an FID detector and a Thermo TG-5MS amine column (30m).

A)

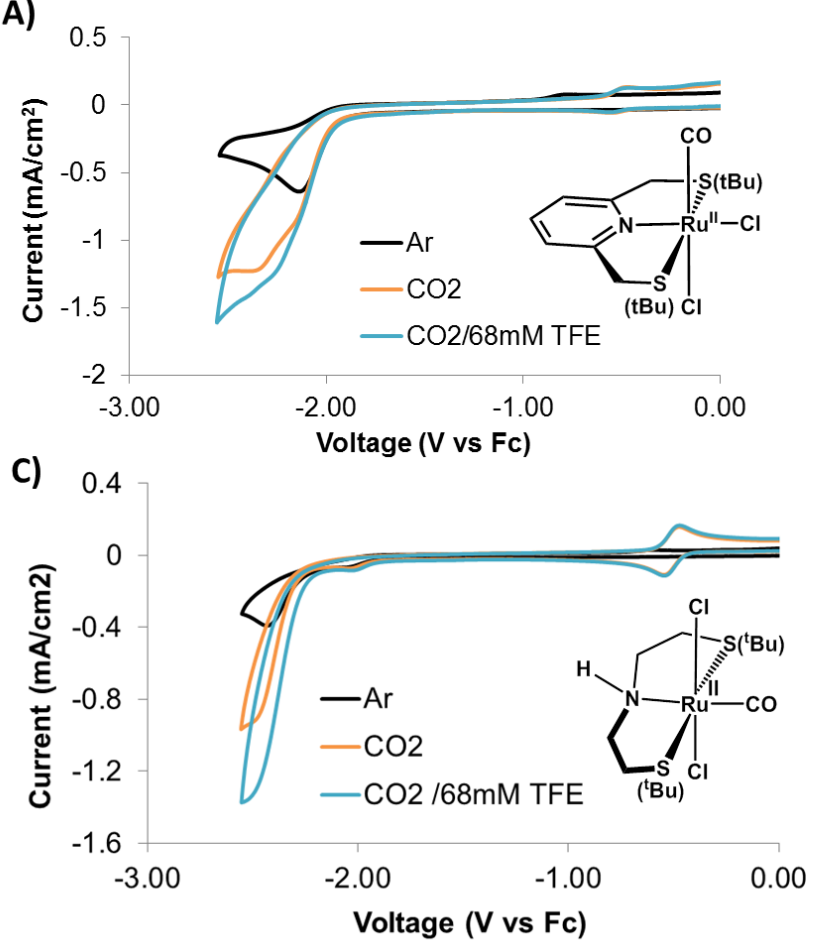

B)

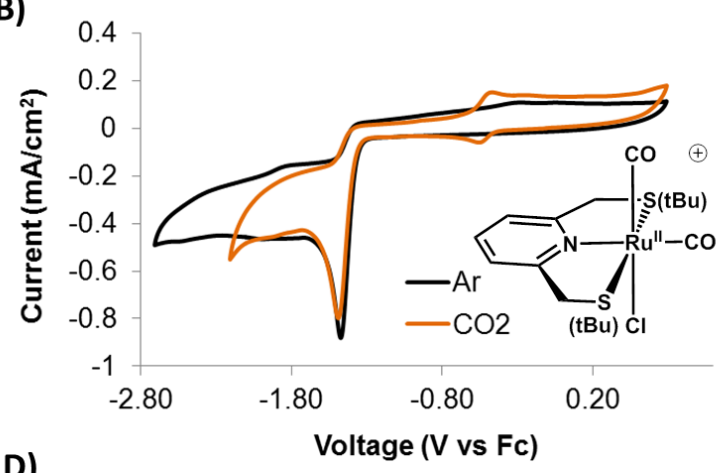

D)

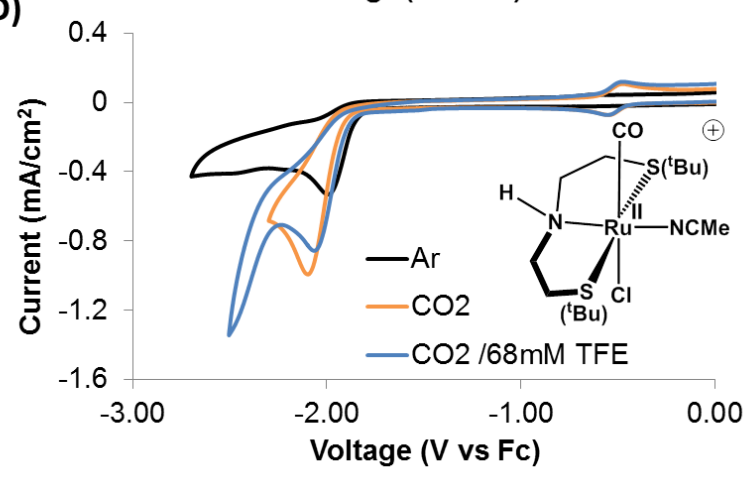

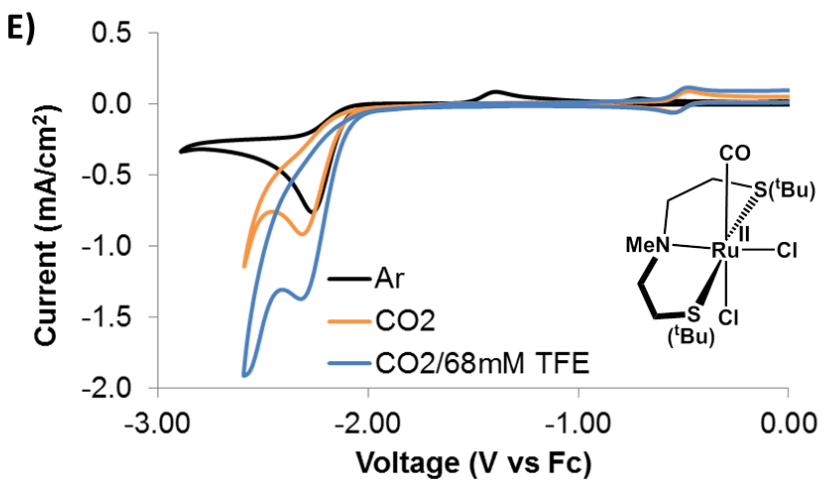

Figure S19: Screening for electrocatalytic activity via cyclic voltammetry for complexes (A) 5-CO, (B) 5-2CO, (C) 7-CO, (D) 7-ACN, and (E) 10-CO. Voltammograms compare reductive currents under inert argon (black), $\mathrm{CO}_{2}$ (orange), and $\mathrm{CO}_{2}$ with added TFE as a proton source (blue). 
Table S3: Faradaic Efficiencies from Electrolysis of Ru SNS Complexes under $\mathrm{CO}_{2}{ }^{\mathrm{a}}$

\begin{tabular}{|c|c|c|c|c|c|c|c|}
\hline $\begin{array}{l}\text { Catalyst } \\
\text { (Conc) }\end{array}$ & $\begin{array}{l}\text { Acid } \\
\text { (conc) }\end{array}$ & $\begin{array}{l}\text { Potential } \\
\text { (V vs Fc) }\end{array}$ & $\begin{array}{c}\text { Charge } \\
\text { (C) }\end{array}$ & $\begin{array}{l}\mathrm{FE} \\
\mathrm{H}_{2}\end{array}$ & $\begin{array}{l}\text { FE } \\
\text { CO }\end{array}$ & $\begin{array}{c}\text { FE } \\
\text { Formate }\end{array}$ & $\begin{array}{c}\text { FE } \\
\text { Oxalate }\end{array}$ \\
\hline $\begin{array}{l}\text { 7-ACN } \\
(1.79 \mathrm{mM})\end{array}$ & $\begin{array}{c}\text { TFE } \\
(68.3 \mathrm{mM})\end{array}$ & -2.33 & 5.616 & $26.3 \%$ & $3.11 \%$ & $2.01 \%$ & n.d. \\
\hline $\begin{array}{l}\text { 7-CO } \\
\text { (Sat.) }\end{array}$ & $\begin{array}{c}\text { TFE } \\
(68.3 \mathrm{mM})\end{array}$ & -2.33 & 5.602 & $30 \%$ & $4.68 \%$ & $4.63 \%$ & n.d. \\
\hline $\begin{array}{l}\text { 7-CO } \\
\text { (Sat.) }\end{array}$ & $\begin{array}{c}\text { TFE } \\
(68.3 \mathrm{mM})\end{array}$ & -2.33 & 5.618 & $32.6 \%$ & $5.02 \%$ & $2.16 \%$ & n.d. \\
\hline $\begin{array}{l}\text { 7-CO } \\
\text { (Sat.) }\end{array}$ & $\begin{array}{c}\mathrm{H}_{2} \mathrm{O} \\
(121 \mathrm{mM})\end{array}$ & -2.34 & 5.608 & n.d. & $6.99 \%$ & $1.25 \%$ & n.d. \\
\hline
\end{tabular}

aElectrolysis was conducted with a glassy carbon rod as the working electrode in ACN with $0.1 \mathrm{M}$ $\mathrm{TBAPF}_{6}$ electrolyte.
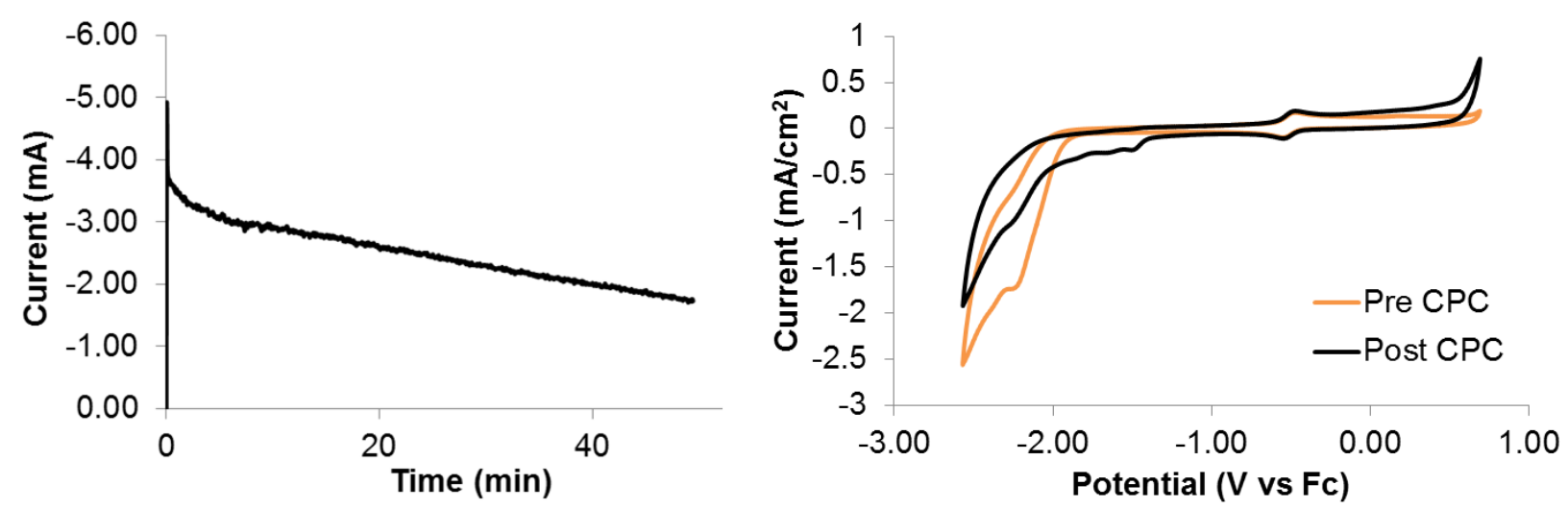

Figure S20: Current output from electrolysis of 5-CO at -2.17V vs Fc (left) and comparison of cyclic voltammograms collected before (orange) and after (black) the electrolysis (right). Data was collected under $\mathrm{CO}_{2}$ with an $\mathrm{ACN}$ solution containing $0.1 \mathrm{M}$ TBAPF, $2 \mathrm{mM} 5-\mathrm{CO}$, and $68 \mathrm{mM}$ TFE. 

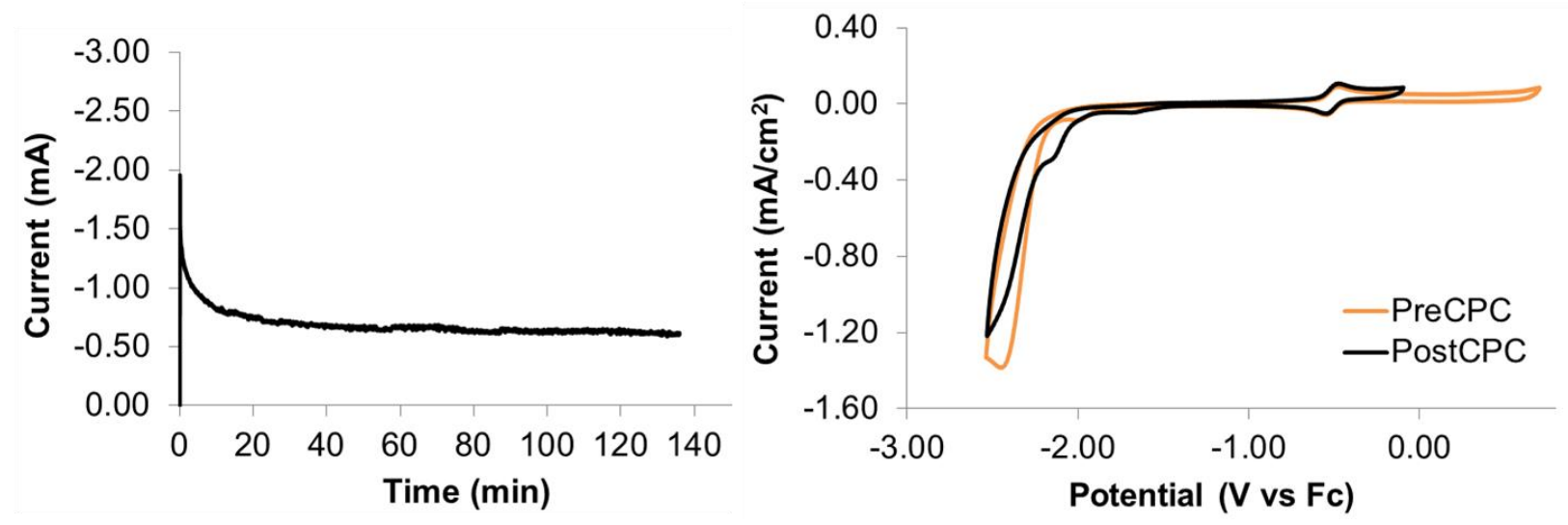

Figure S21: Current output from electrolysis of 7-CO at -2.33V vs Fc (left) and comparison of cyclic voltammograms collected before (orange) and after (black) the electrolysis (right). Data was collected under $\mathrm{CO}_{2}$ with an $\mathrm{ACN}$ solution containing $0.1 \mathrm{M}$ TBAPF 6 , saturated 7-CO, and $68 \mathrm{mM}$ TFE.
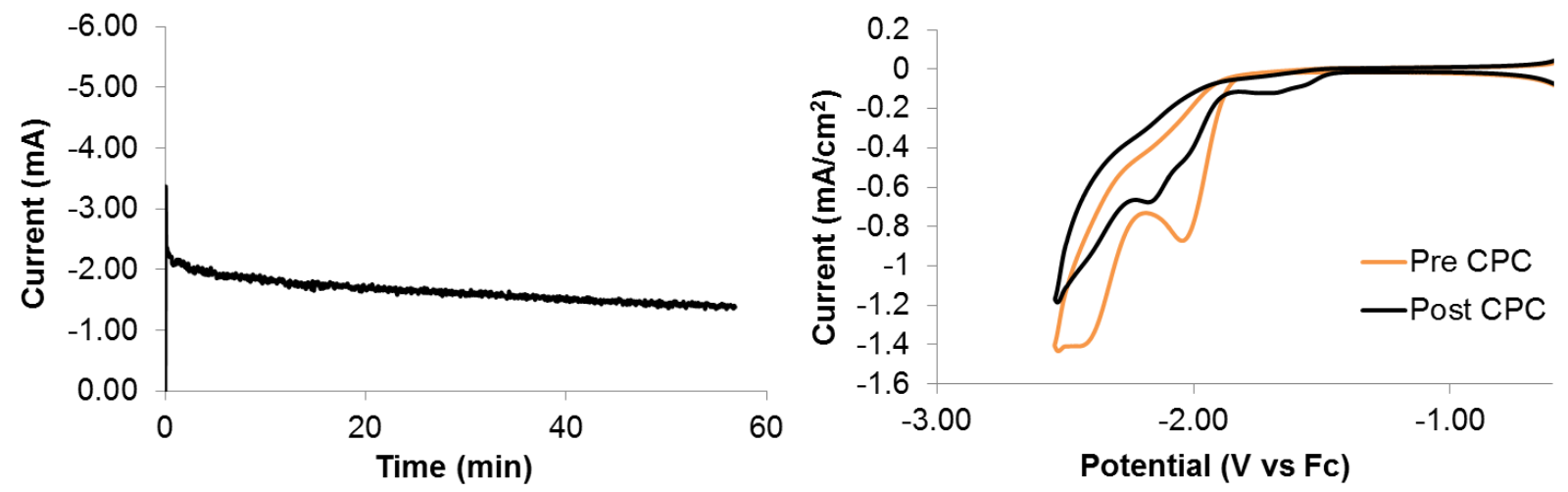

Figure S22: Current output from electrolysis of 7-ACN at -2.33V vs Fc (left) and comparison of cyclic voltammograms collected before (orange) and after (black) the electrolysis (right). Data was collected under $\mathrm{CO}_{2}$ with an ACN solution containing 0.1M TBAPF 6 , 1.79 mM 7-ACN, and $68 \mathrm{mM}$ TFE. 


\section{DFT Calculations:}

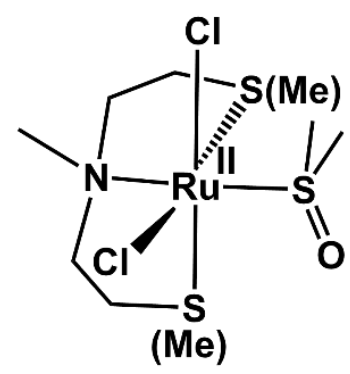

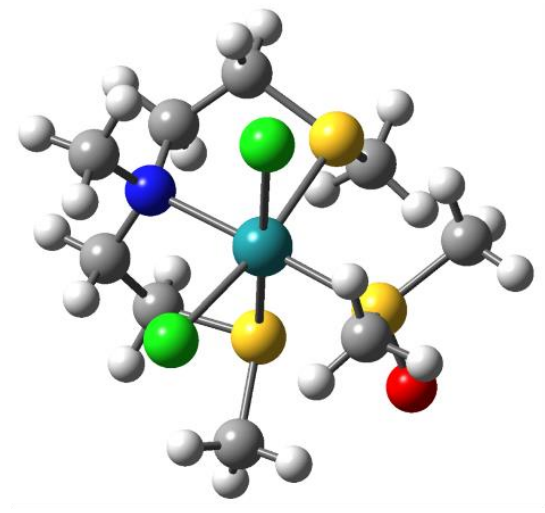

fac

$\Delta \mathrm{G}_{\mathrm{rel}}=0 \mathrm{kcal} / \mathrm{mol}$

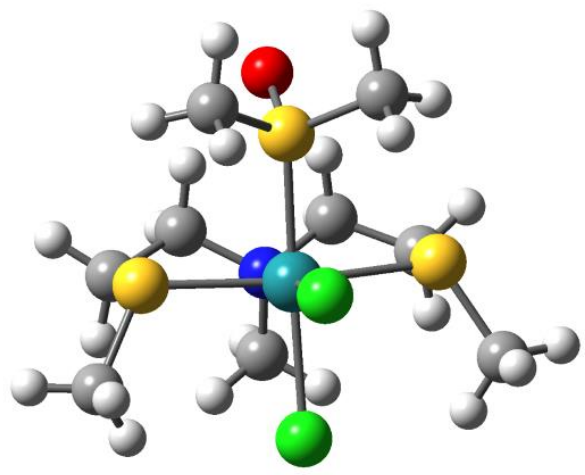

mer

$\Delta \mathrm{G}_{\mathrm{rel}}=+5.76 \mathrm{kcal} / \mathrm{mol}$

Figure S23: Optimized geometries and relative free energies calculated via DFT for fac and mer isomers of 10-DMSO. The sulfur's t-butyl substituents are modeled as methyl groups.

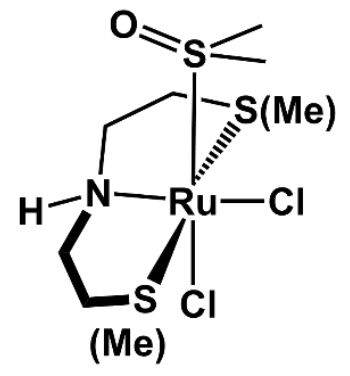

(Me)

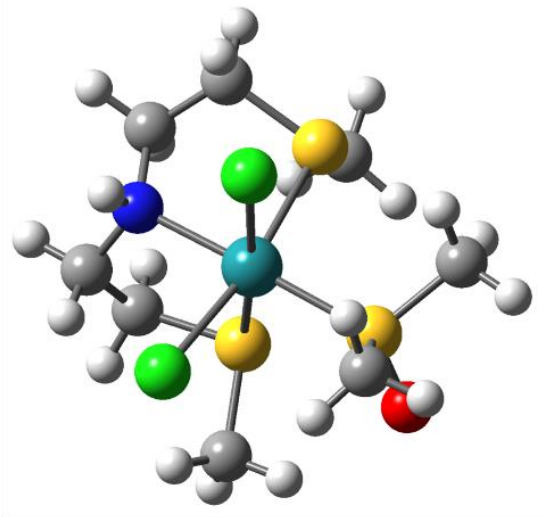

fac

$\Delta \mathrm{G}_{\mathrm{rel}}=+0.49 \mathrm{kcal} / \mathrm{mol}$

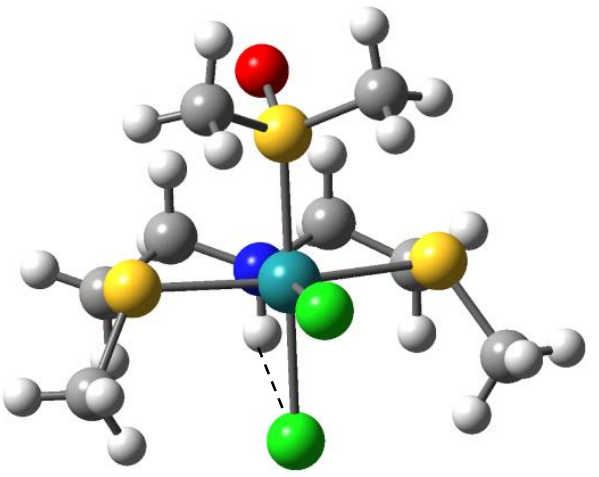

mer

$\Delta \mathrm{G}_{\mathrm{rel}}=0 \mathrm{kcal} / \mathrm{mol}$

Figure S24: Optimized geometries and relative free energies calculated via DFT for fac and mer isomers of 7-DMSO. Favorability of the mer isomer may be related to its shortened $\mathrm{N}-\mathrm{H}$ to $\mathrm{Cl}$ (3.007 vs $3.166 \AA$ ) distance which allows for hydrogen bonding. The sulfur's t-butyl substituents are modeled as methyl groups. 

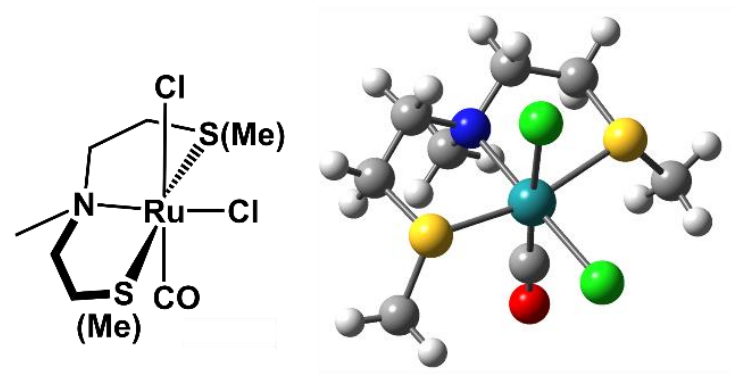

$\Delta \mathrm{G}_{\mathrm{rel}}=0 \mathrm{kcal} / \mathrm{mol}$

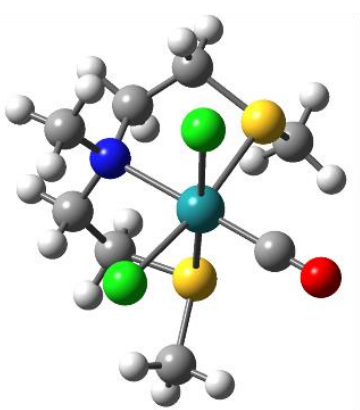

$$
\Delta \mathrm{G}_{\mathrm{rel}}=+0.29 \mathrm{kcal} / \mathrm{mol}
$$

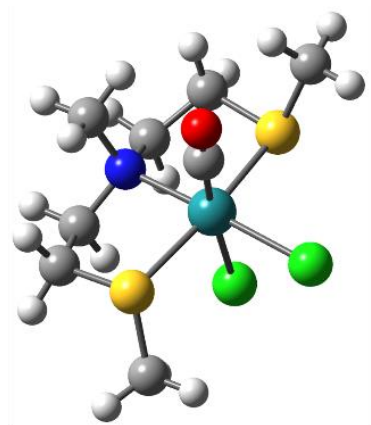

$\Delta \mathrm{G}_{\mathrm{rel}}=+0.69 \mathrm{kcal} / \mathrm{mol}$

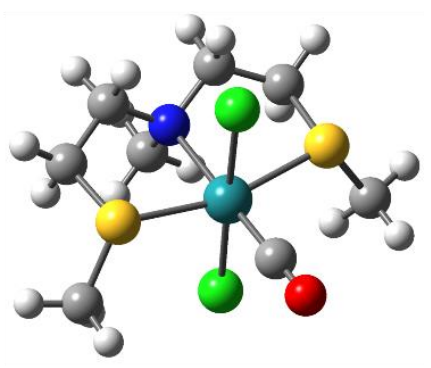

$\Delta \mathrm{G}_{\text {rel }}=+0.45 \mathrm{kcal} / \mathrm{mol}$

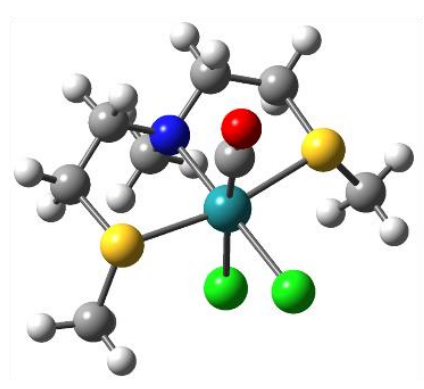

$$
\Delta \mathrm{G}_{\mathrm{rel}}=+3.30 \mathrm{kcal} / \mathrm{mol}
$$

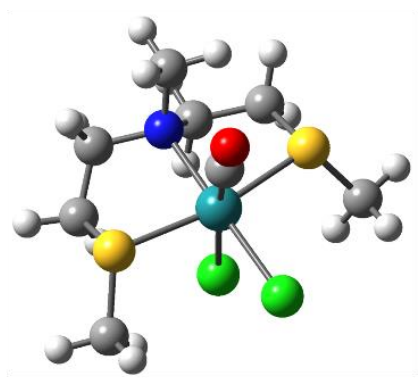

$\Delta \mathrm{G}_{\mathrm{rel}}=+5.81 \mathrm{kcal} / \mathrm{mol}$

Figure S25: Optimized geometries and relative free energies calculated for all likely isomers of 10-CO. The sulfur's t-butyl substituents are modeled as methyl groups.
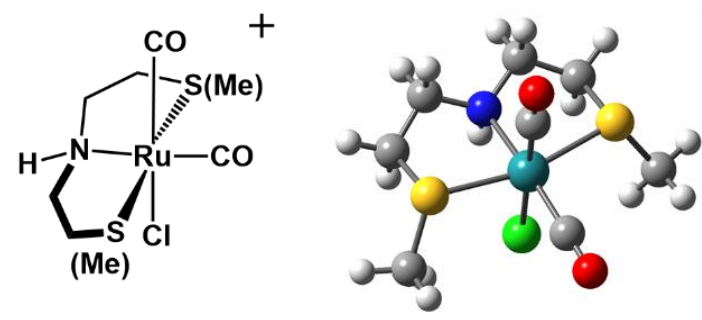

$\Delta \mathrm{G}_{\mathrm{rel}}=0 \mathrm{kcal} / \mathrm{mol}$

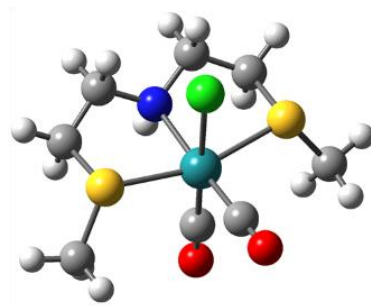

$\Delta \mathrm{G}_{\mathrm{rel}}=+2.03 \mathrm{kcal} / \mathrm{mol}$

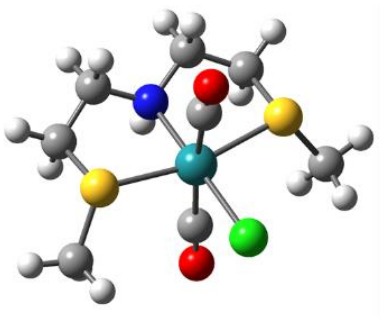

$\Delta \mathrm{G}_{\mathrm{rel}}=+13.28 \mathrm{kcal} / \mathrm{mol}$

Figure S26: Optimized geometries and relative free energies calculated for some possible isomers of 7-2CO. The sulfur's t-butyl substituents are modeled as methyl groups. 


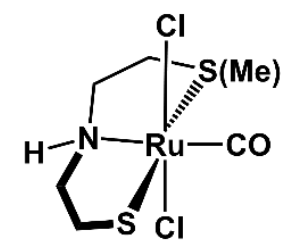

(Me)

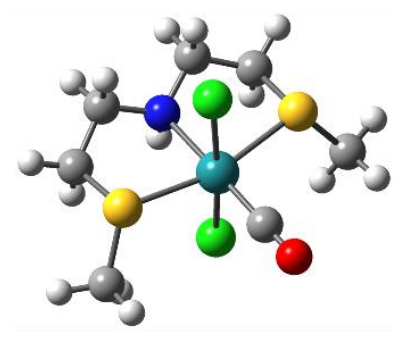

$\Delta \mathrm{G}_{\mathrm{rel}}=0 \mathrm{kcal} / \mathrm{mol}$
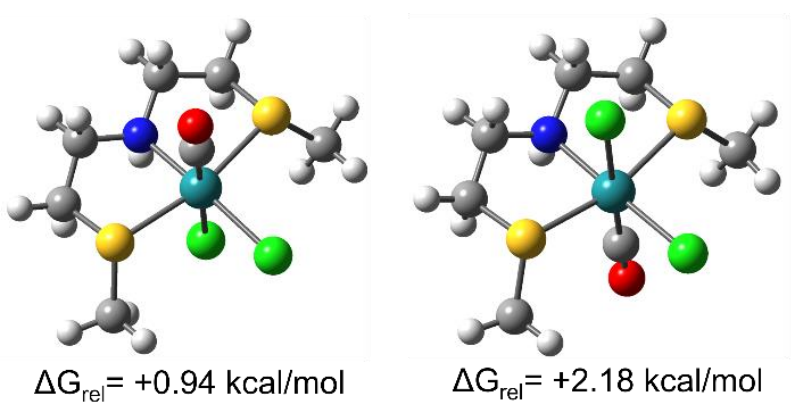

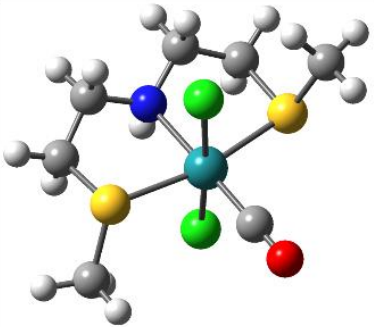

$\Delta \mathrm{G}_{\mathrm{rel}}=+0.0025 \mathrm{kcal} / \mathrm{mol}$

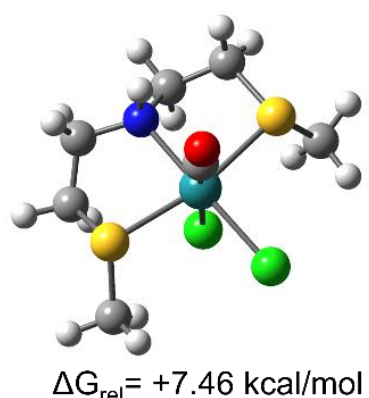

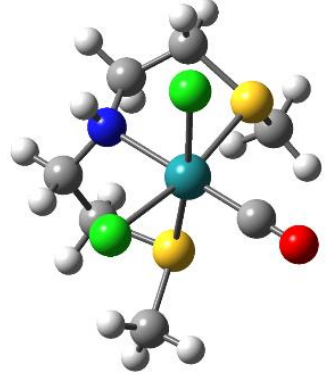

$\Delta \mathrm{G}_{\mathrm{rel}}=+4.59 \mathrm{kcal} / \mathrm{mol}$

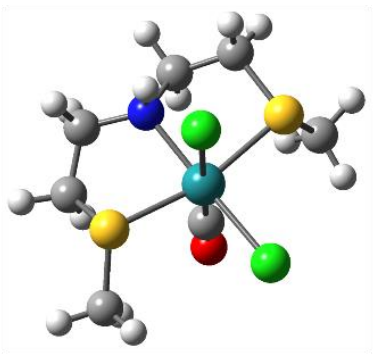

$\Delta \mathrm{G}_{\mathrm{rel}}=+5.10 \mathrm{kcal} / \mathrm{mol}$

Figure S27: Optimized geometries and relative free energies calculated for all likely isomers of 7-CO. The sulfur's t-butyl substituents are modeled as methyl groups.

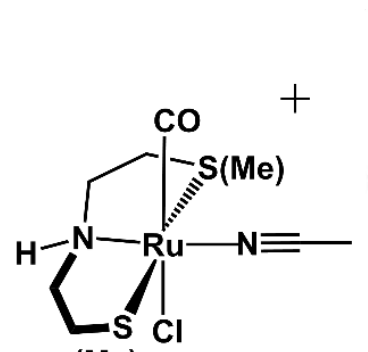

(Me)

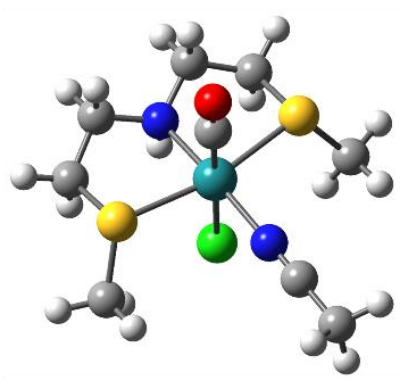

$\Delta \mathrm{G}_{\mathrm{rel}}=0 \mathrm{kcal} / \mathrm{mol}$

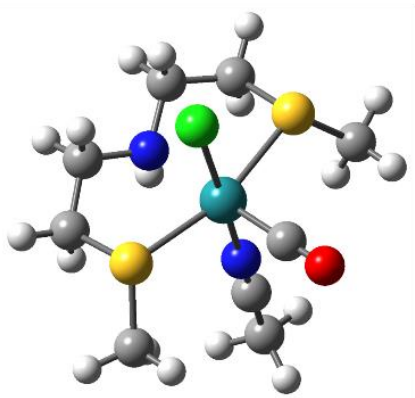

$\Delta \mathrm{G}_{\mathrm{rel}}=+1.83 \mathrm{kcal} / \mathrm{mol}$

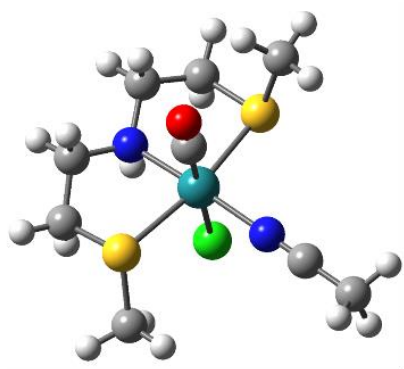

$\Delta \mathrm{G}_{\mathrm{rel}}=+0.31 \mathrm{kcal} / \mathrm{mol}$

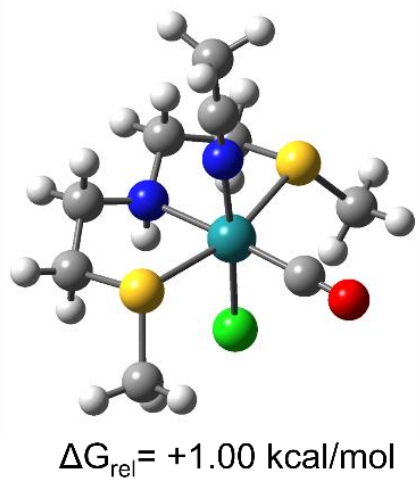

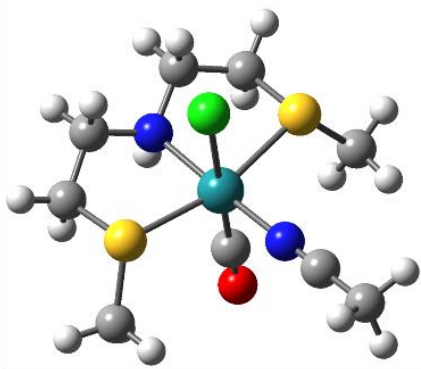

$\Delta \mathrm{G}_{\mathrm{rel}}=+1.57 \mathrm{kcal} / \mathrm{mol}$

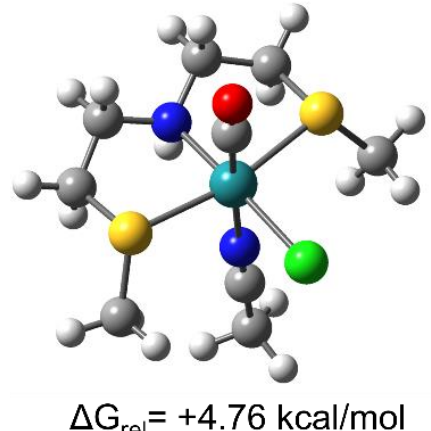

Figure S28: Optimized geometries and relative free energies calculated for probable isomers of 7-ACN. The sulfur's t-butyl substituents are modeled as methyl groups. 

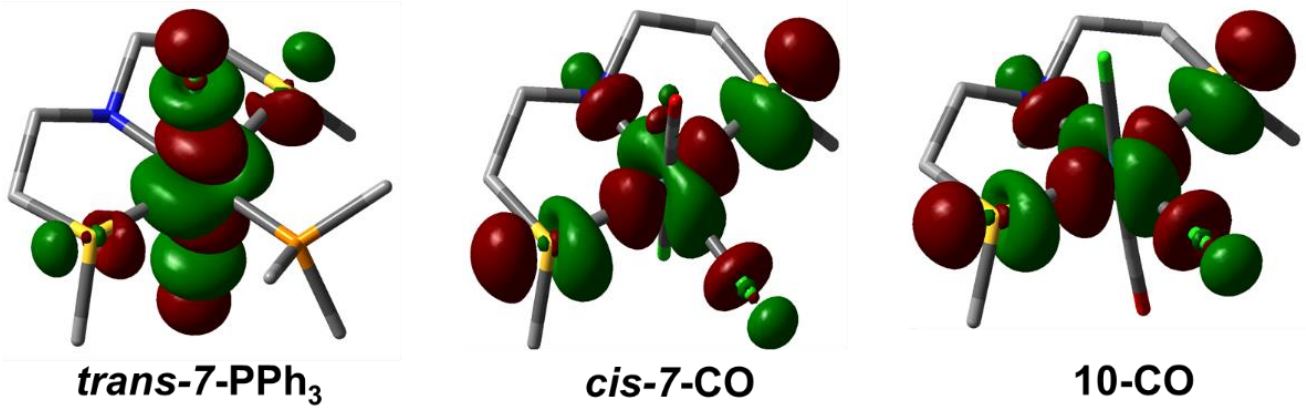

10-CO
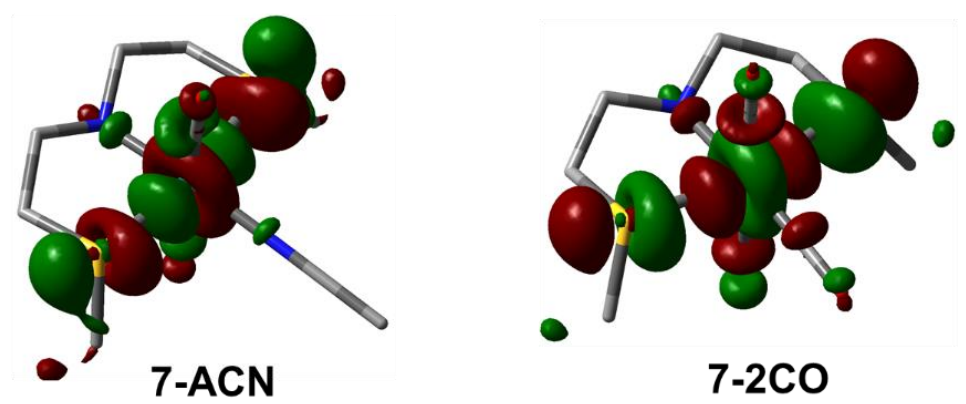

Figure S29: LUMOs calculated for aliphatic SNS Ru complexes using DFT with the B3LYP functional and a split LANL2DZ/6-31+G** basis set. The sulfur's t-butyl substituents are modeled as methyl groups and hydrogen atoms are hidden for clarity. Orbitals were rendered in Gaussview with a 0.04 isovalue.

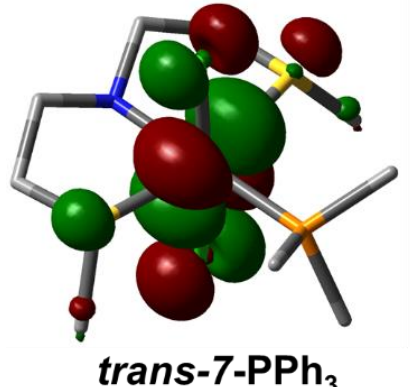

trans-7-PPh

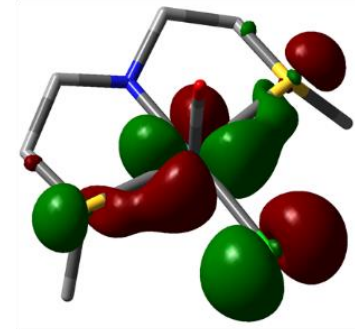

cis-7-CO

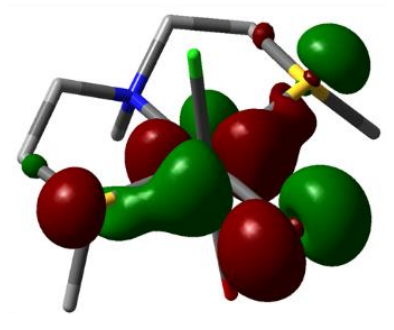

$10-\mathrm{CO}$

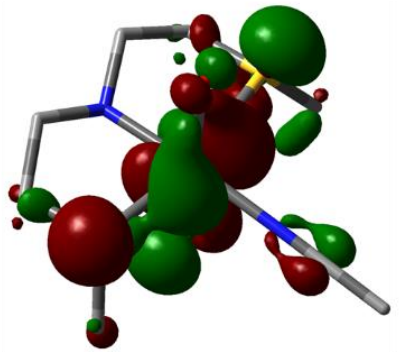

7-ACN

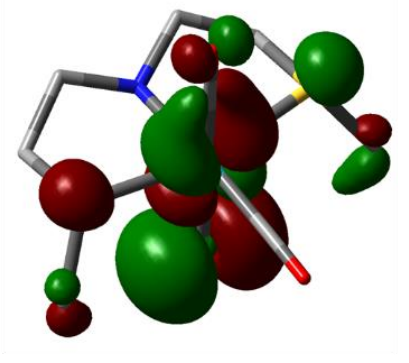

$7-2 \mathrm{CO}$

Figure S30: HOMOs calculated for aliphatic SNS Ru complexes using DFT with the B3LYP functional and a split LANL2DZ/6-31+G** basis set. The sulfur's t-butyl substituents are modeled as methyl groups and hydrogen atoms are hidden for clarity. Orbitals were rendered in Gaussview with a 0.04 isovalue. 


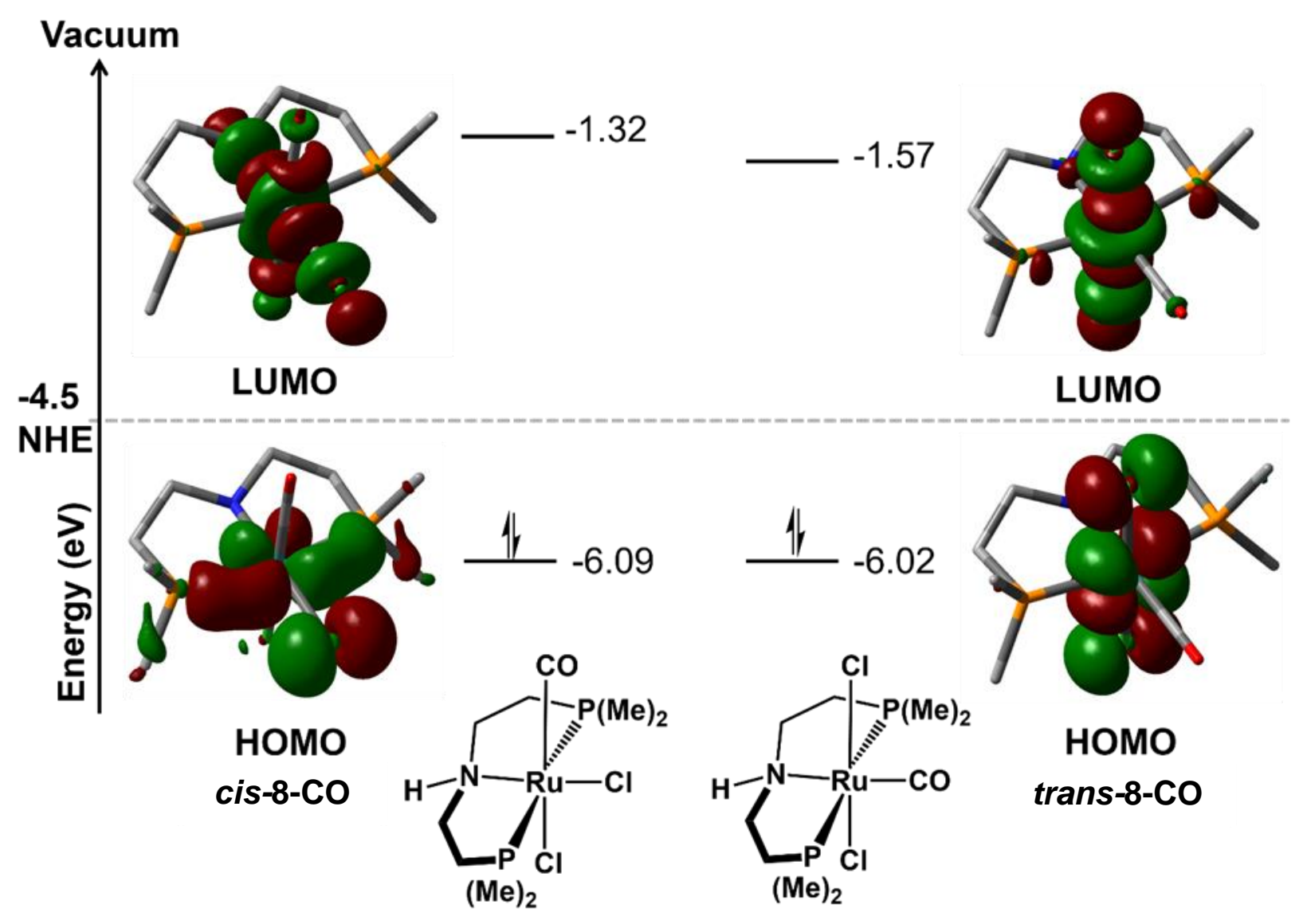

Figure S31: MO diagram showing frontier orbital energies and images calculated for the cis and trans isomers of 8-CO. The isopropyl substituents on the phosphines are modeled as methyl groups. Hydrogen atoms are omitted for clarity. 


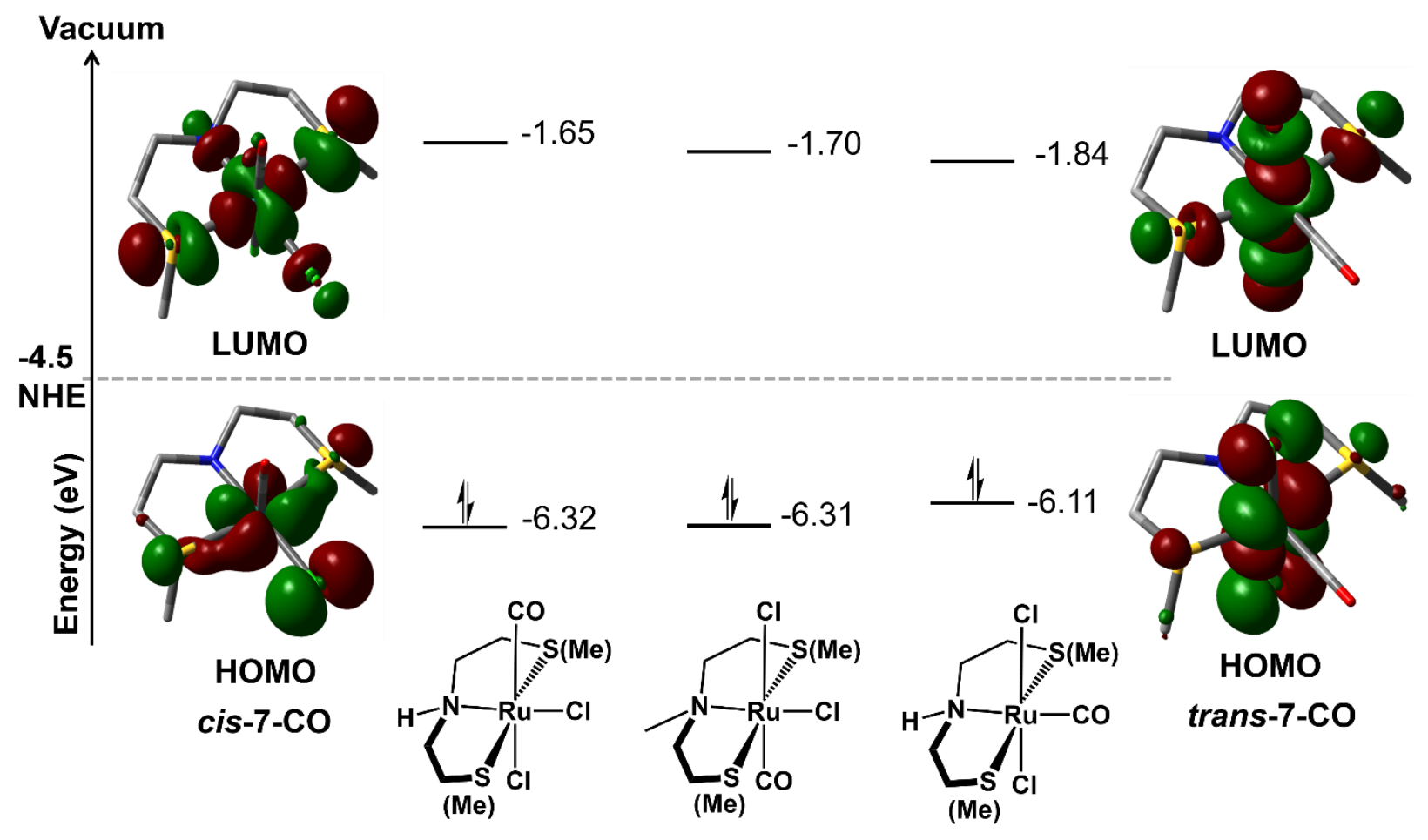

Figure S32: MO diagram comparing frontier orbital energies and some orbital images calculated for the aliphatic SNS carbonyl complexes. Based on the calculated LUMO energies, the more cathodic reduction observed experimentally for 7-CO versus 10-CO should only occur with the cis form of 7-CO. Hydrogen atoms are omitted from orbital renderings for clarity. 


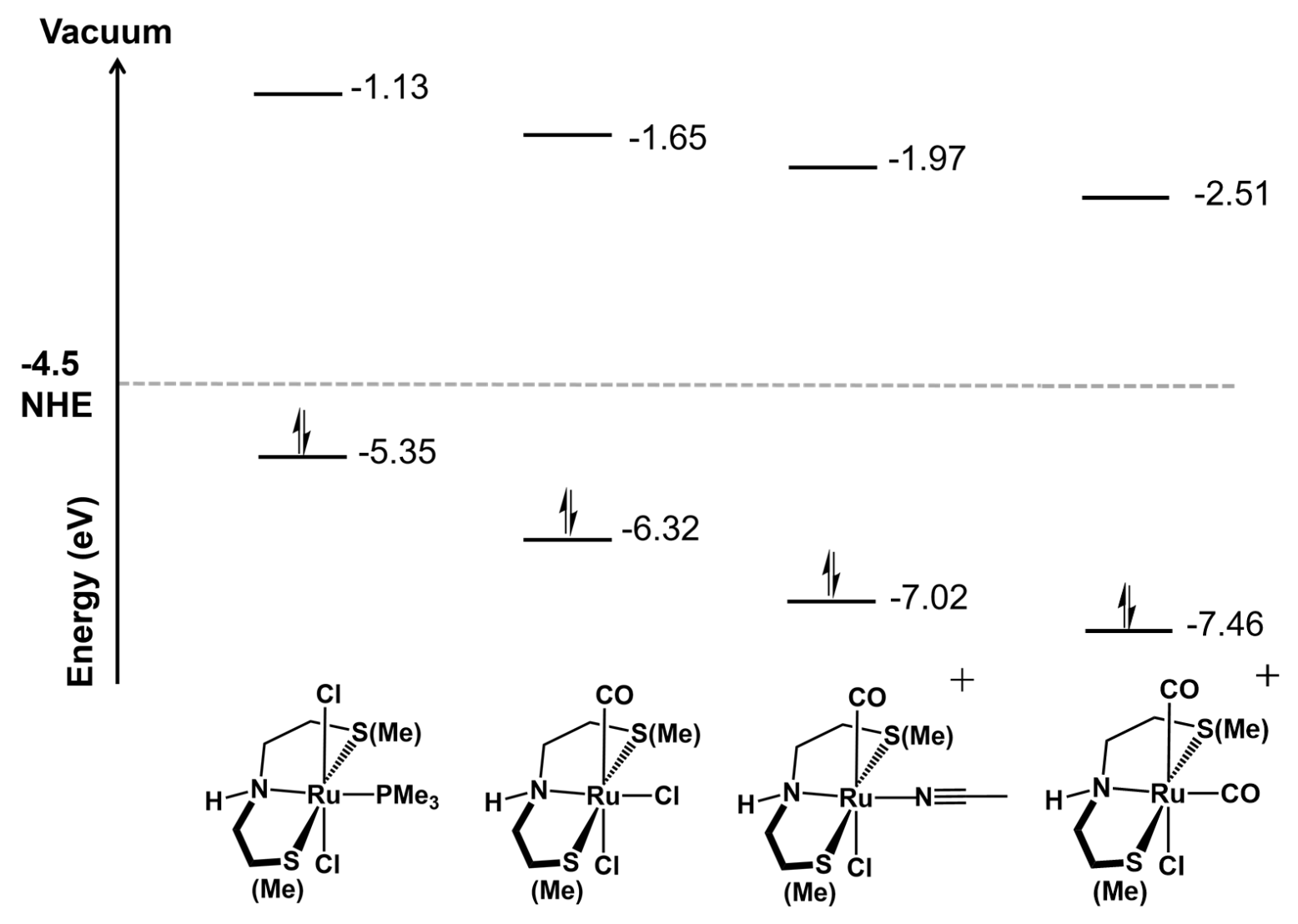

Figure 33: Calculated frontier orbital energies showing the predicted effect of monodentate ligand variation within the subset of Ru complexes having the ${ }^{\mathrm{tBu}} \mathrm{SN}^{\mathrm{H}} \mathrm{S}$ pincer ligand. 


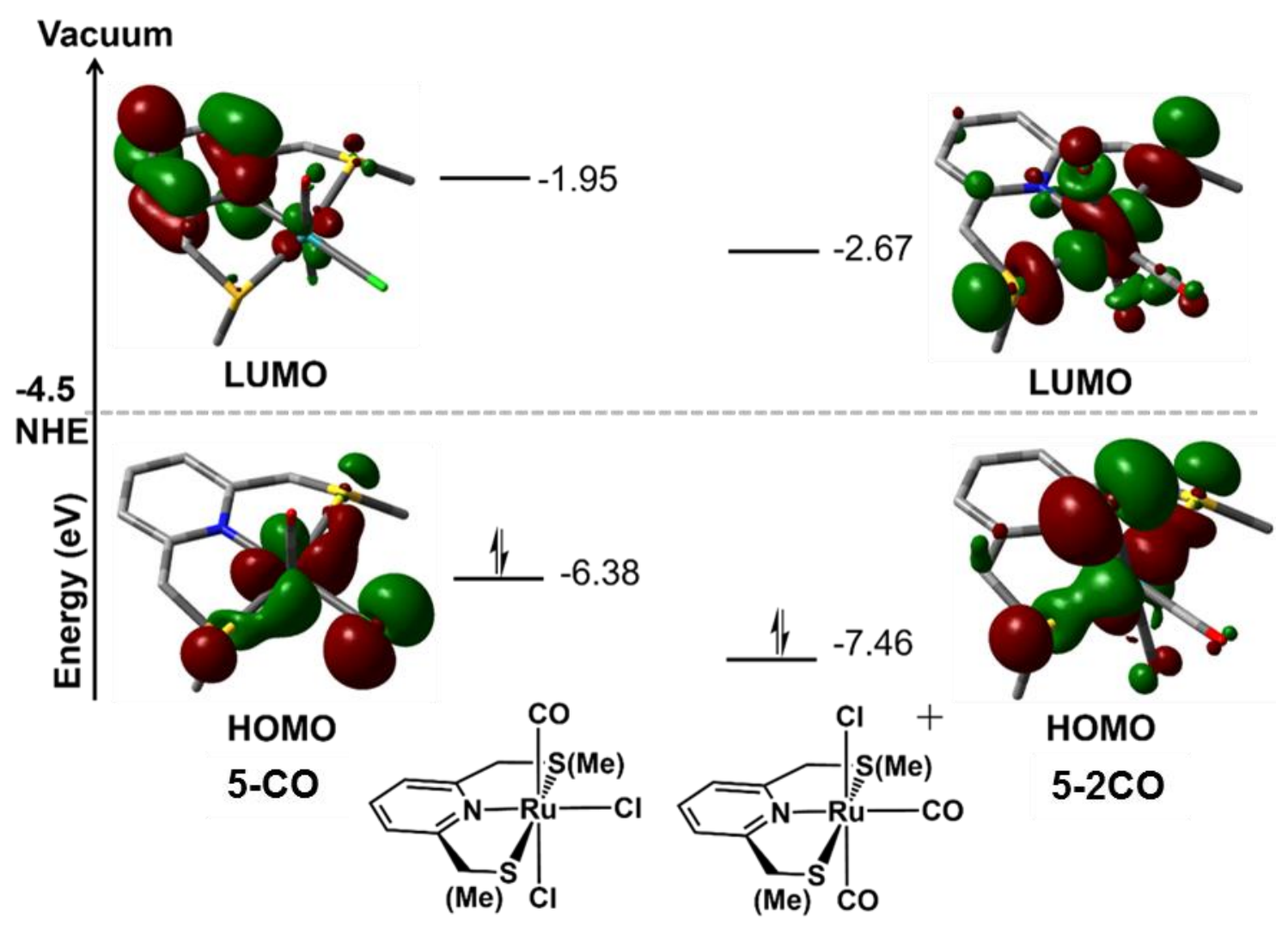

Figure S34: MO diagram comparing frontier orbital energies and images calculated for the Ru carbonyl complexes supported by the ${ }^{\mathrm{tBu}} \mathrm{SN}_{\mathrm{py}} \mathrm{S}$ pincer. Hydrogen atoms are omitted from orbital renderings for clarity. 


\section{Optimized Coordinates:}

Mol files have also been provided for all relevant geometry optimizations.

Table S4: Optimized coordinates for 5-CO

\begin{tabular}{|c|c|c|c|c|c|}
\hline $\begin{array}{l}\text { Center } \\
\text { Number }\end{array}$ & $\begin{array}{l}\text { Atomic } \\
\text { Number }\end{array}$ & $\begin{array}{c}\text { Atomic } \\
\text { Type }\end{array}$ & $x$ & $Y$ & Z \\
\hline 1 & 6 & 0 & -1.5765 & 1.736457 & -0.02035 \\
\hline 2 & 6 & 0 & -0.41265 & 2.658825 & -0.27608 \\
\hline 3 & 1 & 0 & -0.63506 & 3.673278 & 0.059973 \\
\hline 4 & 1 & 0 & -0.20175 & 2.670504 & -1.34979 \\
\hline 5 & 7 & 0 & -1.32626 & 0.415649 & 0.154041 \\
\hline 6 & 6 & 0 & -2.34898 & -0.46237 & 0.298658 \\
\hline 7 & 6 & 0 & -2.0102 & -1.90516 & 0.581531 \\
\hline 8 & 1 & 0 & -1.90199 & -2.05365 & 1.661606 \\
\hline 9 & 1 & 0 & -2.80314 & -2.57289 & 0.237999 \\
\hline 10 & 17 & 0 & 0.669236 & 0.167158 & -2.33981 \\
\hline 11 & 6 & 0 & -0.86734 & -2.76884 & -1.86492 \\
\hline 12 & 1 & 0 & -1.31987 & -1.88579 & -2.31316 \\
\hline 13 & 1 & 0 & 0.052812 & -3.01374 & -2.39601 \\
\hline 14 & 1 & 0 & -1.54654 & -3.6238 & -1.88028 \\
\hline 15 & 6 & 0 & 2.396347 & 2.726526 & -0.59525 \\
\hline 16 & 1 & 0 & 3.361185 & 2.399259 & -0.20551 \\
\hline 17 & 1 & 0 & 2.235063 & 2.326841 & -1.59643 \\
\hline 18 & 1 & 0 & 2.342872 & 3.816977 & -0.58101 \\
\hline 19 & 44 & 0 & 0.650712 & -0.27489 & 0.154523 \\
\hline 20 & 16 & 0 & 1.134623 & 2.067529 & 0.545907 \\
\hline 21 & 16 & 0 & -0.40188 & -2.45939 & -0.12612 \\
\hline 22 & 6 & 0 & -3.67474 & -0.03253 & 0.252068 \\
\hline 23 & 6 & 0 & -2.88515 & 2.22098 & -0.03217 \\
\hline 24 & 6 & 0 & -3.94544 & 1.32594 & 0.094242 \\
\hline 25 & 1 & 0 & -4.47695 & -0.75463 & 0.354201 \\
\hline 26 & 1 & 0 & -4.97002 & 1.682161 & 0.07096 \\
\hline 27 & 1 & 0 & -3.06192 & 3.283385 & -0.1561 \\
\hline 28 & 6 & 0 & 0.720012 & -0.56917 & 1.991007 \\
\hline 29 & 8 & 0 & 0.810387 & -0.74274 & 3.133928 \\
\hline 30 & 17 & 0 & 3.005598 & -1.10639 & 0.025661 \\
\hline
\end{tabular}


Table S5: Optimized coordinates for 5-2CO

\begin{tabular}{|c|c|c|c|c|c|}
\hline $\begin{array}{l}\text { Center } \\
\text { Number }\end{array}$ & $\begin{array}{l}\text { Atomic } \\
\text { Number }\end{array}$ & $\begin{array}{c}\text { Atomic } \\
\text { Type }\end{array}$ & $x$ & $\mathbf{Y}$ & Z \\
\hline 1 & 44 & 0 & 0.582727 & 2.710636 & 4.941871 \\
\hline 2 & 17 & 0 & -0.56732 & 2.773483 & 7.147911 \\
\hline 3 & 16 & 0 & -1.22482 & 1.259588 & 4.206458 \\
\hline 4 & 16 & 0 & 2.495562 & 3.590553 & 6.177697 \\
\hline 5 & 8 & 0 & -0.73451 & 5.432044 & 4.381459 \\
\hline 6 & 7 & 0 & 1.405465 & 0.816012 & 5.534671 \\
\hline 7 & 8 & 0 & 2.009276 & 2.671969 & 2.245601 \\
\hline 8 & 6 & 0 & 0.910403 & -0.33031 & 5.007363 \\
\hline 9 & 6 & 0 & -0.14594 & -0.22051 & 3.938707 \\
\hline 10 & 1 & 0 & -0.77991 & -1.10891 & 3.922758 \\
\hline 11 & 1 & 0 & 0.321747 & -0.1151 & 2.954165 \\
\hline 12 & 6 & 0 & 2.382658 & 0.773123 & 6.46991 \\
\hline 13 & 6 & 0 & -1.78859 & 1.57557 & 2.497595 \\
\hline 14 & 6 & 0 & 3.979115 & 3.637391 & 5.108069 \\
\hline 15 & 6 & 0 & 1.397826 & -1.57352 & 5.406062 \\
\hline 16 & 1 & 0 & 0.977382 & -2.47798 & 4.982029 \\
\hline 17 & 6 & 0 & 2.796394 & 2.055403 & 7.146382 \\
\hline 18 & 1 & 0 & 3.84975 & 2.034648 & 7.433872 \\
\hline 19 & 1 & 0 & 2.198849 & 2.189043 & 8.052961 \\
\hline 20 & 6 & 0 & 2.433273 & -1.62816 & 6.337878 \\
\hline 21 & 1 & 0 & 2.839529 & -2.5846 & 6.649527 \\
\hline 22 & 6 & 0 & 2.933668 & -0.44346 & 6.873446 \\
\hline 23 & 1 & 0 & 3.726591 & -0.45504 & 7.612498 \\
\hline 24 & 6 & 0 & 1.474343 & 2.680141 & 3.262766 \\
\hline 25 & 6 & 0 & -0.23736 & 4.417012 & 4.566725 \\
\hline 26 & 1 & 0 & -2.38918 & 2.485584 & 2.531374 \\
\hline 27 & 1 & 0 & -2.41487 & 0.736074 & 2.190059 \\
\hline 28 & 1 & 0 & -0.9488 & 1.700142 & 1.813619 \\
\hline 29 & 1 & 0 & 4.840357 & 3.844381 & 5.745747 \\
\hline 30 & 1 & 0 & 3.840093 & 4.461359 & 4.406751 \\
\hline 31 & 1 & 0 & 4.118128 & 2.698335 & 4.572036 \\
\hline
\end{tabular}


Table S6: Optimized coordinates for mer-7-DMSO (favored isomer)

\section{Center \\ Number}

1

2

3

4

5

6

7

8

9

10

11

12

13

14

15

16

17

18

19

20

21

22

23

24

25

26

27

28

29

30

31

32

33

34

35

36

37

\section{Atomic \\ Number}

44

17

16

17

16

16

8

7

6

1

1

6

6

1

1

6

1

1

1

6

1

1

6

1

1

6

6

1

1

1

1

1

1

1

1

1

1

\section{Atomic Type}

0

0

0

0

0

0

0

0

0
0

0

0

0

0

0
0

0

0

0

0

0
0

0

0

0

0

0
0

0

0

0

0
0

0

0

0
0

0

0

0

0

0

0
0

0

0

0

$\begin{array}{ccc}\mathbf{X} & \mathbf{Y} & \mathbf{Z} \\ 5.406006 & 10.088814 & 8.126054 \\ 3.08793 & 10.337258 & 9.108297 \\ 4.715498 & 9.001809 & 6.062879 \\ 5.307076 & 12.356786 & 7.017544 \\ 6.608301 & 11.019962 & 10.023811 \\ 5.532589 & 7.984953 & 9.136978 \\ 6.811968 & 7.180006 & 8.933527 \\ 7.343936 & 10.050767 & 7.219205 \\ 7.476489 & 9.018962 & 6.15782 \\ 7.474832 & 8.038827 & 6.641412 \\ 8.428095 & 9.143393 & 5.625187 \\ 3.619125 & 10.02104 & 5.018794 \\ 6.326745 & 9.163675 & 5.165861 \\ 6.378166 & 8.392348 & 4.39433 \\ 6.344249 & 10.147489 & 4.687702 \\ 4.151822 & 6.891228 & 8.677455 \\ 3.216575 & 7.417012 & 8.876754 \\ 4.241572 & 5.980982 & 9.273156 \\ 4.248117 & 6.668894 & 7.615526 \\ 8.455197 & 10.062334 & 8.205959 \\ 9.416144 & 10.196649 & 7.692857 \\ 8.464191 & 9.093515 & 8.711767 \\ 8.248257 & 11.212119 & 9.186792 \\ 8.245704 & 12.174397 & 8.666366 \\ 9.031882 & 11.221353 & 9.947515 \\ 6.185699 & 12.757498 & 10.389088 \\ 5.232445 & 8.038768 & 10.93166 \\ 6.055079 & 8.58928 & 11.386194 \\ 5.210357 & 7.008598 & 11.291847 \\ 4.284671 & 8.550835 & 11.10596 \\ 7.335552 & 10.965704 & 6.757114 \\ 2.628373 & 9.97839 & 5.474098 \\ 3.976366 & 11.050599 & 4.995535 \\ 3.582487 & 9.584366 & 4.018614 \\ 5.220468 & 12.74234 & 10.897812 \\ 6.945588 & 13.170059 & 11.055993 \\ 6.111584 & 13.326763 & 9.462491\end{array}$


Table S7: Optimized coordinates for trans-7-CO (syn S- ${ }^{\mathrm{B} u}$ )

\begin{tabular}{|c|c|c|c|c|c|}
\hline $\begin{array}{l}\text { Center } \\
\text { Number }\end{array}$ & $\begin{array}{l}\text { Atomic } \\
\text { Number }\end{array}$ & $\begin{array}{c}\text { Atomic } \\
\text { Type }\end{array}$ & $x$ & $\mathbf{Y}$ & $\mathbf{Z}$ \\
\hline 1 & 6 & 0 & -1.246401 & 2.420805 & 0.385833 \\
\hline 2 & 1 & 0 & -1.293441 & 3.351379 & 0.965807 \\
\hline 3 & 1 & 0 & -1.230983 & 2.677109 & -0.676323 \\
\hline 4 & 6 & 0 & -2.457168 & 1.560666 & 0.726654 \\
\hline 5 & 1 & 0 & -3.385708 & 2.082837 & 0.485477 \\
\hline 6 & 1 & 0 & -2.464496 & 1.294655 & 1.787693 \\
\hline 7 & 7 & 0 & -0.000033 & 1.676014 & 0.693027 \\
\hline 8 & 1 & 0 & 0.00046 & 1.455356 & 1.692509 \\
\hline 9 & 6 & 0 & 1.245888 & 2.42106 & 0.384651 \\
\hline 10 & 1 & 0 & 1.229455 & 2.677252 & -0.677513 \\
\hline 11 & 1 & 0 & 1.293252 & 3.351697 & 0.964497 \\
\hline 12 & 6 & 0 & 2.457138 & 1.561212 & 0.724465 \\
\hline 13 & 1 & 0 & 3.38535 & 2.083536 & 0.482369 \\
\hline 14 & 1 & 0 & 2.465501 & 1.295347 & 1.785535 \\
\hline 15 & 17 & 0 & -0.001191 & 0.688053 & -2.468239 \\
\hline 16 & 17 & 0 & 0.000736 & -1.116576 & 2.165687 \\
\hline 17 & 6 & 0 & -0.000571 & -2.081885 & -0.895953 \\
\hline 18 & 8 & 0 & -0.000795 & -3.158203 & -1.328971 \\
\hline 19 & 6 & 0 & 3.309557 & -1.128478 & 0.88648 \\
\hline 20 & 1 & 0 & 2.777696 & -1.215419 & 1.834133 \\
\hline 21 & 1 & 0 & 3.365222 & -2.102074 & 0.39648 \\
\hline 22 & 1 & 0 & 4.317977 & -0.734529 & 1.029186 \\
\hline 23 & 6 & 0 & -3.308993 & -1.129214 & 0.888985 \\
\hline 24 & 1 & 0 & -3.364886 & -2.102751 & 0.398898 \\
\hline 25 & 1 & 0 & -2.776336 & -1.216189 & 1.836189 \\
\hline 26 & 1 & 0 & -4.317369 & -0.735473 & 1.032581 \\
\hline 27 & 44 & 0 & -0.000261 & -0.343192 & -0.195597 \\
\hline 28 & 16 & 0 & -2.408007 & -0.017283 & -0.245033 \\
\hline 29 & 16 & 0 & 2.40743 & -0.016883 & -0.246962 \\
\hline
\end{tabular}


Table S8: Optimized coordinates for trans-7-CO (anti S- ${ }^{\mathrm{B} u}$ )

\begin{tabular}{|c|c|c|c|c|c|}
\hline $\begin{array}{l}\text { Center } \\
\text { Number }\end{array}$ & $\begin{array}{l}\text { Atomic } \\
\text { Number }\end{array}$ & $\begin{array}{c}\text { Atomic } \\
\text { Type }\end{array}$ & $x$ & $\mathbf{Y}$ & Z \\
\hline 1 & 6 & 0 & 1.294859 & 2.50062 & -0.395316 \\
\hline 2 & 1 & 0 & 1.283048 & 3.46625 & -0.918368 \\
\hline 3 & 1 & 0 & 1.35635 & 2.690611 & 0.678714 \\
\hline 4 & 6 & 0 & 2.48447 & 1.681555 & -0.882666 \\
\hline 5 & 1 & 0 & 3.430688 & 2.176109 & -0.651137 \\
\hline 6 & 1 & 0 & 2.438857 & 1.525393 & -1.963995 \\
\hline 7 & 7 & 0 & 0.039417 & 1.75286 & -0.65223 \\
\hline 8 & 1 & 0 & -0.02194 & 1.568841 & -1.657319 \\
\hline 9 & 6 & 0 & -1.195906 & 2.464561 & -0.241124 \\
\hline 10 & 1 & 0 & -1.119371 & 2.680967 & 0.826969 \\
\hline 11 & 1 & 0 & -1.292745 & 3.414944 & -0.781503 \\
\hline 12 & 6 & 0 & -2.411125 & 1.595506 & -0.541684 \\
\hline 13 & 1 & 0 & -3.331481 & 2.088081 & -0.220383 \\
\hline 14 & 1 & 0 & -2.481872 & 1.37577 & -1.611021 \\
\hline 15 & 17 & 0 & 0.168733 & 0.678861 & 2.476772 \\
\hline 16 & 17 & 0 & 0.064481 & -1.009368 & -2.201656 \\
\hline 17 & 6 & 0 & 0.204978 & -2.042577 & 0.83178 \\
\hline 18 & 8 & 0 & 0.253366 & -3.131552 & 1.229046 \\
\hline 19 & 6 & 0 & -3.194983 & -1.108028 & -0.794866 \\
\hline 20 & 1 & 0 & -2.704813 & -1.13057 & -1.768344 \\
\hline 21 & 1 & 0 & -3.197071 & -2.105989 & -0.353133 \\
\hline 22 & 1 & 0 & -4.220832 & -0.741898 & -0.8728 \\
\hline 23 & 6 & 0 & 3.403364 & 0.300031 & 1.423508 \\
\hline 24 & 1 & 0 & 3.424282 & -0.64617 & 1.966752 \\
\hline 25 & 1 & 0 & 4.423258 & 0.612141 & 1.189496 \\
\hline 26 & 1 & 0 & 2.881546 & 1.048211 & 2.018537 \\
\hline 27 & 44 & 0 & 0.130594 & -0.286607 & 0.181065 \\
\hline 28 & 16 & 0 & 2.530906 & -0.017851 & -0.150244 \\
\hline 29 & 16 & 0 & -2.277174 & -0.024298 & 0.35265 \\
\hline
\end{tabular}


Table S9: Optimized coordinates for cis-7-CO

\begin{tabular}{|c|c|c|c|c|c|}
\hline $\begin{array}{l}\text { Center } \\
\text { Number }\end{array}$ & $\begin{array}{l}\text { Atomic } \\
\text { Number }\end{array}$ & $\begin{array}{c}\text { Atomic } \\
\text { Type }\end{array}$ & $x$ & $\mathbf{Y}$ & Z \\
\hline 1 & 6 & 0 & 1.252211 & 2.483145 & -0.30054 \\
\hline 2 & 1 & 0 & 1.274081 & 3.409819 & -0.88703 \\
\hline 3 & 1 & 0 & 1.261259 & 2.75211 & 0.75917 \\
\hline 4 & 6 & 0 & 2.461253 & 1.629359 & -0.67136 \\
\hline 5 & 1 & 0 & 3.389534 & 2.154801 & -0.43761 \\
\hline 6 & 1 & 0 & 2.451616 & 1.381018 & -1.73644 \\
\hline 7 & 7 & 0 & -0.00019 & 1.730259 & -0.58121 \\
\hline 8 & 1 & 0 & -0.00017 & 1.493561 & -1.57889 \\
\hline 9 & 6 & 0 & -1.25273 & 2.482905 & -0.30054 \\
\hline 10 & 1 & 0 & -1.26182 & 2.751878 & 0.759171 \\
\hline 11 & 1 & 0 & -1.27478 & 3.409571 & -0.88703 \\
\hline 12 & 6 & 0 & -2.46162 & 1.628886 & -0.67134 \\
\hline 13 & 1 & 0 & -3.39 & 2.154153 & -0.43758 \\
\hline 14 & 1 & 0 & -2.45195 & 1.380534 & -1.73641 \\
\hline 15 & 17 & 0 & 0.000185 & -0.92049 & -2.17786 \\
\hline 16 & 6 & 0 & -3.26873 & -1.09309 & -0.88073 \\
\hline 17 & 1 & 0 & -2.72536 & -1.13638 & -1.82442 \\
\hline 18 & 1 & 0 & -3.27359 & -2.07458 & -0.40412 \\
\hline 19 & 1 & 0 & -4.29461 & -0.74632 & -1.01987 \\
\hline 20 & 6 & 0 & 3.268811 & -1.09246 & -0.88083 \\
\hline 21 & 1 & 0 & 3.27387 & -2.07396 & -0.40423 \\
\hline 22 & 1 & 0 & 2.72541 & -1.13583 & -1.82449 \\
\hline 23 & 1 & 0 & 4.294626 & -0.74551 & -1.02001 \\
\hline 24 & 44 & 0 & 0.00001 & -0.22897 & 0.271184 \\
\hline 25 & 16 & 0 & 2.428004 & 0.03843 & 0.277834 \\
\hline 26 & 16 & 0 & -2.42806 & 0.037969 & 0.277869 \\
\hline 27 & 6 & 0 & 0.000124 & 0.288883 & 2.050366 \\
\hline 28 & 8 & 0 & -0.00039 & 0.569992 & 3.176892 \\
\hline 29 & 17 & 0 & 0.00025 & -2.61833 & 1.017832 \\
\hline
\end{tabular}


Table S10: Optimized coordinates for trans-7-PPh

\begin{tabular}{|c|c|c|c|c|c|}
\hline Center Number & Atomic Number & Atomic Type & $x$ & $\mathbf{Y}$ & Z \\
\hline 1 & 6 & 0 & 4.062869 & 1.196929 & -0.73668 \\
\hline 2 & 1 & 0 & 5.152505 & 1.259786 & -0.61027 \\
\hline 3 & 1 & 0 & 3.8467 & 1.096176 & -1.80353 \\
\hline 4 & 6 & 0 & 3.422788 & 2.455992 & -0.16731 \\
\hline 5 & 1 & 0 & 3.790079 & 3.34753 & -0.68129 \\
\hline 6 & 1 & 0 & 3.635161 & 2.551151 & 0.902007 \\
\hline 7 & 7 & 0 & 3.51966 & 0.002688 & -0.05052 \\
\hline 8 & 1 & 0 & 3.73662 & 0.077214 & 0.946728 \\
\hline 9 & 6 & 0 & 4.070852 & -1.27593 & -0.55391 \\
\hline 10 & 1 & 0 & 3.852663 & -1.33533 & -1.62344 \\
\hline 11 & 1 & 0 & 5.161115 & -1.31178 & -0.42202 \\
\hline 12 & 6 & 0 & 3.440739 & -2.44165 & 0.196657 \\
\hline 13 & 1 & 0 & 3.813067 & -3.39667 & -0.18176 \\
\hline 14 & 1 & 0 & 3.656591 & -2.37704 & 1.267553 \\
\hline 15 & 17 & 0 & 1.273799 & -0.19173 & -2.53467 \\
\hline 16 & 17 & 0 & 1.599721 & 0.186758 & 2.47 \\
\hline 17 & 6 & 0 & 1.122341 & -3.22974 & 1.555301 \\
\hline 18 & 1 & 0 & 1.437301 & -2.62886 & 2.409228 \\
\hline 19 & 1 & 0 & 0.035731 & -3.33095 & 1.553384 \\
\hline 20 & 1 & 0 & 1.576051 & -4.22309 & 1.579442 \\
\hline 21 & 6 & 0 & 1.094064 & 3.425475 & 1.048842 \\
\hline 22 & 1 & 0 & 0.007578 & 3.5249 & 1.02303 \\
\hline 23 & 1 & 0 & 1.402536 & 2.959777 & 1.985578 \\
\hline 24 & 1 & 0 & 1.548077 & 4.411519 & 0.927164 \\
\hline 25 & 44 & 0 & 1.307622 & -0.00203 & -0.01537 \\
\hline 26 & 16 & 0 & 1.581177 & 2.372038 & -0.36488 \\
\hline 27 & 16 & 0 & 1.597877 & -2.40024 & -0.00398 \\
\hline 28 & 15 & 0 & -1.03987 & -0.00617 & 0.010234 \\
\hline 29 & 6 & 0 & -1.85442 & -1.50965 & -0.69588 \\
\hline 30 & 1 & 0 & -1.6002 & -2.39143 & -0.10149 \\
\hline 31 & 1 & 0 & -2.94314 & -1.39283 & -0.70469 \\
\hline 32 & 1 & 0 & -1.49793 & -1.665 & -1.71734 \\
\hline 33 & 6 & 0 & -1.85262 & 1.326202 & -0.98248 \\
\hline 34 & 1 & 0 & -2.94085 & 1.204739 & -0.9797 \\
\hline 35 & 1 & 0 & -1.60639 & 2.307814 & -0.5685 \\
\hline 36 & 1 & 0 & -1.48371 & 1.280604 & -2.01024 \\
\hline 37 & 6 & 0 & -1.89422 & 0.157095 & 1.640178 \\
\hline 38 & 1 & 0 & -1.5925 & 1.090915 & 2.121276 \\
\hline 39 & 1 & 0 & -2.9812 & 0.150192 & 1.508228 \\
\hline 40 & 1 & 0 & -1.60187 & -0.66991 & 2.292134 \\
\hline
\end{tabular}


Table S11: Optimized coordinates for 7-ACN (favored isomer)

\begin{tabular}{|c|c|c|c|c|c|}
\hline $\begin{array}{l}\text { Center } \\
\text { Number }\end{array}$ & $\begin{array}{c}\text { Atomic } \\
\text { Number }\end{array}$ & $\begin{array}{c}\text { Atomic } \\
\text { Type }\end{array}$ & $x$ & $\mathbf{Y}$ & Z \\
\hline 1 & 6 & 0 & 1.251918 & 2.50683 & 0.111922 \\
\hline 2 & 1 & 0 & 1.264842 & 3.510102 & -0.33007 \\
\hline 3 & 1 & 0 & 1.265096 & 2.616262 & 1.199339 \\
\hline 4 & 6 & 0 & 2.46077 & 1.725111 & -0.38962 \\
\hline 5 & 1 & 0 & 3.388919 & 2.20864 & -0.07846 \\
\hline 6 & 1 & 0 & 2.449595 & 1.642878 & -1.47992 \\
\hline 7 & 7 & 0 & 0.000068 & 1.797742 & -0.27478 \\
\hline 8 & 1 & 0 & 0.000349 & 1.717832 & -1.29721 \\
\hline 9 & 6 & 0 & -1.25208 & 2.506651 & 0.111278 \\
\hline 10 & 1 & 0 & -1.26563 & 2.616535 & 1.19864 \\
\hline 11 & 1 & 0 & -1.26509 & 3.50969 & -0.33119 \\
\hline 12 & 6 & 0 & -2.46067 & 1.724521 & -0.39022 \\
\hline 13 & 1 & 0 & -3.38897 & 2.207973 & -0.07936 \\
\hline 14 & 1 & 0 & -2.44928 & 1.641861 & -1.48049 \\
\hline 15 & 17 & 0 & $-8.8 \mathrm{E}-05$ & -0.61193 & -2.22939 \\
\hline 16 & 6 & 0 & -3.28005 & -0.92689 & -1.01776 \\
\hline 17 & 1 & 0 & -2.73015 & -0.83598 & -1.95408 \\
\hline 18 & 1 & 0 & -3.30871 & -1.9686 & -0.69444 \\
\hline 19 & 1 & 0 & -4.29824 & -0.54351 & -1.10868 \\
\hline 20 & 6 & 0 & 3.281159 & -0.92549 & -1.01819 \\
\hline 21 & 1 & 0 & 3.311404 & -1.96717 & -0.69497 \\
\hline 22 & 1 & 0 & 2.730742 & -0.83522 & -1.95426 \\
\hline 23 & 1 & 0 & 4.298777 & -0.54063 & -1.10949 \\
\hline 24 & 44 & 0 & 0.000227 & -0.26689 & 0.256564 \\
\hline 25 & 16 & 0 & 2.438515 & 0.007638 & 0.304129 \\
\hline 26 & 16 & 0 & -2.43806 & 0.007314 & 0.304191 \\
\hline 27 & 6 & 0 & 0.000217 & 0.001186 & 2.11024 \\
\hline 28 & 8 & 0 & 0.001529 & 0.129765 & 3.259517 \\
\hline 29 & 6 & 0 & -0.00059 & -3.48674 & 0.642055 \\
\hline 30 & 6 & 0 & -0.00148 & -4.93417 & 0.788 \\
\hline 31 & 1 & 0 & 0.889601 & -5.25039 & 1.336646 \\
\hline 32 & 1 & 0 & -0.89332 & -5.24928 & 1.336048 \\
\hline 33 & 1 & 0 & -0.00145 & -5.40268 & -0.1997 \\
\hline 34 & 7 & 0 & 0.000071 & -2.33626 & 0.523615 \\
\hline
\end{tabular}


Table S12: Optimized coordinates for fac-10-DMSO (favored isomer)

\begin{tabular}{|c|c|c|c|c|c|}
\hline Center Number & Atomic Number & Atomic Type & $x$ & $Y$ & z \\
\hline 1 & 44 & 0 & 7.920213 & 7.406155 & 5.331617 \\
\hline 2 & 16 & 0 & 9.552147 & 5.897601 & 6.233146 \\
\hline 3 & 17 & 0 & 9.985433 & 8.754444 & 4.719235 \\
\hline 4 & 16 & 0 & 7.739431 & 8.728841 & 7.260736 \\
\hline 5 & 16 & 0 & 6.038876 & 6.046386 & 5.902755 \\
\hline 6 & 17 & 0 & 6.475154 & 9.039134 & 4.073234 \\
\hline 7 & 8 & 0 & 6.540385 & 8.47433 & 8.168012 \\
\hline 8 & 7 & 0 & 7.999792 & 6.088829 & 3.511723 \\
\hline 9 & 6 & 0 & 8.826858 & 4.861141 & 3.762081 \\
\hline 10 & 1 & 0 & 9.145722 & 4.438152 & 2.800321 \\
\hline 11 & 1 & 0 & 8.204501 & 4.107838 & 4.245582 \\
\hline 12 & 6 & 0 & 8.560358 & 6.817128 & 2.339677 \\
\hline 13 & 1 & 0 & 7.997508 & 7.738403 & 2.195643 \\
\hline 14 & 1 & 0 & 8.491817 & 6.189791 & 1.440983 \\
\hline 15 & 1 & 0 & 9.600854 & 7.072503 & 2.531702 \\
\hline 16 & 6 & 0 & 10.043411 & 5.138315 & 4.630128 \\
\hline 17 & 1 & 0 & 10.723299 & 5.861337 & 4.175675 \\
\hline 18 & 1 & 0 & 10.596954 & 4.217038 & 4.830842 \\
\hline 19 & 6 & 0 & 7.751453 & 10.5114 & 6.904944 \\
\hline 20 & 1 & 0 & 8.659969 & 10.743945 & 6.347708 \\
\hline 21 & 1 & 0 & 7.710124 & 11.038494 & 7.860226 \\
\hline 22 & 1 & 0 & 6.872849 & 10.71628 & 6.294978 \\
\hline 23 & 6 & 0 & 6.592188 & 5.699307 & 3.172627 \\
\hline 24 & 1 & 0 & 6.601742 & 4.990318 & 2.33166 \\
\hline 25 & 1 & 0 & 6.091548 & 6.612 & 2.848031 \\
\hline 26 & 6 & 0 & 4.481717 & 7.004205 & 5.941558 \\
\hline 27 & 6 & 0 & 8.872604 & 4.444754 & 7.117049 \\
\hline 28 & 6 & 0 & 5.832344 & 5.079302 & 4.339567 \\
\hline 29 & 1 & 0 & 6.156214 & 4.06071 & 4.562404 \\
\hline 30 & 1 & 0 & 4.766 & 5.033653 & 4.107196 \\
\hline 31 & 6 & 0 & 9.213771 & 8.6536 & 8.324745 \\
\hline 32 & 1 & 0 & 9.272584 & 7.643811 & 8.73106 \\
\hline 33 & 1 & 0 & 9.084565 & 9.379754 & 9.129815 \\
\hline 34 & 1 & 0 & 10.092774 & 8.876248 & 7.717816 \\
\hline 35 & 1 & 0 & 4.363153 & 7.580539 & 5.025224 \\
\hline 36 & 1 & 0 & 4.570223 & 7.674856 & 6.797266 \\
\hline 37 & 1 & 0 & 3.65746 & 6.303308 & 6.090076 \\
\hline 38 & 1 & 0 & 8.10662 & 3.926415 & 6.539645 \\
\hline 39 & 1 & 0 & 9.697231 & 3.766229 & 7.344813 \\
\hline 40 & 1 & 0 & 8.434067 & 4.812248 & 8.045921 \\
\hline
\end{tabular}


Table S13: Optimized coordinates for cis-10-CO (favored isomer)

\begin{tabular}{|c|c|c|c|c|c|}
\hline $\begin{array}{l}\text { Center } \\
\text { Number }\end{array}$ & $\begin{array}{l}\text { Atomic } \\
\text { Number }\end{array}$ & $\begin{array}{c}\text { Atomic } \\
\text { Type }\end{array}$ & $x$ & $\mathbf{Y}$ & Z \\
\hline 1 & 44 & 0 & $-5 E-06$ & -0.04128 & -0.41444 \\
\hline 2 & 16 & 0 & -2.40051 & 0.235461 & -0.59575 \\
\hline 3 & 17 & 0 & 0.000123 & -2.29399 & -1.50139 \\
\hline 4 & 16 & 0 & 2.400521 & 0.235528 & -0.59528 \\
\hline 5 & 17 & 0 & 0.000234 & 1.027143 & -2.73741 \\
\hline 6 & 7 & 0 & $-9.5 E-05$ & 1.981983 & 0.465019 \\
\hline 7 & 6 & 0 & 3.361802 & -0.78544 & 0.575573 \\
\hline 8 & 8 & 0 & -0.0004 & -1.55005 & 2.189034 \\
\hline 9 & 6 & 0 & -3.36201 & -0.78572 & 0.574739 \\
\hline 10 & 6 & 0 & -0.00013 & -0.93237 & 1.204742 \\
\hline 11 & 6 & 0 & 1.226227 & 2.69535 & -0.03264 \\
\hline 12 & 1 & 0 & 1.309989 & 3.668375 & 0.469439 \\
\hline 13 & 1 & 0 & 1.088577 & 2.86843 & -1.10013 \\
\hline 14 & 6 & 0 & -1.22646 & 2.695294 & -0.03264 \\
\hline 15 & 1 & 0 & -1.08874 & 2.868529 & -1.10009 \\
\hline 16 & 1 & 0 & -1.31035 & 3.668247 & 0.469559 \\
\hline 17 & 6 & 0 & 2.510734 & 1.906367 & 0.204503 \\
\hline 18 & 1 & 0 & 2.724316 & 1.75911 & 1.264941 \\
\hline 19 & 1 & 0 & 3.352722 & 2.441956 & -0.24001 \\
\hline 20 & 6 & 0 & -2.51093 & 1.906175 & 0.204259 \\
\hline 21 & 1 & 0 & -3.35291 & 2.441761 & -0.24028 \\
\hline 22 & 1 & 0 & -2.72464 & 1.758754 & 1.264648 \\
\hline 23 & 6 & 0 & $-5.6 \mathrm{E}-05$ & 2.001528 & 1.957727 \\
\hline 24 & 1 & 0 & -0.88158 & 1.493429 & 2.343159 \\
\hline 25 & 1 & 0 & -0.00011 & 3.037508 & 2.316873 \\
\hline 26 & 1 & 0 & 0.881567 & 1.493543 & 2.343095 \\
\hline 27 & 1 & 0 & 2.981281 & -0.69647 & 1.593819 \\
\hline 28 & 1 & 0 & 4.407832 & -0.4761 & 0.530207 \\
\hline 29 & 1 & 0 & 3.271957 & -1.81755 & 0.232757 \\
\hline 30 & 1 & 0 & -4.40805 & -0.47644 & 0.529155 \\
\hline 31 & 1 & 0 & -2.98176 & -0.69687 & 1.593093 \\
\hline 32 & 1 & 0 & -3.27203 & -1.81778 & 0.231807 \\
\hline
\end{tabular}


Table S14: Optimized coordinates for cis-8-CO

\section{Center \\ Number}

1

2

3

4

5

6

7

8

9

10

11

12

13

14

15

16

17

18

19

20

21

22

23

24

25

26

27

28

29

30

31

32

33

34

35

36

37

\section{Atomic \\ Number}

44

15

17

15

7

6

1

6

\section{1}

1

6

1

6

1

6

1

1

6

1

1

6

1

1

6

1

1

1

1

1

1

1

1

1

1

6

8

17

\section{Atomic Type}

$\begin{array}{llll}0 & -9 \mathrm{E}-06 & -0.2698 & 0.142105\end{array}$

$\begin{array}{llll}0 & -2.38656 & -0.01857 & -0.01923\end{array}$

$\begin{array}{lllll}0 & 0.000079 & -1.08314 & -2.28972\end{array}$

$\begin{array}{lllll}0 & 2.386546 & -0.01853 & -0.01906\end{array}$

$\begin{array}{lllll}0 & 0.000006 & 1.677067 & -0.80434\end{array}$

$\begin{array}{llll}0 & 3.411422 & -1.16876 & -1.02007\end{array}$

$\begin{array}{llll}0 & 2.92536 & -1.33725 & -1.98286\end{array}$

$\begin{array}{lllll}0 & -2.47909 & 1.619732 & -0.90403\end{array}$

$\begin{array}{lllll}0 & -2.51442 & 1.410741 & -1.97919\end{array}$

$\begin{array}{llll}0 & -3.39419 & 2.160935 & -0.6437\end{array}$

$\begin{array}{lllll}0 & -3.41134 & -1.16883 & -1.02032\end{array}$

$\begin{array}{lllll}0 & -2.92521 & -1.33729 & -1.98308\end{array}$

$\begin{array}{lllll}0 & 3.382332 & 0.209502 & 1.51366\end{array}$

$\begin{array}{llll}0 & 4.42138 & 0.444792 & 1.263585\end{array}$

$\begin{array}{lllll}0 & 1.245978 & 2.466355 & -0.57425\end{array}$

$\begin{array}{llll}0 & 1.249276 & 2.78383 & 0.472365\end{array}$

$\begin{array}{lllll}0 & 1.225777 & 3.368707 & -1.19768\end{array}$

$\begin{array}{lllll}0 & 2.479112 & 1.619782 & -0.90386\end{array}$

$\begin{array}{lllll}0 & 3.394176 & 2.161002 & -0.64346\end{array}$

$\begin{array}{lllll}0 & 2.514521 & 1.410793 & -1.97901\end{array}$

$\begin{array}{lllll}0 & -1.246 & 2.466329 & -0.57434\end{array}$

$\begin{array}{lllll}0 & -1.22577 & 3.368683 & -1.19776\end{array}$

$\begin{array}{lllll}0 & -1.24938 & 2.783802 & 0.472279\end{array}$

$\begin{array}{lllll}0 & -3.38246 & 0.209434 & 1.51342\end{array}$

$\begin{array}{lllll}0 & -2.96705 & 1.020244 & 2.117116\end{array}$

$\begin{array}{llll}0 & 0.000043 & 1.389111 & -1.78803\end{array}$

$\begin{array}{lllll}0 & 3.491625 & -2.12411 & -0.49424\end{array}$

$\begin{array}{llll}0 & 4.413829 & -0.75673 & -1.1725\end{array}$

$\begin{array}{llll}0 & 3.35428 & -0.71109 & 2.103306\end{array}$

$\begin{array}{lllll}0 & 2.966863 & 1.020306 & 2.117325\end{array}$

$\begin{array}{lllll}0 & -3.49154 & -2.12419 & -0.49449\end{array}$

$\begin{array}{lllll}0 & -4.41374 & -0.75682 & -1.17281\end{array}$

$\begin{array}{llll}0 & -3.35443 & -0.71116 & 2.103067\end{array}$

$\begin{array}{lllll}0 & -4.42149 & 0.444706 & 1.263269\end{array}$

$\begin{array}{llll}0 & -8.1 \mathrm{E}-05 & 0.337026 & 1.884055\end{array}$

$\begin{array}{lllll}0 & -7.1 \mathrm{E}-05 & 0.681238 & 2.996636\end{array}$

$\begin{array}{llll}0 & -0.00002 & -2.63115 & 1.019315\end{array}$ 
Table S15: Optimized coordinates for trans-8-CO

\section{Center \\ Number}

1

2

3

4

5

6

7

8

9

10

11

12

13

14

15

16

17

18

19

20

21

22

23

24

25

26

27

28

29

30

31

32

33

34

35

36

37

\section{Atomic Number}

44

15

17

17

15

7

6

1

8

6

1

1

6

1

6

6

1

6

\section{1}

\section{1}

6

1

1

6

1

1

6

1

\section{1}

1

1

1

1

1

1

1

1

\section{Atomic Type}

0

0

0

0

0

0

0

0

0

0

0

0

0

0

0

0

0

0

0
0

0

0

0

0

0
0

0

0

0

0

0

0
0

0

0

0

0

0

0
0

0

0

0
X Y

6.373523

4.01049

6.229421

6.278963

6.513944

4.016645

6.149394

8.296526

8.534886

5.829101

$5.708182 \quad 5.024423$

9.821325

4.87363

9.366912

7.28016

3.985495

7.783001

3.374501

5.21111

3.341115

4.17959

5.49345

2.353215

3.302121

5.521147

3.757756

6.931501

9.490715

4.54223

7.186999

10.35438

7.224082

6.845167

$6.666992 \quad 5.071543$

$6.622596 \quad 6.079765$

6.3591814 .363404

8.080177

4.363404

4.742693

8.803603

4.850975

9.771343

$\begin{array}{lll}8.128055 & 3.703191 & 10.93137\end{array}$

$\begin{array}{lll}4.30501 & 5.306658 & 10.82755\end{array}$

$\begin{array}{lll}3.990566 & 4.599167 & 10.0493\end{array}$

$\begin{array}{lll}4.287656 & 6.312184 & 10.39889\end{array}$

3.081592

$\begin{array}{ll}7.861454 & 13.28642\end{array}$

3.338009

8.354446

12.34713

5.736088

10.23436

4.080585

11.62979

$$
10.62928
$$

5.493727

13.73614

9.838747

4.579782

12.25796

$\begin{array}{ll}7.878074 & 12.11023\end{array}$

$\begin{array}{lll}8.84659 & 7.805984 & 10.64408\end{array}$

$\begin{array}{lll}3.527246 & 6.159371 & 15.80824\end{array}$

$\begin{array}{lll}2.216516 & 5.416029 & 14.85656\end{array}$

$\begin{array}{lll}3.367325 & 8.521065 & 14.1108\end{array}$

$\begin{array}{lll}2.003926 & 7.675545 & 13.33058\end{array}$ 


\section{References:}

${ }^{1}$ Armarego, W.L.F and Christina Li Lin Chai. Purification of Laboratory Chemicals. $5^{\text {th }}$ ed. Butterworth-Heinemann, 2003.

${ }^{2}$ McCusker, C.E.; McCusker, J.K. Inorg. Chem. 2011, 50, 1656-1669.

${ }^{3}$ Gómez-Beńitez, V.; Olvera-Mancilla, J.; Hernández-Ortega, S.; Morales-Morales, D. J. Mol. Struct. 2004, 689, 137-141.

${ }^{4}$ Anderson, P.A. et al. Inorg. Chem. 1995, 34, 6145-6157.

${ }^{5}$ Schörgenhumer, J.; Zimmermann, A.; Waser, M. Org. Process Res. Dev. 2018, 22(7), 862-870.

${ }^{6}$ AbdEl-Halim, H.F.; Mohamed, G.G.; Hofmann, K.; Albert, B. Comp. Ren. Chim. 2015, 18(6), 619625.

${ }^{7}$ Frisch, M.J.; Trucks, G.W.; Schlegel, H.B.; Scuseria, G. E.; Robb, M.A.; Cheeseman, J.R.; Scalmani, G.; Barone, V.; Petersson, G.A.; Nakatsuji, H.; Li, X.; Caricato, M.; Marenich, A.V.; Bloino, J.; Janesko, B.G.; Gomperts, R.; Mennucci, B.; Hratchian, H.P.; Ortiz, J.V.; Izmayloy, A.F.; Sonnenberg, J.L.; Williams-Young, D.; Ding, F.; Lipparini, F.; Egidi, F.; Goings, J.; Peng, B.; Petrone, A.; Henderson, T.; Ranasinghe, D.; Zakrzewski, G.; Gao, J.; Rega, N.; Zheng, G.; Liang, W.; Hada, M.; Ehara, M.; Toyota, K.; Fukuda, R.; Hasegawa, J.; Ishida, M.; Nakajima, T.; Honda, Y.; Kitao, O.; Nakai, H.; Vreven, T.; Throssell, K.; Montgomery Jr, J.A.' Peralta, J.E.; Ogliaro, F.; Bearpark, M.J.; Heyd, J.J.; Brothers, E.N.; Kudin, K.N.; Staroverov, V.N.: Keith, T.A.; Kobayashi, R.; Normand, J.; Raghavachari, K.; Rendell, A.P.; Burant, J.C.; Iyengar, S.S.; Tomasi, J.; Cossi, M.; Millam, J.M.; Klene, M.; Adamo, C.; Cammi, R.; Ochterski, J.W.; Martin, R.L.; Martin, R.L.; Morokuma, K.; Farkas, O.; Foresman, J.B.; Fox, D.J. Gaussian 16, Revision A.03; Gaussian Inc.; Wallingford, CT, 2016.

8 (a) Becke, A. D. J. Chem. Phys. 1993, 98, 5648- 5652. (b) Lee, C.; Yang, W.; Parr, R. G. Phys. Rev. B: Condens. Matter Mater. Phys. 1988, 37, 785 789. (c) Miehlich, B.; Savin, A.; Stoll, H.; Preuss, H. Chem. Phys. Lett. 1989, 157, 200- 206.

${ }_{9}^{9}$ Aranzaes, J.R.; Daniel, M.-C.; Astruc, D. Can. J. Chem. 2006, 84, 288-299.

10 Spasyuk, D.; Smith, S.; Gusev, D. G. Angew. Chem. 2013, 125(9), 2598-2602.

${ }^{11}$ Viñas, C.; Anglès, P.; Sánchez, G.; Lucena, N.; Teixidor, F.; Escriche, L.; Casabó, J.; Piniella, J.; Alvarez-Larena, A.; Kivekäs, R.; Sillanpää, R. Inorg. Chem. 1998, 37, 701-707.

12 Page, M.J.; Wagler, J.; Messerle, B.A. Organomet. 2010, 29, 3790-3798.

13 Spasyuk, D.; Gusev, D. G. Organomet. 2012, 31(15), 5239-5242.

14 Jenkins, J.M.; Shaw, B.L. Proc. Chem. Soc. 1963, 279.

15 To synthesize the triflate salt, triflic acid was reacted with [Fe( $\left.\left.{ }^{\text {iPrPNP}}\right)(\mathrm{CO}) \mathrm{H}\right]$ which is described in ref (16). Spectral characterization matches results reported previously for the chloride salt in: Koehne, I. et al. Inorg. Chem. 2014, 53, 2133-2143.

${ }^{16}$ Bielinski, E.A.; Lagaditis, P.O.; Zhang, Y.; Mercado, B.Q.; Würtele, C.; Bernskoetter, W.H.; Hazari, N.; Schneider, S. J. Am. Chem. Soc. 2014, 136, 10234-10237.

17 Sample was contaminated with poly(tetrahydrofuran) from synthesis.

18 Jayarathne, U.; Hazari, N.; Bernskoetter, W.H. ACS Catal. 2018, 8, 1338-1345.

19 Zhang, Y.; Maclntosh, A.D.; Wong, J.L.; Bielinski, E.A.; Williard, P.G.; Mercado, B.; Hazari, N.; Bernskoetter, W.H. Chem. Sci. 2015, 6, 4291-429. 